Organización de las Naciones
Unidas para la Alimentación
y la Agricultura POLITÉCNICA UPM $\left.\mid \begin{array}{l}\text { i t d } \\ \text { UPM }\end{array}\right\} \begin{aligned} & \text { Centro de } \\ & \text { Innovación en } \\ & \text { Tecnología } \\ & \text { para el } \\ & \text { Desarrollo Humano }\end{aligned}$

Metodología para el monitoreo y evaluación de buenas prácticas en agricultura para la adaptación al cambio climático y la gestión integral del riesgo de desastres

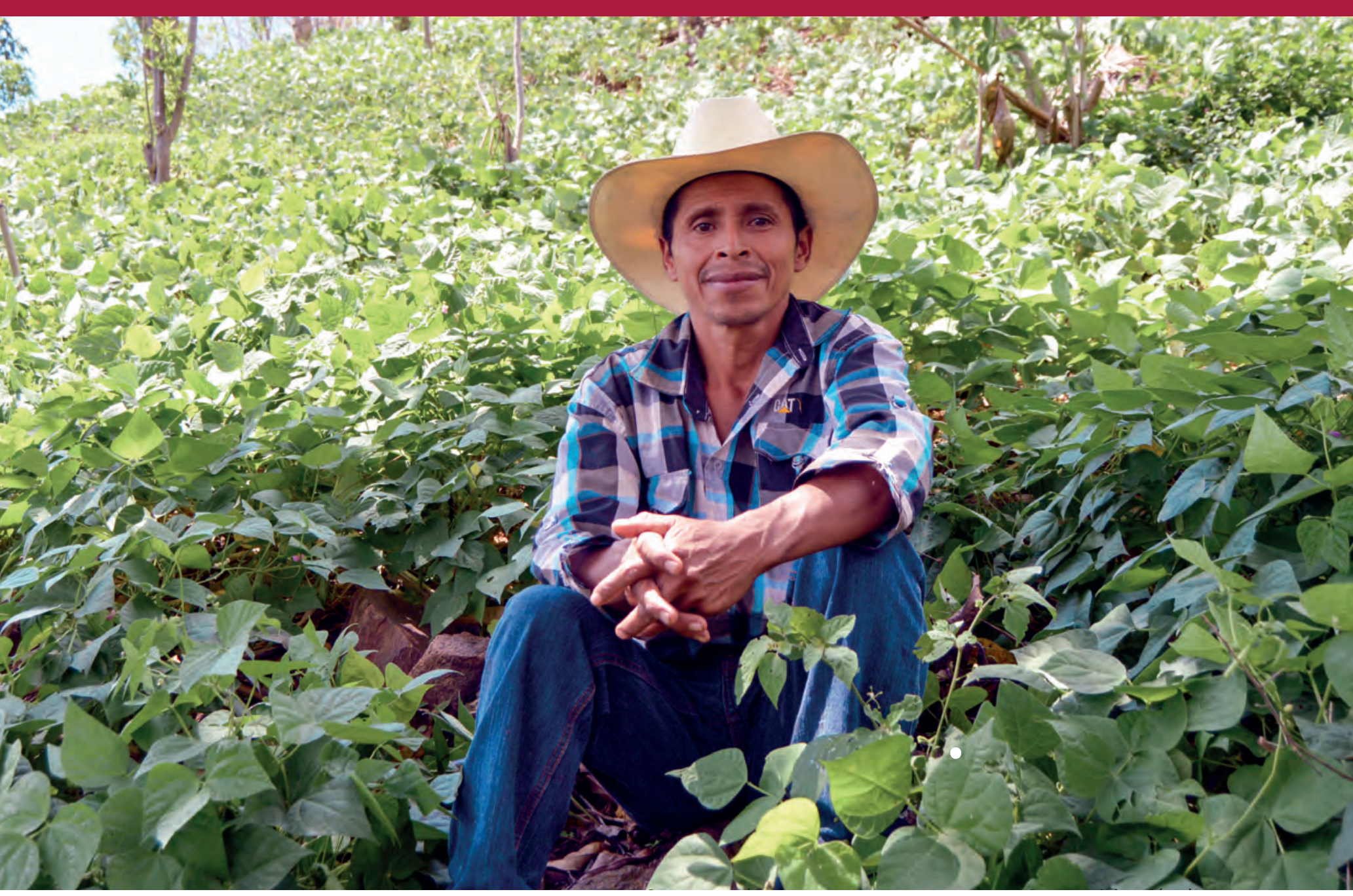




\section{Metodología para el monitoreo y evaluación de buenas prácticas en agricultura para la adaptación al cambio climático y la gestión integral del riesgo de desastres}

\section{Autores:}

Carlos G. H. Díaz-Ambrona, Centro de Innovación en Tecnología para el Desarrollo Humano (itdUPM) y AgSystems, CEIGRAM, Escuela Técnica Superior de Ingeniería Agronómica, Alimentaria y Biosistemas, Universidad Politécnica de Madrid, España.

Margarita Ruiz-Ramos, Centro de Innovación en Tecnología para el Desarrollo Humano (itdUPM) y AgSystems, CEIGRAM, Escuela Técnica Superior de Ingeniería Agronómica, Alimentaria y Biosistemas, Universidad Politécnica de Madrid, España.

Leonor Rodríguez, Centro de Innovación en Tecnología para el Desarrollo Humano (itdUPM), Universidad Politécnica de Madrid y Hidráulica del Riego, Escuela Técnica Superior de Ingeniería Agronómica, Alimentaria y Biosistemas, Universidad Politécnica de Madrid, España.

Julia Urquijo, Centro de Innovación en Tecnología para el Desarrollo Humano (itdUPM) y Departamento de Ingeniería Agroforestal, Escuela Técnica Superior de Ingeniería Agronómica, Alimentaria y Biosistemas, Universidad Politécnica de Madrid, España.

Ivanka Puigdueta, Centro de Innovación en Tecnología para el Desarrollo Humano (itdUPM) y Centro de Estudios e Investigación para la Gestión de Riesgos Agrarios y Medioambientales (CEIGRAM), Universidad Politécnica de Madrid, España.

José Luís Postigo, Centro de Innovación en Tecnología para el Desarrollo Humano (itdUPM), Universidad Politécnica de Madrid y Universidad Rey Juan Carlos (URJC), España.

Eduardo Sánchez Jacob, Centro de Innovación en Tecnología para el Desarrollo Humano (itdUPM) y Escuela Técnica Superior de Ingenieros Industriales, Universidad Politécnica de Madrid, España.

Laura Juárez, Centro de Innovación en Tecnología para el Desarrollo Humano (itdUPM), Universidad Politécnica de Madrid, España.

Jaime Moreno, Centro de Innovación en Tecnología para el Desarrollo Humano (itdUPM), Universidad Politécnica de Madrid, España.

Marco Minelli, Oficina Subregional de FAO para Mesoamérica, Organización de las Naciones Unidas para la Alimentación y la Agricultura.

Raixa Elena Llauger Riverón, Oficina Subregional de FAO para Mesoamérica, Organización de las Naciones Unidas para la Alimentación y la Agricultura.

Dina López Meléndez, Oficina de la FAO para Mesoamérica, Organización de las Naciones Unidas para la Alimentación y la Agricultura.

Barbara Vanni, Oficina Subregional de FAO para Mesoamérica, Organización de las Naciones Unidas para la Alimentación y la Agricultura.

Publicado por

la Organización de las Naciones Unidas para la Alimentación y la Agricultura

$y$

Centro de Innovación en Tecnología para el Desarrollo, Universidad Politécnica de Madrid 
Referencia requerida:

FAO y UPM. 2021. Metodología para el monitoreo y evaluación de buenas prácticas en agricultura para la adaptación al cambio climático y la gestión integral del riesgo de desastres. Panamá. https://doi.org/10.4060/cb4486es

Las denominaciones empleadas en este producto informativo y la forma en que aparecen presentados los datos que contiene no implican, por parte de la Organización de las Naciones Unidas para la Alimentación y la Agricultura (FAO) O Centro de Innovación en Tecnología para el Desarrollo, Universidad Politécnica de Madrid (UPM), juicio alguno sobre la condición jurídica o nivel de desarrollo de países, territorios, ciudades o zonas, o de sus autoridades, ni respecto de la delimitación de sus fronteras o límites. La mención de empresas o productos de fabricantes en particular, estén o no patentados, no implica que la FAO O UPM los apruebe o recomiende de preferencia a otros de naturaleza similar que no se mencionan.

Las opiniones expresadas en este producto informativo son las de su(s) autor(es), y no reflejan necesariamente los puntos de vista o políticas de la FAO O UPM.

ISBN 978-92-5-134343-2 [FAO]

ISBN 978-92-5-134343-2 [UPM]

(c) FAO y UPM, 2021

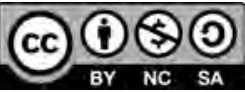

Algunos derechos reservados. Este obra está bajo una licencia de Creative Commons Reconocimiento-NoComercialCompartirlgual 3.0 Organizaciones intergubernamentales.; https://creativecommons.org/licenses/by-nc-sa/3.0/igo/deed. es_ES).

De acuerdo con las condiciones de la licencia, se permite copiar, redistribuir y adaptar la obra para fines no comerciales, siempre que se cite correctamente, como se indica a continuación. En ningún uso que se haga de esta obra debe darse a entender que la FAO O UPM refrenda una organización, productos o servicios específicos. No está permitido utilizar el logotipo de la FAO O UPM. En caso de adaptación, debe concederse a la obra resultante la misma licencia o una licencia equivalente de Creative Commons. Si la obra se traduce, debe añadirse el siguiente descargo de responsabilidad junto a la referencia requerida: "La presente traducción no es obra de Organización de las Naciones Unidas para la Alimentación y la Agricultura (FAO) O UPM. La FAO/UPM no se hacen responsable del contenido ni de la exactitud de la traducción. La edición original en inglés será el texto autorizado".

Toda controversia que surja en el marco de la licencia y no pueda resolverse de forma amistosa se resolverá a través de mediación y arbitraje según lo dispuesto en el artículo 8 de la licencia, a no ser que se disponga lo contrario en el presente documento. Las reglas de mediación aplicables serán las del Reglamento de Mediación de la Organización Mundial de la Propiedad Intelectual http://www.wipo.int/amc/en/mediation/rules y todo arbitraje se llevará a cabo de conformidad con el Reglamento de Arbitraje de la Comisión de las Naciones Unidas para el Derecho Mercantil Internacional (CNUDMI).

Materiales de terceros. Si se desea reutilizar material contenido en esta obra que sea propiedad de terceros, por ejemplo, cuadros, gráficos o imágenes, corresponde al usuario determinar si se necesita autorización para tal reutilización y obtener la autorización del titular del derecho de autor. El riesgo de que se deriven reclamaciones de la infracción de los derechos de uso de un elemento que sea propiedad de terceros recae exclusivamente sobre el usuario.

Ventas, derechos y licencias. Los productos informativos de la FAO están disponibles en la página web de la Organización (http://www.fao.org/publications/es) y pueden adquirirse dirigiéndose a publications-sales@fao.org. Las solicitudes de uso comercial deben enviarse a través de la siguiente página web: www.fao.org/contact-us/licence-request. Las consultas sobre derechos y licencias deben remitirse a: copyright@fao.org. 


\section{Índice}

Siglas y acrónimos ..................................................................... II

Agradecimientos ......................................................................... IV

1. Introducción .............................................................................. 1

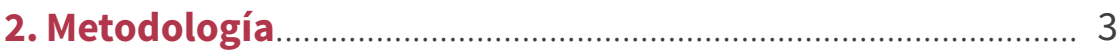

2.1. Objetivo de la metodología.................................................... 3

2.2. Enfoque y alcance................................................................. 3

2.3. Desarrollo del marco analítico............................................... 4

2.4. Aplicación de la metodología ................................................. 5

2.5. Tabla de síntesis para el uso de este documento................. 7

3. Herramientasmetodológicas..................................................... 9

Herramienta 1: Revisión de la literatura sobre opciones

de buenas prácticas.

Herramienta 2: Criterios para la identificación de BPA

adaptados al Corredor Seco Centroamericano y zonas áridas de

la República Dominicana.

Herramienta 3: Estructura analítica y valoración de criterios

y sub criterios.

Herramienta 4: Propuesta de línea de tiempo para la identificación de BPA en el Corredor Seco Centroamericano y zonas áridas de la República Dominicana.

Herramienta 5: Cuestionarios para la evaluación de BPA en el Corredor Seco Centroamericano y zonas áridas de la República Dominicana.

Herramienta 6: Nota de orientación para la cumplimentación de los cuestionarios.

Herramienta 7: Análisis Costo-Beneficio (ACB) incluyendo los componentes de agua y energía.

Herramienta 8: Instrumento para la evaluación integrada........... 70

Herramienta 9: Modelización de los impactos de una BPA........... 78

Herramienta 10: Evaluación comparativa de los beneficios por unidad de producción/finca................................................................. 83

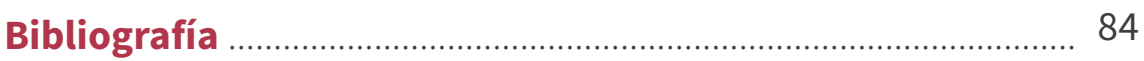




\section{Siglas y acrónimos}

$\begin{array}{ll}\text { ACB } & \text { Análisis Costo-Beneficio } \\ \text { AECID } & \text { Agencia Española de Cooperación Internacional para el Desarrollo } \\ \text { ASAC } & \text { Agricultura Sostenible Adaptada al Clima } \\ \text { BPA } & \text { Buenas Prácticas en Agricultura } \\ \text { CAC } & \text { Consejo Agropecuario Centroamericano } \\ \text { CEPREDENAC } & \begin{array}{l}\text { Centro de Coordinación para la Prevención de Desastres Naturales } \\ \text { en América Central }\end{array} \\ \text { PCD } & \text { Proyecto de Conocimiento para el Desarrollo } \\ \text { EASAC } & \text { Implementación de la Estrategia de Agricultura Sostenible } \\ \text { FAO } & \text { Adaptada al Clima } \\ \text { GEI } & \text { Organización de las Naciones Unidas para la Alimentación y la } \\ \text { GIRD } & \text { Agricultura } \\ \text { IPCC } & \text { Gases de Efecto Invernadero } \\ \text { MDS } & \text { Grupo Intergubernamental de Expertos sobre el Cambio Climático } \\ \text { ODS } & \text { (por su siglas en inglés) } \\ \text { PRRD } & \text { Modelos de Dinámica de Sistemas } \\ \text { RCP } & \text { Objetivo de Desarrollo Sostenible } \\ \text { TIR } & \text { Plan Regional para la Reducción del Riesgo de Desastres } \\ \text { WAN } & \text { Trayectoria de Concentración Representativa (por sus siglas en } \\ \text { inglés) }\end{array}$




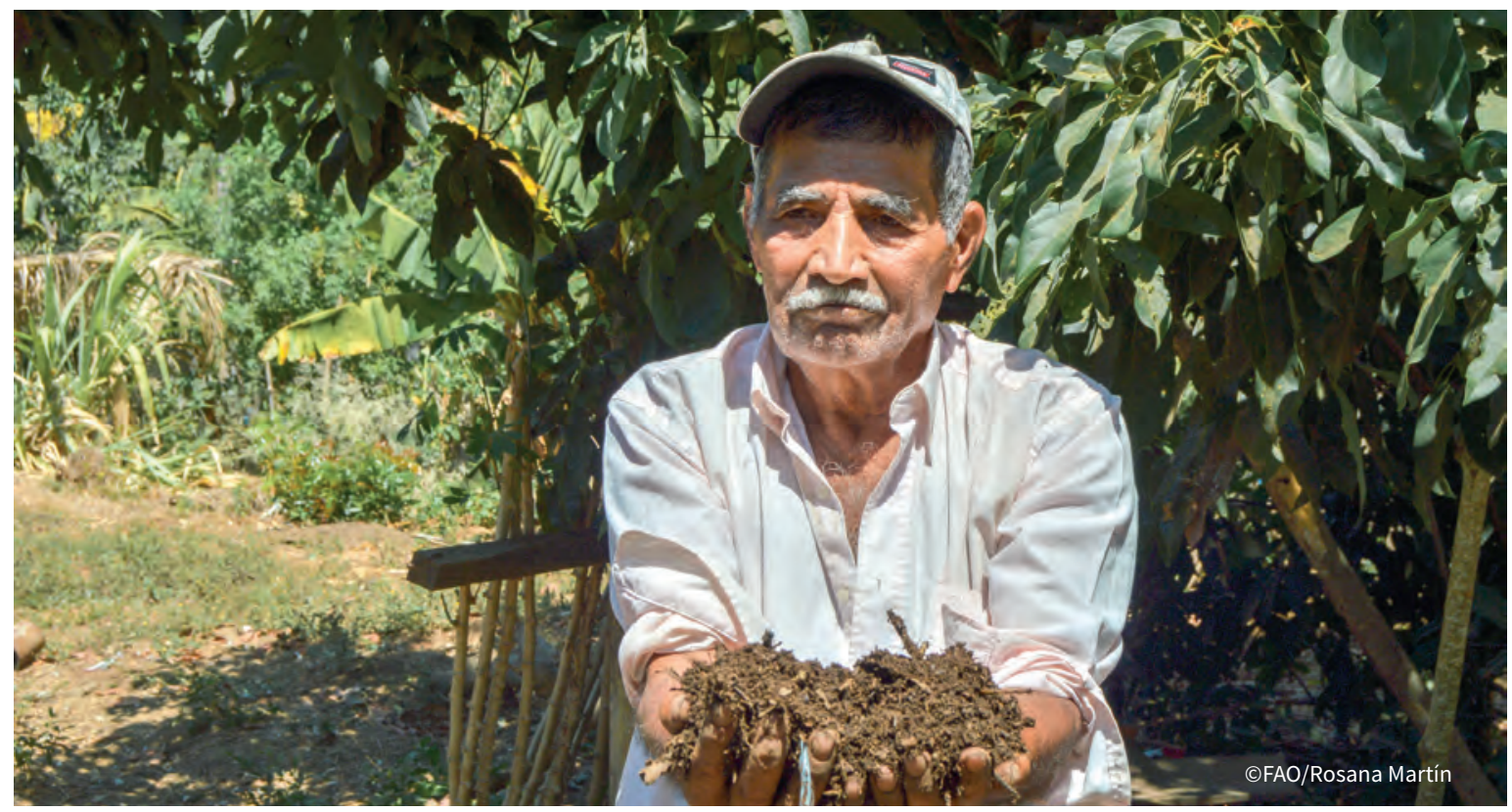

\section{Agradecimientos}

La metodología para el monitoreo y la evaluación de opciones de buenas prácticas para la reducción del riesgo de desastres en la agricultura fue elaborada por el equipo técnico de la Oficina de Emergencia y Resiliencia de la FAO que trabaja bajo la coordinación general del Sr. Stephan Baas. Esta metodología fue utilizada para los análisis de costo-beneficio realizados en diferentes países del mundo, en prácticas de reducción de riesgo de desastres a nivel de finca (FAO 2017; FAO 2019).

El presente documento es el resultado de un proceso de adaptación, enriquecimiento y actualización de dicha metodología para los países miembros del Sistema de la Integración Centroamericana (SICA).

Se agradece al Sr. Niccoló Lombardi, especialista de alerta y acción temprana/acción anticipatoria de la FAO, por su contribución en la revisión del presente documento. Además, se agradece la colaboración interinstitucional e interdisciplinar del personal de las Secretarías del Consejo Agropecuario Centroamericano (CAC) y del Centro de Coordinación para la Prevención de Desastres Naturales en América Central (CEPREDENAC).

Esta publicación ha sido posible gracias a la contribución financiera de la Agencia Española de Cooperación Internacional para el Desarrollo (AECID), a través del proyecto Buenas Prácticas Agrícolas y Evaluación de Daños y Pérdidas para la Gestión Integral del Riesgo de Desastres (GIRD) y la Agricultura Sostenible Adaptada al Clima (ASAC), en el marco del Proyecto de Conocimiento para el Desarrollo del Plan de Transferencia, Intercambio y Gestión de Conocimiento para el Desarrollo de la Cooperación Española en América Latina y el Caribe, INTERCOONECTA. 


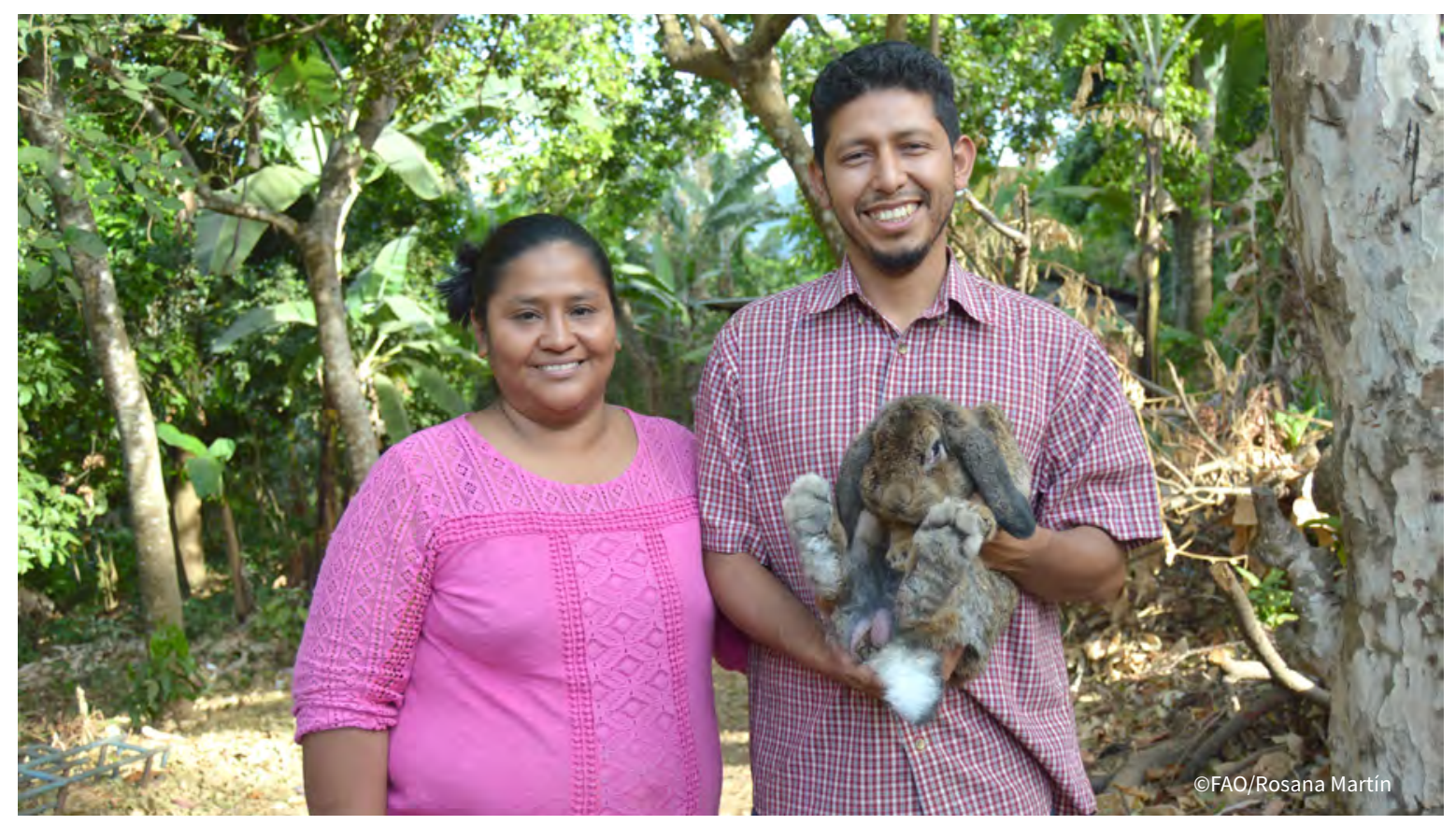

\section{Introducción}

En el último decenio, el número de desastres causados por amenazas naturales ha aumentado considerablemente y, con ellos, ha incrementado tanto el número de personas afectadas como las pérdidas económicas asociadas. En la década de 1980, las pérdidas económicas debidas a desastres inducidos por amenazas naturales han alcanzado los 50 mil millones de dólares estadounidenses (en adelante, dólares) cada año. Este número se ha cuadruplicado, alcanzando casi 200 mil millones de dólares cada año en la última década (Banco Mundial y GFDRR, 2013).

Entre el 2006 y 2016, el sector de la agricultura en los países en desarrollo ha absorbido aproximadamente el $23 \%$ de los daños y las pérdidas causados por los desastres inducidos por amenazas naturales (FAO, 2017). Siendo la agricultura el principal medio de vida de más del 35\% de la población mundial, resulta crucial invertir en tecnologías para la reducción del riesgo de desastres con el fin de reducir el impacto de las amenazas naturales y contribuir a la reducción de la pobreza y al aumento de la seguridad alimentaria.

En este marco, la Organización de las Naciones Unidas para la Alimentación y la Agricultura (FAO) ha consolidado su capacidad de apoyo técnico y financiero por medio de la incorporación de la reducción del riesgo de desastres en el sector de la agricultura en su Objetivo Estratégico 5: "Incrementar la resiliencia de los medios de vida ante las amenazas y crisis". Como parte de la asistencia técnica para reducir los riesgos y la vulnerabilidad de los hogares y las comunidades ante los desastres, la FAO captura, valida y difunde "buenas prácticas", es decir, experiencias exitosas que han sido probadas y validadas en varios contextos y que pueden ser difundidas y recomendadas como modelo. 
Anteriormente, la FAO había desarrollado una metodología para el monitoreo y la evaluación de opciones de buenas prácticas para la reducción del riesgo de desastres en la agricultura. Sin embargo, la diversidad de los sistemas agropecuarios, de las realidades socioculturales existentes y de las amenazas a las cuales se enfrentan, ha requerido adaptar dicha metodología a cada contexto, atendiendo a las especificidades y necesidades de los diferentes países y territorios. En el caso de la Región del Sistema de la Integración Centroamericana (SICA) ${ }^{1}$, dicha metodología ha sido enriquecida, adaptada y actualizada para incluir la evaluación de las necesidades hídricas y energéticas que son un aspecto clave en la prevención del riesgo de desastres y la adaptación al cambio climático, además se han incluido consideraciones de género y relacionadas con los pueblos indígenas. De esta manera, los países de la Región SICA tienen a disposición unas directrices para el Monitoreo y la Evaluación (M\&E) de las buenas prácticas para la Adaptación al Cambio Climático y la Gestión Integral del Riesgo de Desastres.

Este proceso se ha realizado en el marco del apoyo al Proyecto de Conocimiento para el Desarrollo del Plan de Transferencia, Intercambio y Gestión de Conocimiento para el Desarrollo de la Cooperación Española en América Latina y el Caribe - INTERCOONECTA: Buenas Prácticas Agrícolas y Evaluación de Daños y Pérdidas para la Gestión Integral del Riesgo de Desastres (GIRD) y la Agricultura Sostenible Adaptada al Clima (ASAC), financiado por la Agencia Española de Cooperación Internacional para el Desarrollo (AECID). Dicho proyecto apunta a mejorar la gestión del conocimiento y el fortalecimiento de la sostenibilidad, inclusión y resiliencia de los sistemas productivos ante el riesgo de desastres y el cambio climático.

Esta iniciativa se focaliza en el Corredor Seco Centroamericano y las Zonas Áridas de República Dominicana, donde habita una población altamente vulnerable a la sequía y responde a las prioridades identificadas en la Estrategia de Agricultura Sostenible Adaptada al Clima (EASAC) y en el Plan Regional para la Reducción del Riesgo de Desastres (PRRD).

La metodología aquí proporcionada pretende establecer una guía práctica que oriente al personal técnico de los países en el monitoreo y la evaluación de las BPA para la adaptación al cambio climático y la gestión integral del riesgo de desastres. La finalidad es validar y consolidar las estrategias de adaptación al cambio climático y la gestión integral del riesgo de desastres que ya se han puesto a prueba y replicarlas en contextos geográficos más amplios.

El documento se compone de dos partes: la primera describe la metodología y la segunda recoge cada una de las herramientas que deberán utilizarse para el levantamiento de la información necesaria para la aplicación de la metodología.

${ }^{1}$ La Región SICA incluye Belice, Costa Rica, El Salvador, Guatemala, Honduras, Nicaragua, Panamá, República Dominicana. 


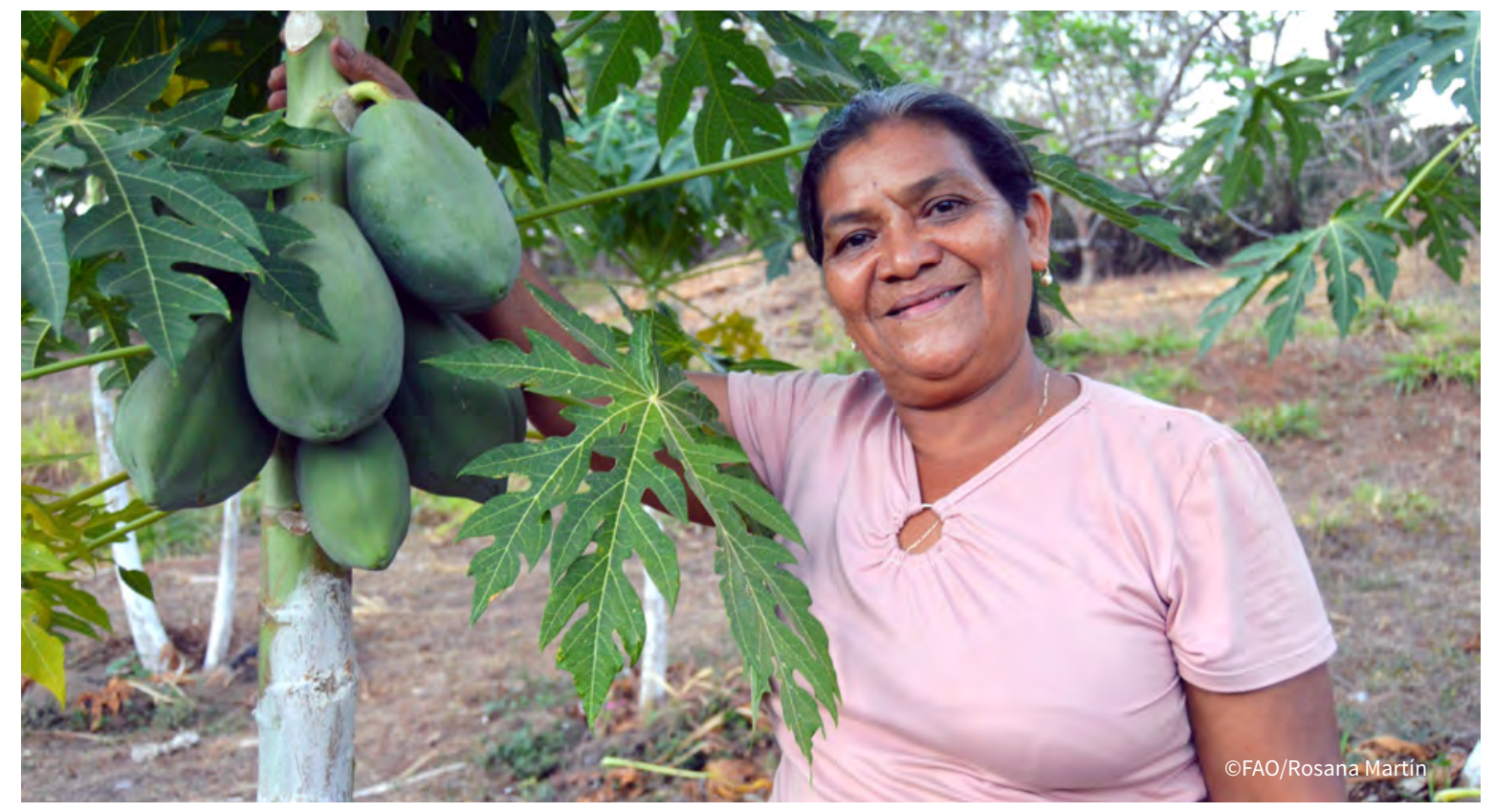

\section{Metodología}

\subsection{Objetivo de la metodología}

Orientar al personal técnico de los países en el monitoreo y la evaluación de las buenas prácticas en agricultura (BPA) para la adaptación al cambio climático y la gestión integral del riesgo de desastres.

\subsection{Enfoque y alcance}

Esta metodología se centra en proporcionar directrices para analizar:

- Países específicos, en este caso los del Corredor Seco Centroamericano y Zonas Áridas de República Dominicana.

- Un número limitado de buenas prácticas previamente seleccionadas en los subsectores: (a) cultivo, (b) ganadería, (c) pesca/acuicultura y (d) forestal y agroforestal.

- Amenazas específicas (altas y bajas temperaturas, granizo, huracanes, incremento variabilidad interanual, inundaciones, olas de calor, plagas y enfermedades, sequía, tormentas).

Posteriormente, mediante investigaciones adicionales, se podrá extender la metodología a:

- Un mayor número de buenas prácticas.

- Amenazas naturales adicionales.

- Otros países. 


\subsection{Desarrollo del marco analítico}

El marco analítico se compone de tres fases consecutivas: análisis de gabinete, validación y escalamiento.

\section{Análisis de gabinete}

En esta fase se realiza una primera identificación de los elementos necesarios para la evaluación de las BPA. El análisis comienza con una revisión bibliográfica sobre las opciones de buenas prácticas (Herramienta 1) que permite extraer y caracterizar las Buenas Prácticas en Agricultura con base en cuatro criterios: (i) adecuación y pertinencia agroecológica; (ii) viabilidad socioeconómica; (iii) incremento de la resiliencia de los medios de vida ante los desastres inducidos por amenazas naturales y; (iv) cobeneficios ambientales (p. ej. impactos en la reducción de emisiones de los gases de efecto invernadero - GEI). Se contempla además la posibilidad de incorporar otros criterios relevantes (Herramienta 2). Dichos criterios se analizan y miden considerando también los aspectos transversales de perspectiva de género y de los pueblos indígenas (Herramienta 3). El procedimiento propuesto permite realizar un primer análisis de la pertinencia de la BPA a evaluar respecto a los diferentes grupos de amenazas y subsectores agropecuarios que puedan aplicar. Adicionalmente, contribuye a orientar sobre la información a recolectar en los cuestionarios (Herramientas 5 y 6 ) y a presentar una metodología sencilla de valoración cualitativa de los criterios de la BPA analizada.

Hay que tener en cuenta que algunas variables de cumplimiento de los criterios pueden ser válidas para una amplia gama de contextos, mientras que otras son específicas para ciertas amenazas y/o zonas agroecológicas y/o estaciones agrícolas (Herramientas 2 y 3). Todos los indicadores de desempeño deben ser fáciles de usar a nivel local y analizar de manera conjunta en un contexto dado. La combinación de la información proveniente de los indicadores de desempeño permite demostrar el valor agregado de las buenas prácticas para la adaptación al cambio climático y la gestión integral del riesgo de desastres. De hecho, un indicador que muestra un resultado positivo durante varias campañas o ciclos agrícolas en condiciones de variabilidad climática o concurrencia de alguna amenaza, cuenta con un argumento para su replicabilidad o escalamiento a contextos más amplios; por esta razón se propone una evaluación en ciertos momentos (Herramienta 10) y, como mínimo, antes y después de la implementación de la BPA. En el caso de que se haya mantenido la BPA, la evaluación se debería repetir cada cinco años desde su implementación.

\section{Diseño de la investigación-acción de campo}

En esta fase, una BPA debería validarse mediante una investigación de campo que permite evaluar su desempeño en comparación con una práctica tradicional (véase fase de validación). Las observaciones basadas en pruebas de campo y monitoreo de ambas prácticas deberían volverse a recopilar en cada temporada (p. ej. insumos, producción, beneficio económico y cobeneficios ambientales). 


\section{Escalamiento de los resultados a través de modelos}

En esta etapa, los impactos a largo plazo de las buenas prácticas para la GIRD en los subsectores de la agricultura y el medio ambiente se evalúan a través de la aplicación de modelos matemáticos específicos (Herramienta 9).

\subsection{Aplicación de la metodología}

En la Herramienta 4 se recoge la línea de tiempo de los pasos descritos a continuación.

\section{Revisión de la literatura}

En el marco del proyecto "Buenas Prácticas Agrícolas (BPA) y Evaluación de Daños y Pérdidas para la Gestión Integral del Riesgo de Desastres (GIRD) y la Agricultura Sostenible Adaptada al Clima (ASAC)", se ha desarrollado un inventario de las BPA aplicadas o propuestas en la zona de estudio o en otras áreas que presenten afinidad en algún aspecto. Considerando que con el paso del tiempo se supone que se irán desarrollando y caracterizando nuevas BPA, se recomienda una revisión periódica de la literatura centrada en el estudio de BPA para la GIRD de cada país con respecto a las amenazas naturales más representativas. La Herramienta 1 proporciona una guía con la estructura y contenido a incluir en un inventario de BPA para la adaptación al cambio climático y la gestión integral del riesgo de desastres.

Adicionalmente, se sugiere consultar otras fuentes similares como la base de datos desarrollada por la FAO en la plataforma TECA que recoge un repositorio de tecnologíasy prácticas en agricultura que se han verificado como exitosas en el ámbito de los pequeños productores y de la agricultura familiar (disponible en: www.fao.org/teca/es/) o la bases de datos de WOCAT, desarrollada en el marco de la Convención de las Naciones Unidas para Combatir la Desertificación (disponible en: www.wocat.net/en/global-slm-database/).

\section{Evaluación cualitativa}

Es recomendable aplicar cuestionarios para realizar evaluaciones cualitativas ex-ante y ex-post de una BPA con el fin de obtener información de las comunidades locales (Herramientas 5 y 7 ). Los cuestionarios se centran en aspectos como la aceptación sociocultural de las nuevas prácticas de GIRD y sus impactos en los medios de vida y otros elementos cualitativos que se consideren relevantes. Para su elaboración se utilizan también los criterios definidos en la primera fase de Inventario de BPA. Asímismo, se incluye una Guía para la aplicación del cuestionario (Herramienta 6). Las evaluaciones cualitativas permiten complementar y llenar las lagunas de los datos cuantitativos (para el análisis de costo-beneficio y la línea de base, entre otras).

Los componentes de agua y energía se analizan mediante la inclusión en el cuestionario de preguntas relacionadas con su disponibilidad y uso, tanto en los sistemas productivos, como en el ámbito doméstico. Esta información se completa con la percepción de los agricultores sobre 
como las amenazas climáticas afectan al suministro de agua y energía, con aspectos relacionados con la calidad del agua (p. ej. depuración) y con las preferencias en cuanto a adopción de nuevas fuentes de energía.

\section{Análisis costo-beneficio}

Este análisis ayuda a guiar la selección de las buenas prácticas que maximizan los retornos (Herramienta 7). Se revisan algunas de las metodologías existentes para el análisis costobeneficio (p. ej. para tecnologías o prácticas específicas) y, si es necesario, se complementan con datos adicionales extraídos de la literatura. Sin embargo, en el caso en que no se disponga de un análisis costo-beneficio, la información deberá ser recogida en campo y/o a través de la revisión bibliográfica.

Los indicadores se deben expresar en términos monetarios, e incluir (i) costos; (ii) beneficios agregados (económicos, sociales y ambientales); (iii) costos (económicos, sociales y ambientales) evitados; y (iv) co-beneficio, cuando aplique.

\section{Evaluación integrada}

Los resultados de la evaluación cuantitativa y cualitativa (Herramientas de 1 a 6) y del análisis costo-beneficio (Herramienta 7) se combinan para proporcionar una evaluación final de la BPA, siempre que en ambas evaluaciones la BPA supere el umbral de aceptabilidad por parte del agricultor. Esta síntesis se facilita a través de la aplicación de la matriz de valoración de los criterios de la Tabla 1 de la Herramienta 8 (mayoría de cumplimiento de criterios), que se complementa con el resultado estimado de rentabilidad según la Herramienta 7 y la valoración de los cuestionarios recogida en la Herramienta 5.

A través de este proceso, cada BPA queda caracterizada por tres indicadores: grado de cumplimiento de los criterios, rentabilidad (según análisis costo-beneficio) y valoración de los cuestionarios.

\section{Modelado}

Sería recomendable dar continuidad a esta línea de trabajo mediante el uso de modelos de simulación (por ejemplo, mediante modelos de dinámica de sistemas utilizados por MarínGonzález et al., 2018²), con el fin de simular simultáneamente los impactos de las buenas prácticas en una serie de indicadores y proyectar escenarios alternativos. El objetivo de este paso es verificar si los indicadores de desempeño de una BPA cambian significativamente en diferentes situaciones en el corto, mediano y largo plazo (por ejemplo, una práctica local expuesta a un

2 Marín-González, O.; Parsons D.; Arnes-Prieto E.; Díaz-Ambrona, C.G.H. 2018. Building and evaluation of a dynamic model for assessing impact of smallholder endowments on food security in agricultural systems in highland areas of central America. Agricultural systems, 164:152-164. https://doi.org/10.1016/j.agsy.2018.02.005 
riesgo en comparación con otras buenas prácticas expuestas a las mismas condiciones) y bajo diferentes supuestos de evolución de los escenarios de cambio climático. La recopilación de los datos de la línea base es un paso crítico (Herramienta 9). Los análisis de costo-beneficio, así como de los datos históricos recogidos en la escala más pequeña disponible, se deberían utilizar para alimentar el modelo. El resto de los datos debería ser extrapolado o reemplazado por las aproximaciones más fiables disponibles.

\section{Validación}

Las experiencias de campo permiten validar las BPA de acuerdo con el esquema de la Herramienta 10. En este ámbito, se compara el desempeño de las BPA en años "normales", es decir cuando no se produce ningún desastre y en años en los cuales se produce un desastre.

La línea base, obtenida a partir del desempeño de las prácticas locales, se compara con los datos históricos. El monitoreo estacional del desempeño de las prácticas puede llevarse a cabo por medio de escuelas de campo para agricultores (ECA) o de modelos de demostración agrícola.

Los indicadores de desempeño para el monitoreo de parcelas de campo serán recogidos por agricultores encargados de realizar el monitoreo del proyecto, así como por el personal de extensión, por medio de la recolección de datos de campo y entrevistas cuantitativas y cualitativas con los agricultores.

\subsection{Tabla de síntesis para el uso de este documento}

\begin{tabular}{|c|c|c|}
\hline Fase & Herramientas & Tabla /encuesta / figura \\
\hline \multirow{4}{*}{$\begin{array}{l}\text { Revisión de la } \\
\text { literatura }\end{array}$} & $\begin{array}{l}\text { Herramienta } 1 \\
\text { Propósito: estructurar el contenido del Inventario } \\
\text { en función del análisis sistemático de la BPA. }\end{array}$ & Tabla 1.1. Matriz de inventario \\
\hline & $\begin{array}{l}\text { Herramienta } 2 \\
\text { Propósito: analizar el grado en que la BPA incluye } \\
\text { los enfoques agroecológicos, socioeconómicos, de } \\
\text { resiliencias, de cobeneficios ambientales y otros. }\end{array}$ & \\
\hline & $\begin{array}{l}\text { Herramienta } 3 \\
\text { Propósito: realizar un primer análisis de la } \\
\text { pertinencia de la aplicación de la BPA para para la } \\
\text { ACC y la GIRD. }\end{array}$ & $\begin{array}{l}\text { Tabla 3.1. Matriz de análisis ex- } \\
\text { ante de la pertinencia }\end{array}$ \\
\hline & $\begin{array}{l}\text { Herramienta } 4 \\
\text { Propósito: evaluar las BPA, definiendo las } \\
\text { actividades o pasos, el objetivo marcado, las } \\
\text { tareas a realizar, su duración y el resultado } \\
\text { esperado. }\end{array}$ & $\begin{array}{l}\text { Tabla 4.1. Matriz de pasos, } \\
\text { objetivos, actividades, resultados } \\
\text { y tiempo necesarios. }\end{array}$ \\
\hline
\end{tabular}




\begin{tabular}{|c|c|c|}
\hline $\begin{array}{l}\text { Evaluación } \\
\text { cualitativa }\end{array}$ & $\begin{array}{l}\text { Herramienta } 5 \\
\text { Propósito: caracterizar y evaluar la utilidad de las } \\
\text { buenas prácticas en agricultura (BPA), haciendo } \\
\text { un seguimiento en el tiempo. }\end{array}$ & $\begin{array}{l}\text { Encuesta para productores. } \\
\text { Encuesta para municipios. }\end{array}$ \\
\hline $\begin{array}{l}\text { Evaluación } \\
\text { cualitativa }\end{array}$ & $\begin{array}{l}\text { Herramienta } 6 \\
\text { Propósito: orientar al personal técnico en la } \\
\text { realización de las encuestas. }\end{array}$ & $\begin{array}{l}\text { Tabla 6.1. Objetivos y } \\
\text { destinatarios de las encuestas. } \\
\text { Figura 6.1. Estructura de los } \\
\text { cuestionarios para productores/as } \\
\text { (C1) y representantes municipales } \\
\text { (C2). } \\
\text { Tabla 6.2. Comentarios sobre } \\
\text { cuestionario } 1 . \\
\text { Tabla 6.3. Comentarios sobre } \\
\text { cuestionario } 2 \text {. }\end{array}$ \\
\hline $\begin{array}{l}\text { Análisis costo- } \\
\text { beneficio }\end{array}$ & $\begin{array}{l}\text { Herramienta } 7 \\
\text { Propósito: calcular la relación entre el coste y el } \\
\text { beneficio que se deriva de la implantación de una } \\
\text { buena práctica en agricultura (BPA). }\end{array}$ & $\begin{array}{l}\text { Tabla 7.1. Resumen Análisis } \\
\text { coste-beneficio para comparar } \\
\text { BPA a nivel económico, social } \\
\text { y ambiental. } \\
\text { Tabla 7.2. Datos necesarios } \\
\text { para el ACB. }\end{array}$ \\
\hline $\begin{array}{l}\text { Evaluación } \\
\text { integrada }\end{array}$ & $\begin{array}{l}\text { Herramienta } 8 \\
\text { Propósito: ayudar a valorar las BPA de manera } \\
\text { integrada para el conjunto de criterios } \\
\text { considerados en base a los datos recopilados con } \\
\text { las diferentes herramientas presentadas. }\end{array}$ & $\begin{array}{l}\text { Tabla 8.1. Matriz de valoración } \\
\text { cuantitativa de los sub-criterios. } \\
\text { Tabla 8.2. Resumen de } \\
\text { valoración de cada tipo de } \\
\text { criterio según el desempeño } \\
\text { de los sub-criterios. } \\
\text { Tabla 8.3. Resumen de } \\
\text { valoración global de los } \\
\text { criterios. }\end{array}$ \\
\hline Modelado & $\begin{array}{l}\text { Herramienta } 9 \\
\text { Propósito: evaluar la posibilidad de replicar la } \\
\text { práctica a gran escala, sus beneficios e impactos y } \\
\text { las tecnologías empleadas. }\end{array}$ & $\begin{array}{l}\text { Figura 9.1. Ejemplo diagrama } \\
\text { causa-efecto. } \\
\text { Figura 9.2. Modelo SASHACA: } \\
\text { Diagrama de flujos. }\end{array}$ \\
\hline Validación & $\begin{array}{l}\text { Herramienta } 10 \\
\text { Propósito: establecer las temporadas o línea } \\
\text { de tiempo que permita el seguimiento de la } \\
\text { buena práctica en agricultura (BPA) en diferentes } \\
\text { condiciones meteorológicas y ambientales. }\end{array}$ & $\begin{array}{l}\text { Figura 10.1. Esquema de la } \\
\text { evaluación comparativa. }\end{array}$ \\
\hline
\end{tabular}




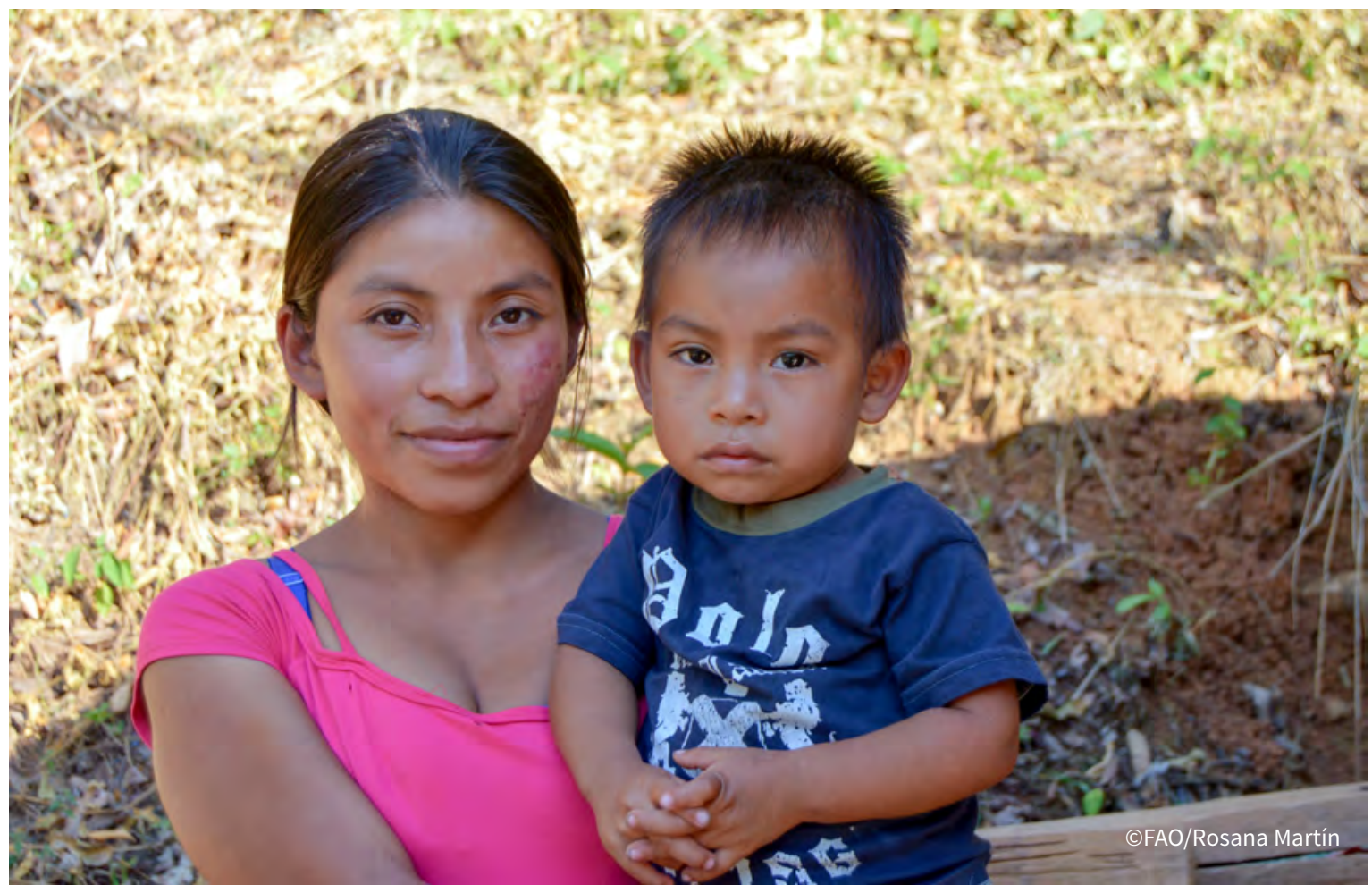

\section{Herramientas metodológicas}

En este apartado se presentan las herramientas que deben utilizarse para levantar la información necesaria para la aplicación de la metodología.

\section{Herramienta 1:}

Revisión de la literatura sobre opciones de buenas prácticas

Para qué sirve la herramienta: Muestra la estructura del contenido del inventario que ha sido desarrollado para el análisis sistemático de BPA para la adaptación al cambio climático y la gestión integral del riesgo de desastres.

Quién tiene que rellenar la tabla: Personal técnico del proyecto.

Cómo y cuándo se aplica: Se prepara al inicio del proyecto, se registra en una base de datos con una entrada para cada BPA identificada. 
Tabla 1.1. Matriz de inventario. Estructura y contenido a incluir en un inventario de BPA para la adaptación al cambio climático y la gestión integral del riesgo de desastres en el Corredor Seco Centroamericano y Zonas Áridas de República Dominicana.

\begin{tabular}{|c|c|c|}
\hline Título BPA & $\begin{array}{c}\text { Nombre de la buena } \\
\text { práctica existente/ } \\
\text { potencial }\end{array}$ & $\begin{array}{c}\text { Insertar nombre de la práctica o sistemas } \\
\text { de prácticas }\end{array}$ \\
\hline \multirow{27}{*}{ Caracterización } & Sector & Agricultura \\
\hline & \multirow{8}{*}{ Subsector } & Seleccionar entre: \\
\hline & & 1. Agroforestal \\
\hline & & 2. Agro-Silvo-Pastoral \\
\hline & & 3. Cultivos \\
\hline & & 4. Forestal \\
\hline & & 5. Ganadero/Pecuario \\
\hline & & 6. Pesca/acuicultura \\
\hline & & 7. Otro \\
\hline & \multirow{10}{*}{ Tipo de amenazas } & Seleccionar entre: \\
\hline & & 1. Altas temperaturas \\
\hline & & 2. Bajas temperaturas \\
\hline & & 3. Granizo \\
\hline & & $\begin{array}{l}\text { 4. Huracanes } \\
5 . \text { Incremento variabilidad interanual }\end{array}$ \\
\hline & & 6. Inundaciones \\
\hline & & 7. Olas de calor \\
\hline & & 8. Plagas y enfermedades \\
\hline & & 9. Sequía \\
\hline & & 10. Tormentas \\
\hline & País & $\begin{array}{l}\text { Países de Centroamérica u otros países/regiones con } \\
\text { condiciones similares o de interés. }\end{array}$ \\
\hline & $\begin{array}{l}\text { Zona agroecológica } \\
\text { donde se desarrolla } \\
\text { la BPA }\end{array}$ & $\begin{array}{l}\text { Seleccionar características zona agroclimática } \\
\text { (Desplegable) }\end{array}$ \\
\hline & \multirow{6}{*}{ Categoría } & Seleccionar entre: \\
\hline & & 1. Infraestructuras y equipamiento para mejorar la resiliencia \\
\hline & & $\begin{array}{l}\text { 2. Prácticas agropecuaria y diversificación de los medios de } \\
\text { vida }\end{array}$ \\
\hline & & $\begin{array}{l}\text { 3. Mejora de variedades resistentes a las sequías y/o } \\
\text { inundaciones }\end{array}$ \\
\hline & & 4. Combinación de prácticas que se refuerzan mutuamente \\
\hline & & 5. Otras \\
\hline Descripción BPA & Resumen de la BPA & $\begin{array}{l}\text { Incluir un resumen conciso sobre la BPA, con la información } \\
\text { suficiente para que se comprenda su utilidad }\end{array}$ \\
\hline
\end{tabular}




\begin{tabular}{|c|c|c|}
\hline Título BPA & $\begin{array}{l}\text { Nombre de la buena práctica } \\
\text { existente/ potencial }\end{array}$ & $\begin{array}{l}\text { Insertar nombre de la práctica o sistemas de } \\
\text { prácticas }\end{array}$ \\
\hline & $\begin{array}{l}\text { Descripción técnica detallada } \\
\text { de la BPA }\end{array}$ & $\begin{array}{l}\text { Incluir descripción más detallada de la BPA, así } \\
\text { como las especificaciones pertinentes para su } \\
\text { implementación }\end{array}$ \\
\hline & $\begin{array}{l}\text { Descripción de la práctica } \\
\text { "normal" (comparativa } \\
\text { o valor añadido de la BPA } \\
\text { respecto de la práctica } \\
\text { normal) }\end{array}$ & $\begin{array}{l}\text { Incluir aspectos de la práctica que se realizaría } \\
\text { en ausencia de la BPA, frente a los que la BPA } \\
\text { proporciona mayores beneficios o innovaciones }\end{array}$ \\
\hline Beneficios & $\begin{array}{l}\text { Beneficios esperados/ } \\
\text { observados }\end{array}$ & $\begin{array}{l}\text { Seleccionar entre: } \\
\text { 1. Aumento de los beneficios económicos } \\
\text { 2. Aumento de la producción } \\
\text { 3. Aumento de los ingresos } \\
\text { 4. Disminución de los costes de producción } \\
\text { 5. Reducción de la mano de obra } \\
\text { 6. Diversificación y mejoras en la alimentación } \\
\text { 7. Mayor resistencia a restricciones climáticas } \\
\text { 8. Prácticas de medios de vida más seguras } \\
\text { 9. Otros (especificar) }\end{array}$ \\
\hline Limitaciones & $\begin{array}{l}\text { Factores limitantes o riesgos } \\
\text { esperados/observados }\end{array}$ & Incluir factores limitantes o riesgos \\
\hline \multirow{5}{*}{ Criterios } & $\begin{array}{l}\text { Criterios Agroecológico: } \\
\text { Adecuación Agroecológica }\end{array}$ & Seleccionar criterios (Desplegable). \\
\hline & $\begin{array}{l}\text { Criterios Socioeconómico: } \\
\text { Viabilidad Socioeconómica }\end{array}$ & Seleccionar criterios (Desplegable) \\
\hline & $\begin{array}{l}\text { Criterio Resiliencia: Aumento } \\
\text { resiliencia a fenómeno } \\
\text { natural específico }\end{array}$ & Seleccionar criterios (Desplegable) \\
\hline & $\begin{array}{l}\text { Criterio ambiental: } \\
\text { Cobeneficios ambientales }\end{array}$ & Seleccionar criterios (Desplegable) \\
\hline & Otros Criterios & Seleccionar criterios (Desplegable) \\
\hline Comentarios & Comentarios adicionales & Incluir comentarios adicionales \\
\hline \multirow{3}{*}{ Referencia } & $\begin{array}{l}\text { Organización que } \\
\text { implementa/ documenta la } \\
\text { BPA }\end{array}$ & $\begin{array}{l}\text { Incluir las organizaciones que han } \\
\text { implementado o documentado la BP }\end{array}$ \\
\hline & Fuente de información & $\begin{array}{l}\text { Referencia bibliográfica en formato APA } \\
\text { preferiblemente }\end{array}$ \\
\hline & Enlace & A la web o documento, en el caso de que exista \\
\hline
\end{tabular}

Fuente: Elaboración propia. 


\section{Herramienta 2:}

\section{Criterios para la identificación de BPA}

Para qué sirve la herramienta: Para analizar el grado en que una BPA incluye los enfoques agroecológicos, socioeconómicos, de resiliencia, de cobeneficios ambientales y otros.

A quién va dirigida esta herramienta: A cualquier persona interesada en la metodología.

Cómo y cuándo se aplica: Durante todo el proceso de identificación, implementación y evaluación de una BPA.

A partir de los niveles de análisis del estudio "Disaster risk reduction at farm level: Multiple benefits, no regrets" (FAO, 2019), se ha definido una serie de criterios de evaluación de buenas prácticas que incorporan los componentes de agua y energía, para la gestión integral del riesgo de desastres y adaptación al cambio climático en el Corredor Seco Centroamericano y zonas áridas de la República Dominicana.

Una buena práctica, según la FAO (2013), "no es tan solo una práctica que se define buena en sí misma, sino que es una práctica que se ha demostrado que funciona bien y produce buenos resultados, $y$, por tanto, se recomienda como modelo. Se trata de una experiencia exitosa, que ha sido probada y validada, en un sentido amplio, que se ha repetido y que merece ser compartida con el fin de ser adoptada por el mayor número de personas".

En el ámbito de esta metodología, consideramos que una buena práctica en agricultura es adecuada para la adaptación al cambio climático y la reducción del riesgo de desastres, bajo las condiciones climáticas y socioeconómicas actuales, cuando cumple con el mayor número de los criterios que se exponen a continuación:

\subsection{Criterios agroecológicos}

En el Corredor Seco Centroamericano y zonas áridas de la República Dominicana, una buena práctica se puede considerar agroecológicamente adecuada a nivel de parcela si los subcriterios aplicados en el contexto de adaptación de los medios de vida al cambio climático y reducción del riesgo de desastres son los siguientes:

1. Se consigue aumentar el reciclaje de biomasa, con miras a optimizar la descomposición de materia orgánica y el ciclo de nutrientes a través del tiempo.

2. Se proveen las condiciones de suelo más favorables para el crecimiento vegetal, en particular mediante el manejo de la materia orgánica y el mejoramiento de la actividad biológica del suelo.

3. Se minimizan las pérdidas de energía, agua, nutrientes y recursos genéticos, mejorando la conservación y regeneración de suelos, recursos hídricos y la diversidad biológica agrícola. 
4. Aumenta el nivel de adopción de prácticas de apoyo a la biodiversidad en la granja a nivel de ecosistema, especie y genético.

5. Se articula el sistema de producción a nivel local mediante su pertenencia a organizaciones, el establecimiento de sinergias en servicios, insumos y la participación en innovaciones, entre otros.

6. Aumenta la autonomía en el autoabastecimiento en alimentos, insumos, energía, tecnologías y otros.

7. Aumenta la capacidad de resiliencia a eventos extremos externos (cambio climático u otros).

8. Se Contribuye a la seguridad y soberanía alimentaria local, ofreciendo al mercado, o por otras vías, diversidad de productos sanos e inocuos a la población de manera continua.

\subsection{Criterios socioeconómicos}

Una buena práctica es económica y socialmente beneficiosa cuando contribuye a mejorar los medios de vida y también puede ser accesible a personas con recursos limitados, tanto en presencia como incluso en ausencia de amenazas y peligros. Estos criterios están alineados a la Agenda 2030 y a los Objetivos de Desarrollo Sostenible (ODS). Los sub-criterios aplicados en el contexto de adaptación de los medios de vida al cambio climático y reducción del riesgo de desastres son:

1. Se mejora los medios de vida y la seguridad alimentaria del productor y/o de la comunidad.

2. Existe la posibilidad de reducción de costes totales y aumento del beneficio económico en relación con la práctica tradicional (ODS 1 ).

3. Existe la posibilidad de mantener mejores beneficios económicos incluso después de un desastre en comparación con la práctica tradicional.

4. Se mejoran las capacidades técnicas y funcionales tanto institucionales como individuales de los productores y promotores para superar las limitaciones productivas, así como el fortalecimiento de asociaciones de productores y mejora del acompañamiento técnico adaptado al contexto.

5. Se promueve un modelo de consumo y producción agroalimentario responsable con el objetivo de paliar las necesidades alimentarias y nutricionales del productory/o la comunidad (ODS 12).

6. Existe la posibilidad de producir autónomamente (semillas, abonos, forrajes, etc.) sin depender de los mercados.

7. Existe coordinación entre actores involucrados en la buena práctica.

8. Se incide especialmente en la situación socioeconómica de las mujeres. Promoción de la igualdad de género y fomento de la equidad y del empoderamiento de las mujeres (ODS 5)

9. Repercute en la mejora de indicadores sociales: acceso a servicios de agua potable y saneamiento, salud, educación, etc. (ODS 3, ODS 4 y ODS 6)

10.Se reducen tiempo y esfuerzo dedicado a las labores (ODS 8).

11.Se genera empleo local y/o en agricultura y empleo decente - trabajo en agricultura no calificado tasa de salario diario. 
12. Mejora del acceso al mercado y ajuste de la oferta productiva (productos, tiempo y cantidad) al mismo con preferencia por mercados locales y oportunidades especialmente ventajosas de exportación.

13. Creación de capacidades para la introducción de tecnología renovable (ODS 9).

14. Se promueve el acceso universal y seguro al agua potable (Derecho Humano al agua, ODS 6.1)

\subsection{Criterios de resiliencia}

Una buena práctica en agricultura aumenta la resiliencia ante el impacto de amenazas climáticas. La buena práctica en agricultura debe aumentar la resiliencia de los medios de vida contra los impactos de las amenazas climáticas (sequías, inundaciones, tormentas, huracanes, incendios incontrolados, deslaves, etc.) También, aunque en un segundo plano, se valora que la buena práctica pueda hacer frente a crisis prolongadas, ya sean provocadas por el ser humano (conflictos, inestabilidad socioeconómica, etc.), por la naturaleza o por combinación de los dos. Los sub-criterios aplicados en el contexto de adaptación de los medios de vida al cambio climático y reducción del riesgo de desastres son:

1. Fortalecimiento de las capacidades a todos los niveles para reducir y gestionar el riesgo de desastres. Trabajo conjunto de comunidades, científicos y responsables de políticas para mejorar la adaptación.

2. Sistemas de adaptación a las amenazas del clima y al cambio climático.

3. Reducción de impactos y/o pérdidas vinculadas a amenazas naturales y cambio climático.

4. Inclusión de sistemas integrados agroforestales: cultivos, ganadería, árboles y arbustos, que puedan diversificar la producción y aumentar los ingresos.

5. Inclusión de la agricultura de conservación de suelos: cobertura del suelo, mínima perturbación del suelo, mejora de los suelos, rotación de cultivos, medidas que reduzcan la erosión y mejoran la captación de agua.

6. Inclusión de variedades más resistentes a situaciones de estrés biótico y abiótico.

7. Mejora de los derechos de acceso y tenencia de la tierra.

8. Gestión integrada de los recursos hídricos a todos los niveles.

9. Gestión sostenible de los recursos y sistemas energéticos resilientes a fenómenos climáticos extremos.

10. Prácticas que permiten la estabilización de los ingresos de los sistemas productivos, la disponibilidad de herramientas de disminución del riesgo, el acceso a créditos y seguros.

11. Estrategias de organización social (redes de solidaridad, intercambio de alimento, etc.).

12. Mantenimiento y mejora de las infraestructuras viales para la producción de energía y de suministro de agua.

\subsection{Criterios relacionados con los cobeneficios ambientales}

La buena práctica debe proveer cobeneficios ambientales que, de acuerdo con el IPCC son aquellos que se derivan de las políticas que se implementan, incluyendo, las más concretas dirigidas a la mitigación del cambio climático (ODS 13 Acción por el clima). Debe tenerse en 
cuenta que la mayoría de las políticas diseñadas para mitigar la emisión de Gases de Efecto Invernadero (GEI) tienen otros efectos de al menos igual importancia, por ejemplo, relacionados con los objetivos de desarrollo, sostenibilidad y equidad.

Los sub-criterios aplicados en el contexto de adaptación de los medios de vida al cambio climático y reducción de riesgo de desastres son:

1. Uso eficiente de recursos hídricos y reducción del estrés hídrico.

2. Mejora del acceso al agua para uso doméstico y para el riego.

3. Mejora de la calidad del agua.

4. Reducción o mayor eficiencia en el uso de fertilizantes, pesticidas u otros insumos agropecurarios.

5. Utilización de insumos fácilmente reciclables.

6. Conservación de recursos naturales y sus funciones en los ecosistemas.

7. Reducción de la degradación del suelo (Incluida la erosión del suelo, disminución de la fertilidad del suelo, salinización de la tierra regada y anegamiento).

8. Reducción de la contaminación del agua y de los suelos.

9. Aumento de la captura de carbono por encima y por debajo del suelo.

10. Promoción de la eficiencia energética y el uso de energía renovable.

11. Introducción de tecnología para reducir el consumo de leña y la deforestación.

12. Refugios para la biodiversidad integrados en el sistema agricola.

13. Rescatar y conservar variedades locales o la biodiversidad local.

14. Fomento de la mitigación del cambio climático a través de la reducción de emisiones de gases de efecto invernadero.

\subsection{Otros criterios}

A parte de los anteriores, una buena práctica, debe beneficiar tanto al productor, como a la comunidad y su entorno. Entre otros, pero sin limitarse a estos, los subcriterios aplicados en el contexto de adaptación de los medios de vida al cambio climático y reducción del riesgo de desastres son:

1. Generación de empleo indirecto.

2. Inversión del sector privado.

3. Ahorro de gasto público.

4. Innovación tecnológica o social.

5. Dinamización y revitalización de zonas rurales.

6. Fomento de la facilidad de apropiación.

7. Énfasis en la agricultura campesina y familiar.

8. Reducción de desperdicios de los alimentos.

9. Promoción de patrones de consumo y dietas sostenibles.

10. Fomento de sinergias entre medidas.

11. Inclusión de perspectiva de largo plazo.

12. Garantizar el acceso a una energía asequible, fiable, sostenible y moderna. 


\section{Herramienta 3:}

\section{Estructura analítica y valoración de criterios y subcriterios}

Para qué sirve la herramienta: Para realizar un primer análisis de la pertinencia de la aplicación de BPA para la adaptación al cambio climático y la gestión integral del riesgo de desastres en los diferentes subsectores agropecuarios.

Quién tiene que rellenar la tabla: Personal técnico en colaboración con los agricultores.

Cómo y cuándo se aplica: (1) al inicio del análisis de la BPA, a modo de evaluación ex-ante, para ayudar a centrar los ámbitos sobre los que incide la BPA, y (2) durante la implementación de la BPA, para guiar el análisis de campo y de costo-beneficio.

Como primer paso para el análisis de una BPA es importante analizar la pertinencia de la BPA sobre la GIRD a través de una matriz que relaciona y valora los criterios con respecto a:

- Las amenazas.

- Los sub-sectores agropecuarios.

- Otros aspectos complementarios y transversales, como la igualdad de género y el respeto a las culturas indígenas.

Las amenazas se han clasificado en cuatro grupos para facilitar el análisis, de manera que se valora cada BPA respecto a cada uno de estos grupos y se realizan comentarios específicos respecto a las amenazas secundarias consideradas.

1. Sequía (incluye olas de calor).

2. Inundaciones (incluye tormentas, granizo, huracanes).

3. Variabilidad interanual (incluye altas o bajas temperaturas, adelanto o retraso de la época de lluvias/seca).

4. Plagas y enfermedades.

Los subsectores considerados son cuatro:

1. Cultivos.

2. Ganadería.

3. Pesca o acuicultura.

4. Forestal, agroforestal o agrosilvopastoral.

La escala de valoración establecida es de 0 = nada, $1=$ poco/algo y 2 = mucho

En cuanto a los aspectos complementarios y transversales se pretende identificar si son relevantes o no (se marca con sí o no): 
- Época de lluvias o época seca.

- Existencia de componente agua y/o energía

- Inclusión de la perspectiva de género y/o de los pueblos indígenas.

La matriz a completar se presenta en la Tabla 3.1 y pretende ayudar a identificar cuáles son las situaciones más relevantes de aplicación de la BPA.

Esta plantilla se puede adaptar a las condiciones específicas de otros casos de estudio.

Tabla 3.1. Matriz de análisis ex-ante de la pertinencia de las BPA sobre la Gestión Integral del Riesgo de Desastres.

\begin{tabular}{|c|c|c|c|c|c|c|}
\hline \multirow[b]{2}{*}{ Amenazas } & \multirow[b]{2}{*}{ Criterios } & Cultivos & Ganadería & $\begin{array}{c}\text { Pesca } \\
\text { (incl. } \\
\text { acuicultura) }\end{array}$ & $\begin{array}{l}\text { Forestal/ Agro- } \\
\text { forestal (incl. } \\
\text { Agro-silvo-pas- } \\
\text { toral) }\end{array}$ & Pertinencia global \\
\hline & & $\begin{array}{l}\text { Puntuar con } \\
\text { un: } \\
\text { 0=nada; } \\
\text { 1=poco/algo; } \\
\text { 2= mucho }\end{array}$ & $\begin{array}{l}\text { Puntuar con } \\
\text { un: } \\
\text { 0=nada; } \\
\text { 1=poco/algo; } \\
\text { 2= mucho }\end{array}$ & $\begin{array}{l}\text { Puntuar con } \\
\text { un: } \\
\text { 0=nada; } \\
\text { 1=poco/algo; } \\
\text { 2= mucho }\end{array}$ & $\begin{array}{l}\text { Puntuar con un: } \\
\text { 0=nada; } \\
\text { 1=poco/algo; } \\
\text { 2= mucho }\end{array}$ & $\begin{array}{l}\text { Valor medio de la } \\
\text { puntuación obtenida } \\
\text { para los sub-sectores } \\
\text { Cultivos+ganade- } \\
\text { ría+Pesca+Forestal }\end{array}$ \\
\hline \multirow{5}{*}{$\begin{array}{l}\text { Sequía } \\
\text { *Olas de calor }\end{array}$} & $\begin{array}{l}\text { Criterios } \\
\text { agroecológicos }\end{array}$ & & & & & \\
\hline & $\begin{array}{l}\text { Criterios viabilidad } \\
\text { socioeconómica }\end{array}$ & & & & & \\
\hline & Criterios de resiliencia & & & & & \\
\hline & $\begin{array}{l}\text { Criterios de } \\
\text { co-beneficios } \\
\text { ambientales } \\
\end{array}$ & & & & & \\
\hline & Otros criterios & & & & & \\
\hline \multirow{5}{*}{$\begin{array}{l}\text { Inundaciones } \\
\text { ^Tormentas, } \\
\text { granizo, } \\
\text { huracanes }\end{array}$} & $\begin{array}{l}\text { Criterios } \\
\text { agroecológicos }\end{array}$ & & & & & \\
\hline & $\begin{array}{l}\text { Criterios viabilidad } \\
\text { socioeconómica }\end{array}$ & & & & & \\
\hline & Criterios de resiliencia & & & & & \\
\hline & $\begin{array}{l}\text { Criterios de } \\
\text { co-beneficios } \\
\text { ambientales }\end{array}$ & & & & & \\
\hline & Otros criterios & & & & & \\
\hline \multirow{5}{*}{$\begin{array}{l}\text { Variabilidad } \\
\text { interanual } \\
\text { ^Altas o bajas } \\
\text { temperaturas }\end{array}$} & $\begin{array}{l}\text { Criterios } \\
\text { agroecológicos }\end{array}$ & & & & & \\
\hline & $\begin{array}{l}\text { Criterios viabilidad } \\
\text { socioeconómica }\end{array}$ & & & & & \\
\hline & Criterios de resiliencia & & & & & \\
\hline & $\begin{array}{l}\text { Criterios de } \\
\text { co-beneficios } \\
\text { ambientales }\end{array}$ & & & & & \\
\hline & Otros criterios & & & & & \\
\hline
\end{tabular}




\begin{tabular}{|c|c|c|c|c|c|c|}
\hline \multirow[b]{2}{*}{ Amenazas } & \multirow[b]{2}{*}{ Criterios } & Cultivos & Ganadería & $\begin{array}{c}\text { Pesca } \\
\text { (incl. } \\
\text { acuicultura) }\end{array}$ & $\begin{array}{l}\text { Forestal/ Agro- } \\
\text { forestal (incl. } \\
\text { Agro-silvo-pas- } \\
\text { toral) }\end{array}$ & Pertinencia global \\
\hline & & $\begin{array}{l}\text { Puntuar con } \\
\text { un: } \\
\text { 0=nada; } \\
\text { 1=poco/algo; } \\
\text { 2= mucho }\end{array}$ & $\begin{array}{c}\text { Puntuar con } \\
\text { un: } \\
0=\text { nada; } \\
\text { 1=poco/algo; } \\
2=\text { mucho }\end{array}$ & $\begin{array}{l}\text { Puntuar con } \\
\text { un: } \\
\text { 0=nada; } \\
\text { 1=poco/algo; } \\
\text { 2= mucho }\end{array}$ & $\begin{array}{l}\text { Puntuar con un: } \\
\text { 0=nada; } \\
\text { 1=poco/algo; } \\
\text { 2= mucho }\end{array}$ & $\begin{array}{l}\text { Valor medio de la } \\
\text { puntuación obtenida } \\
\text { para los sub-sectores } \\
\text { Cultivos+ganade- } \\
\text { ría+Pesca+Forestal }\end{array}$ \\
\hline \multirow{5}{*}{$\begin{array}{l}\text { Plagas y } \\
\text { enfermedades }\end{array}$} & $\begin{array}{l}\text { Criterios } \\
\text { agroecológicos }\end{array}$ & & & & & \\
\hline & $\begin{array}{l}\text { Criterios viabilidad } \\
\text { socioeconómica }\end{array}$ & & & & & \\
\hline & Criterios de resiliencia & & & & & \\
\hline & $\begin{array}{l}\text { Criterios de } \\
\text { co-beneficios } \\
\text { ambientales }\end{array}$ & & & & & \\
\hline & Otros criterios & & & & & \\
\hline
\end{tabular}

\begin{tabular}{|l|l|l|l|l|l|l|l|}
\hline \multicolumn{9}{|c|}{$\begin{array}{c}\text { Aspectos complementarios } \\
\text { (marcar sí o no) }\end{array}$} & \multicolumn{2}{c|}{$\begin{array}{c}\text { Aspectos transversales } \\
\text { (marcar sí o no) }\end{array}$} & Observaciones \\
\hline & $\begin{array}{c}\text { Época } \\
\text { seca }\end{array}$ & $\begin{array}{c}\text { Época } \\
\text { Iluvias }\end{array}$ & $\begin{array}{c}\text { Compo- } \\
\text { nente agua }\end{array}$ & $\begin{array}{c}\text { Componen- } \\
\text { te energía }\end{array}$ & $\begin{array}{c}\text { Enfoque de } \\
\text { Género }\end{array}$ & $\begin{array}{c}\text { Aspectos } \\
\text { indígenas }\end{array}$ & \\
\hline Sequía & & & & & & & \\
\hline Inundaciones & & & & & & & \\
\hline $\begin{array}{l}\text { Variabilidad } \\
\text { interanual }\end{array}$ & & & & & & & \\
\hline $\begin{array}{l}\text { Plagas y } \\
\text { enfermedades }\end{array}$ & & & & & & & \\
\hline
\end{tabular}

\section{Herramienta 4:}

Propuesta de línea de tiempo para la identificación de BPA en el Corredor Seco Centroamericano y zonas áridas de la República Dominicana

Para qué sirve la herramienta: reproduce la matriz de trabajo para la evaluación de las BPA definiendo las actividades o pasos, el objetivo marcado, las tareas a realizar, su duración y el resultado esperado.

Quién tiene que rellenar la tabla: Personal técnico del proyecto.

Cómo y cuándo se aplica: Se prepara al inicio del proyecto y se verifica en función de la línea de tiempo establecida y se puede incorporar en el resultado las fuentes de verificación. 

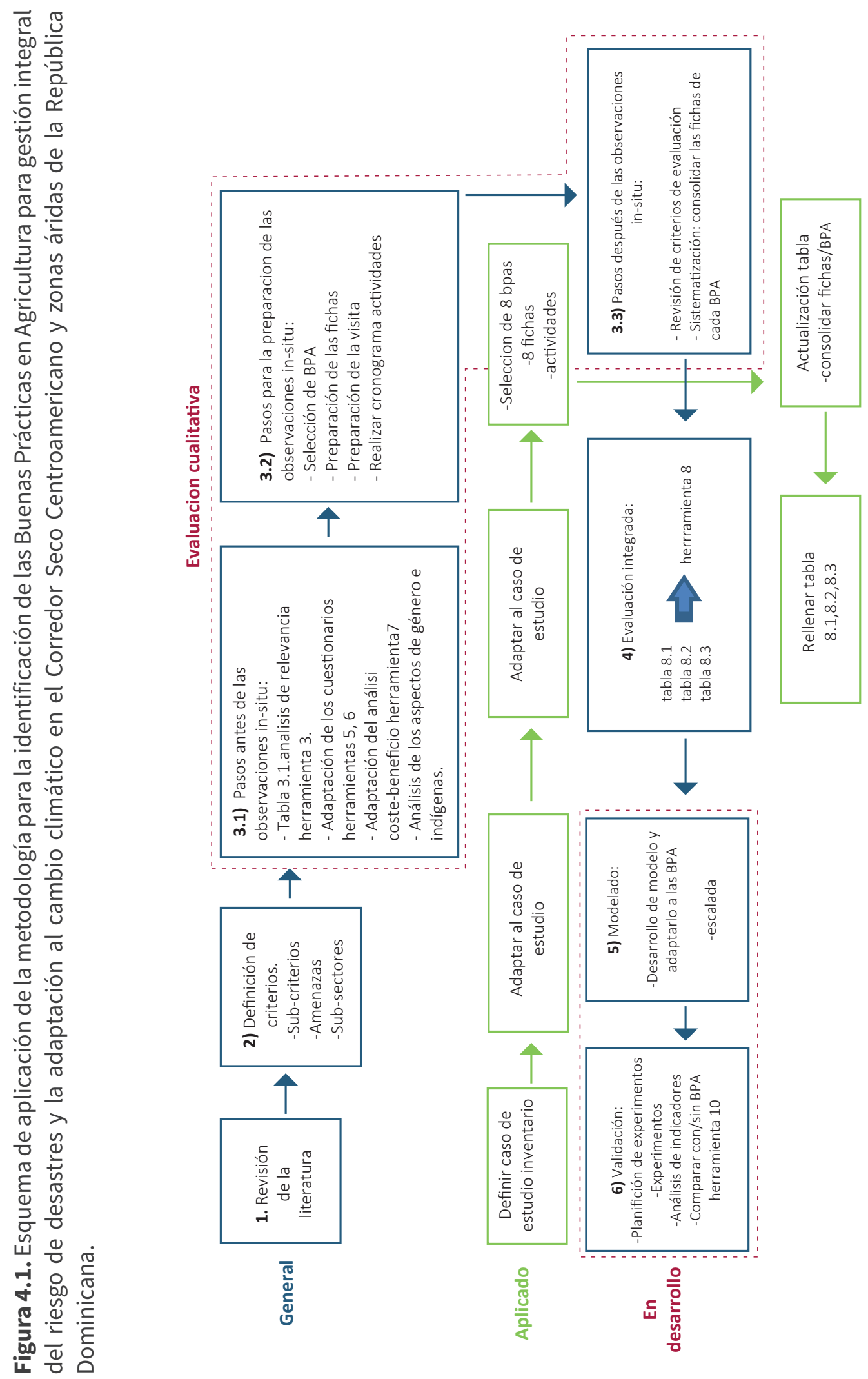


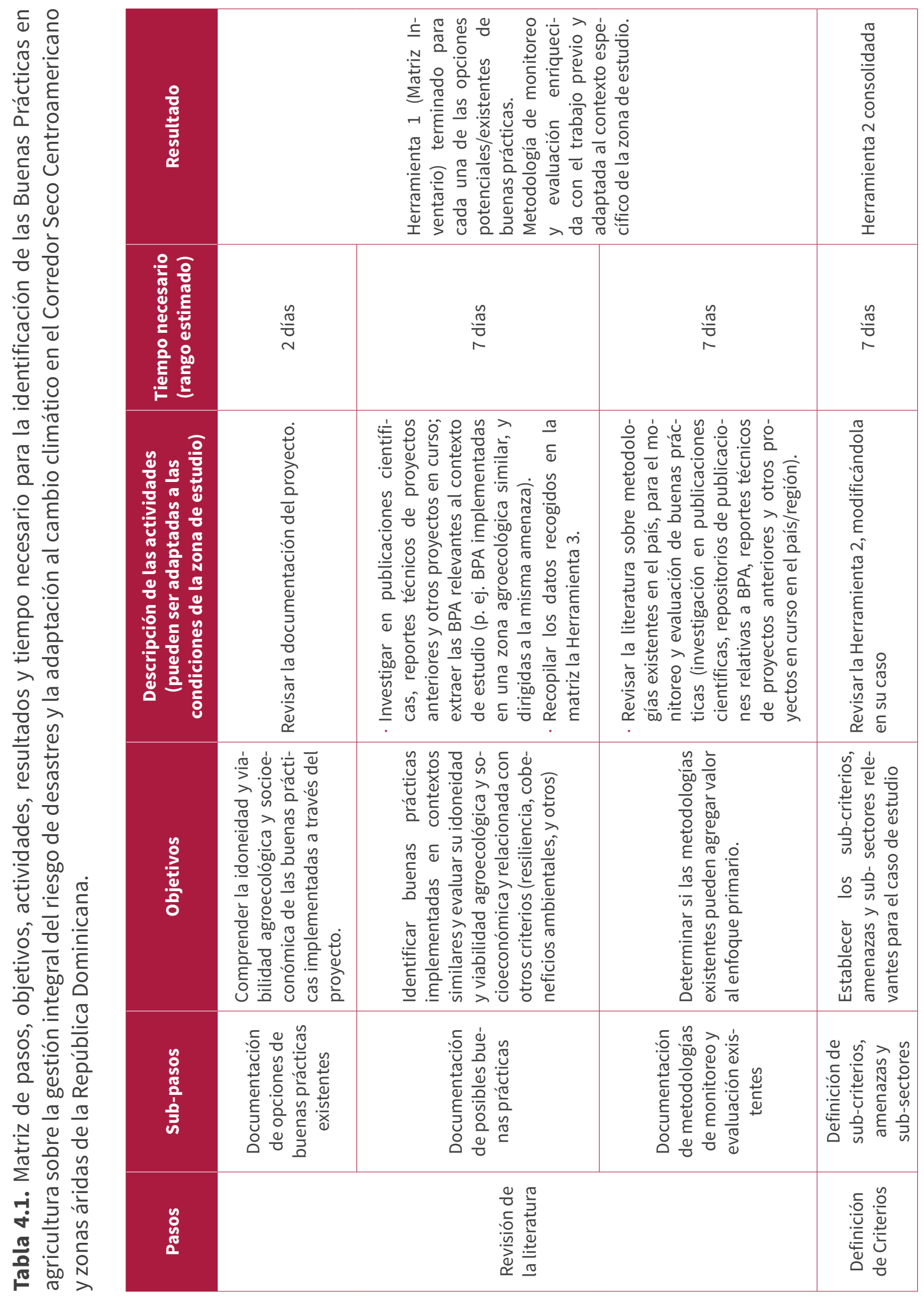




\begin{tabular}{|c|c|c|c|}
\hline 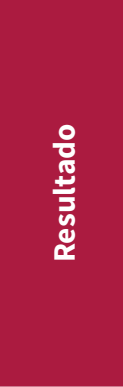 & $\begin{array}{l}\frac{\pi}{0} \\
\frac{0}{0} \\
\frac{0}{E} \\
0 \\
-1 \\
m \\
\frac{\pi}{0} \\
\frac{\pi}{0} \\
\frac{\pi}{n}\end{array}$ & 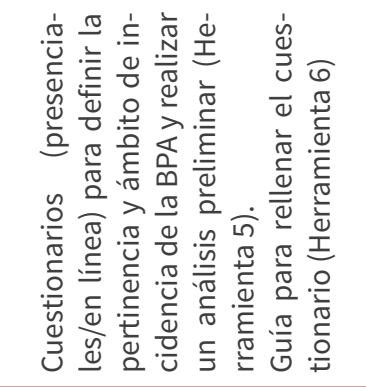 & 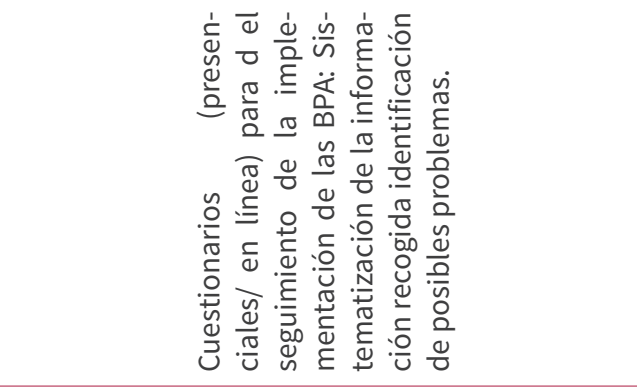 \\
\hline 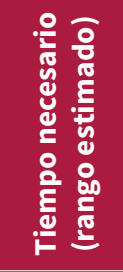 & $\frac{n}{\frac{n}{0}}$ & 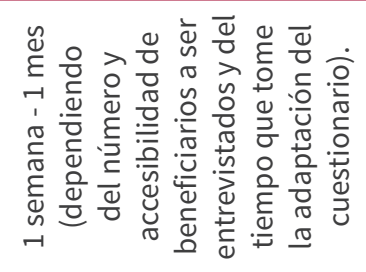 & 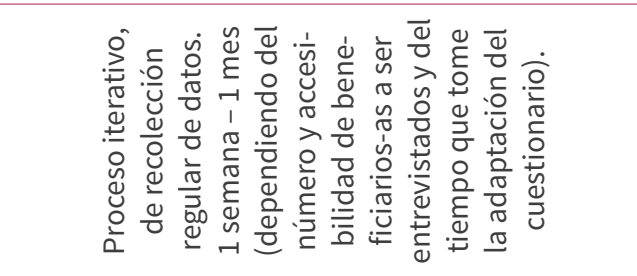 \\
\hline 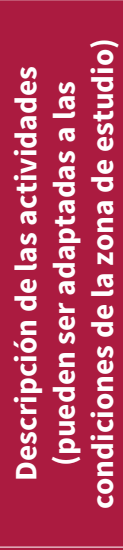 & 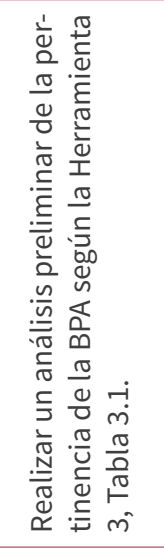 & 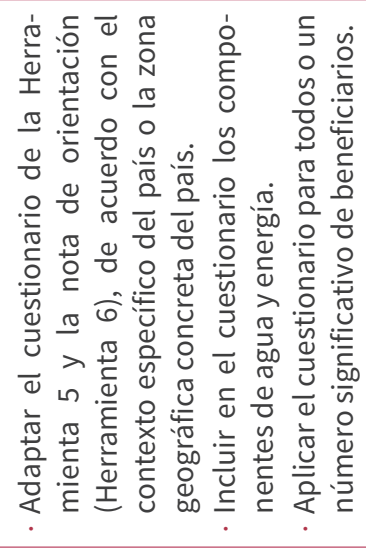 & 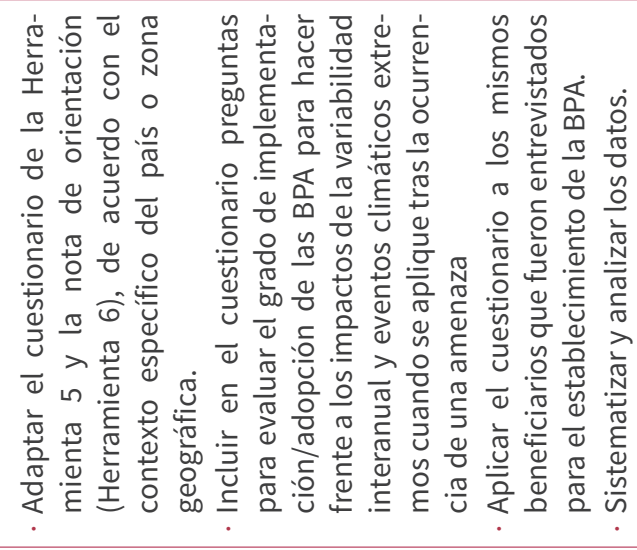 \\
\hline 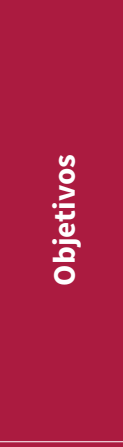 & 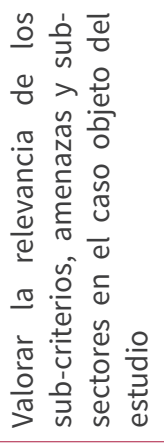 & 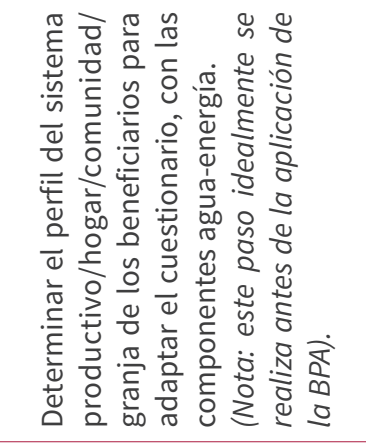 & 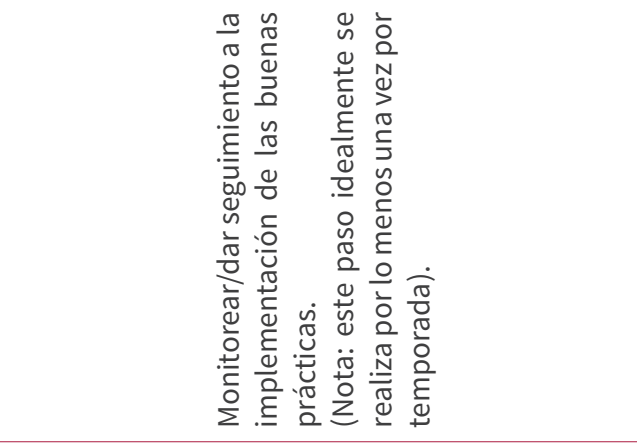 \\
\hline 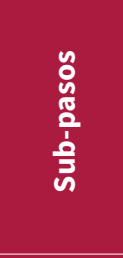 & 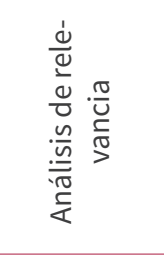 & 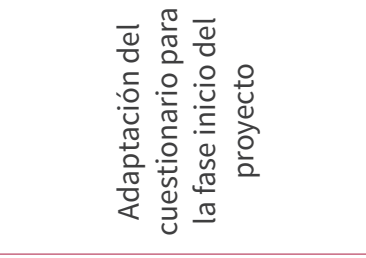 & 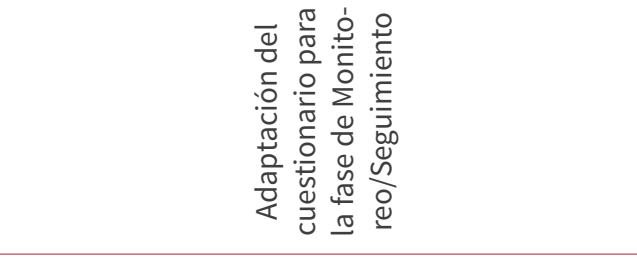 \\
\hline 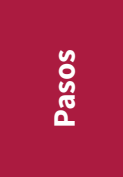 & \multicolumn{3}{|c|}{ 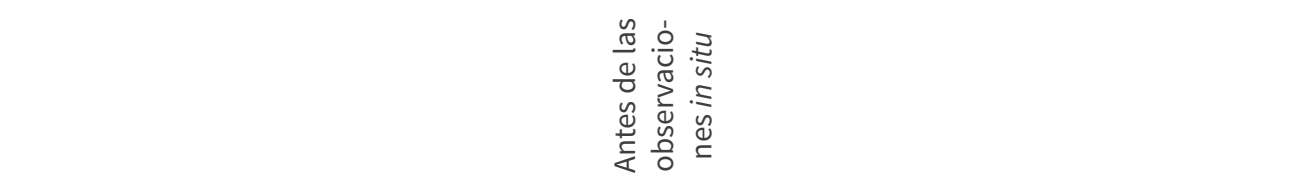 } \\
\hline
\end{tabular}




\begin{tabular}{|c|c|c|c|}
\hline 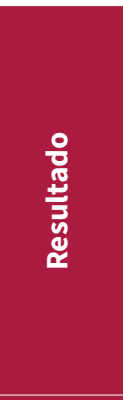 & 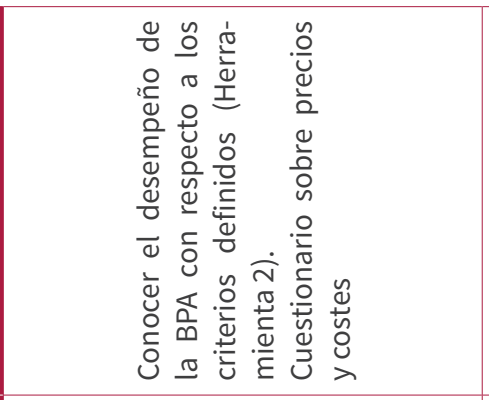 & 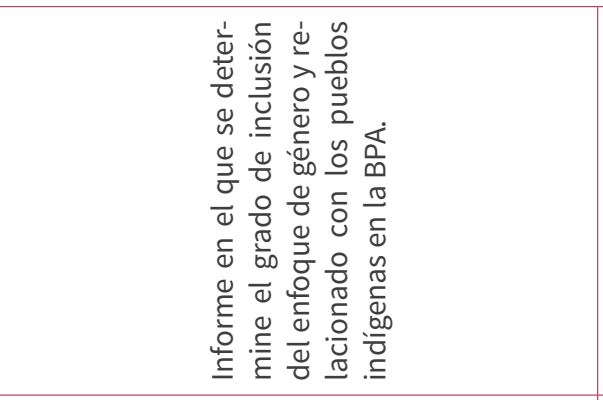 & 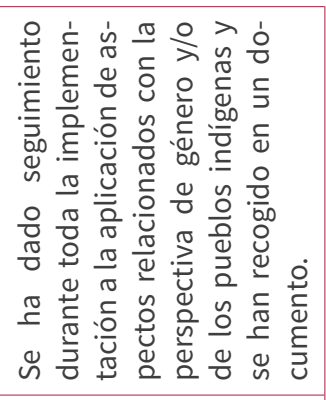 \\
\hline 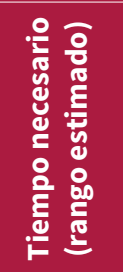 & 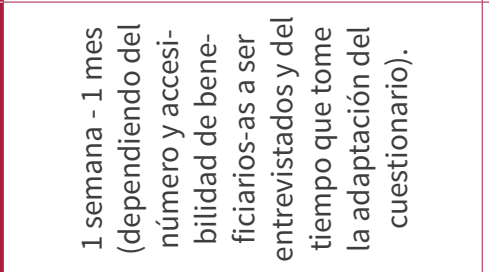 & 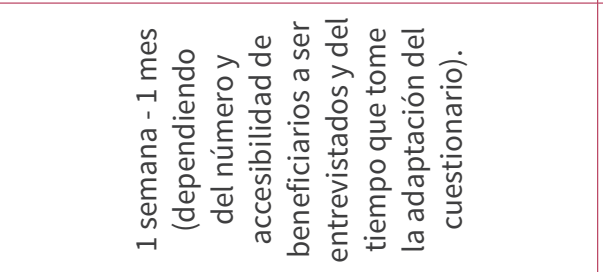 & 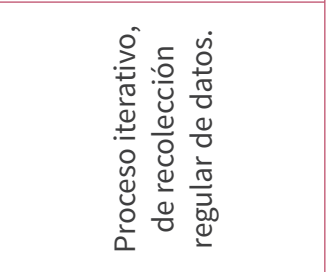 \\
\hline 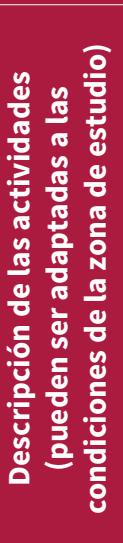 & 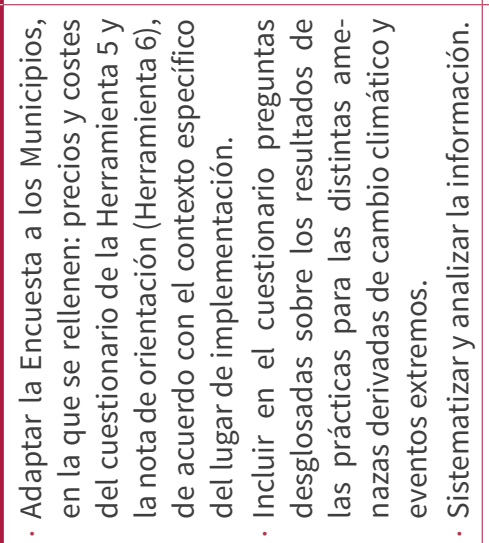 & 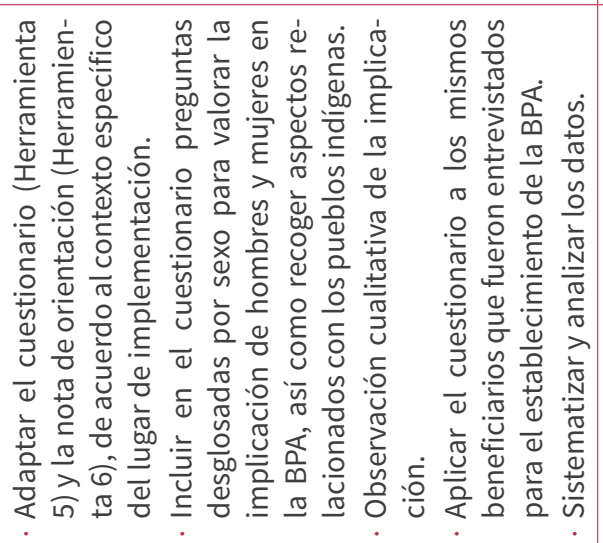 & 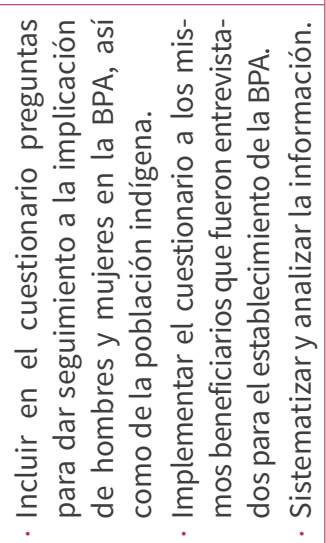 \\
\hline 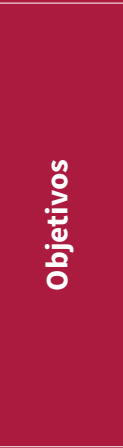 & 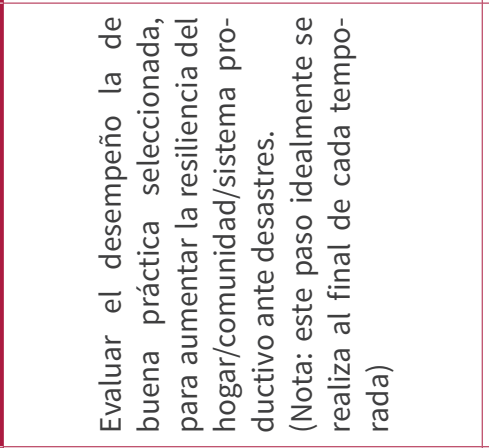 & 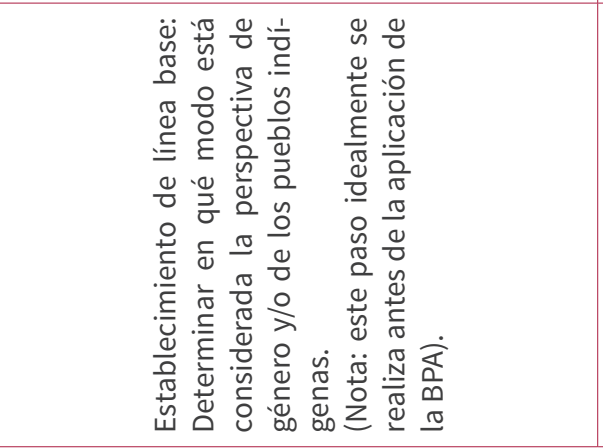 & 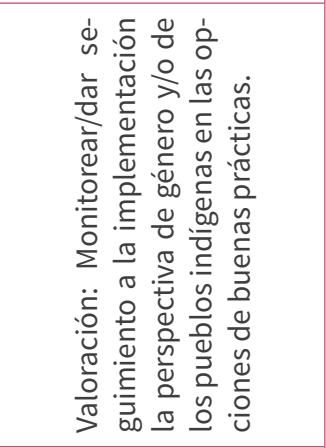 \\
\hline 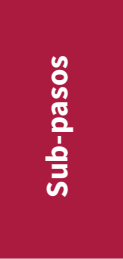 & 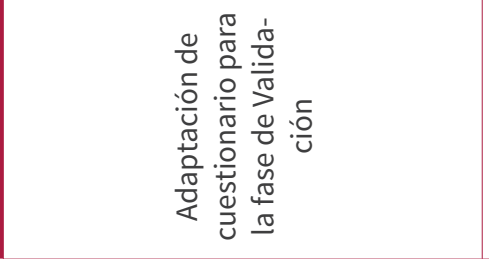 & \multicolumn{2}{|l|}{ 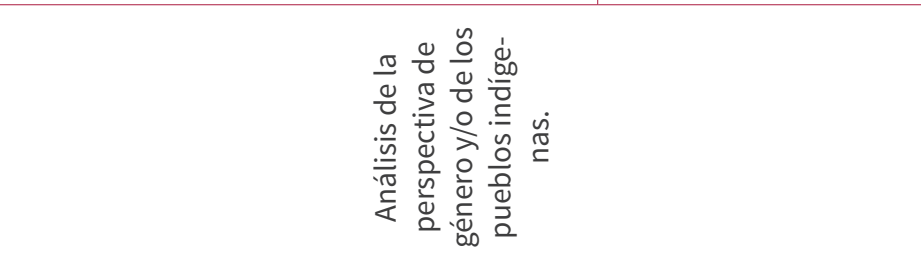 } \\
\hline 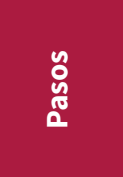 & & 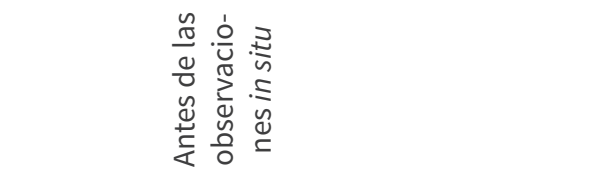 & \\
\hline
\end{tabular}




\begin{tabular}{|c|c|c|c|c|c|}
\hline 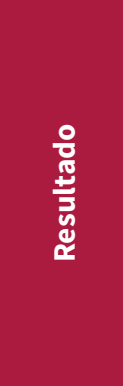 & 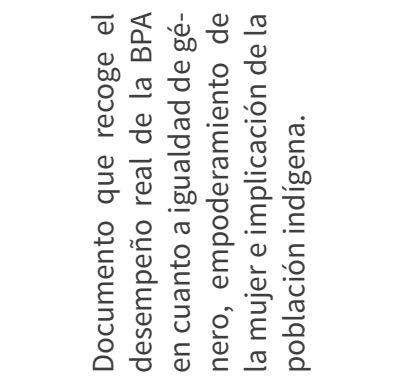 & \multicolumn{4}{|c|}{ 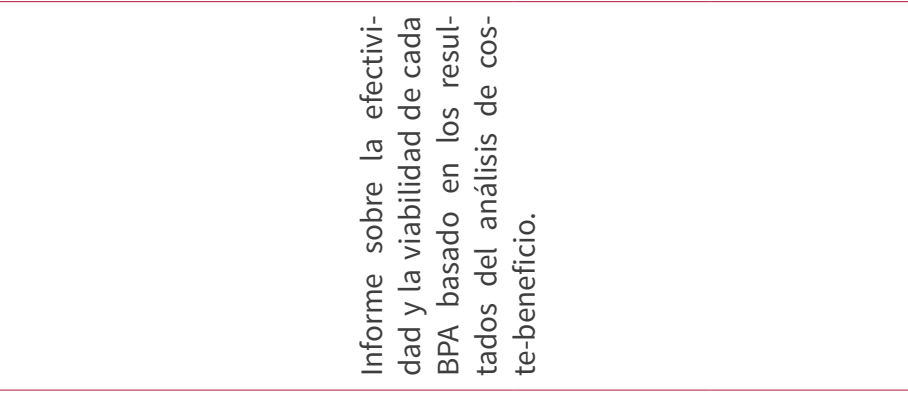 } \\
\hline 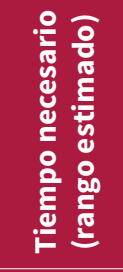 & 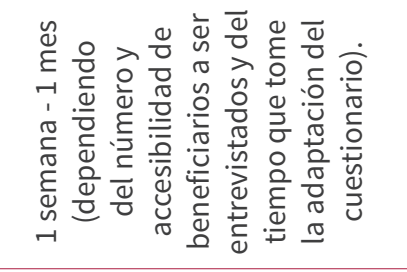 & \multicolumn{4}{|c|}{ 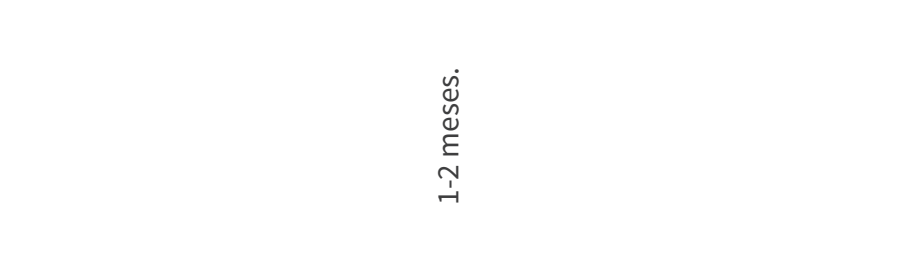 } \\
\hline 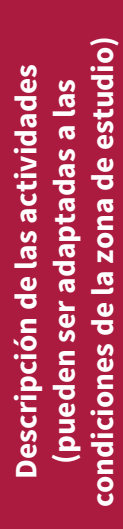 & 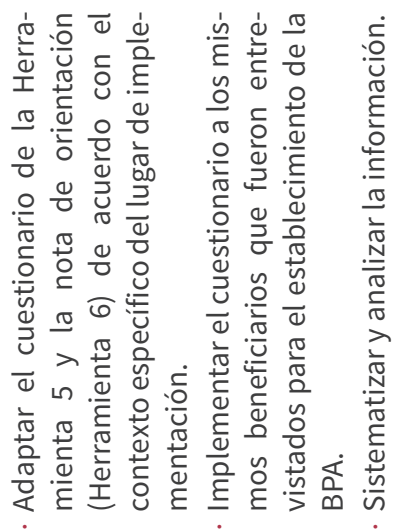 & 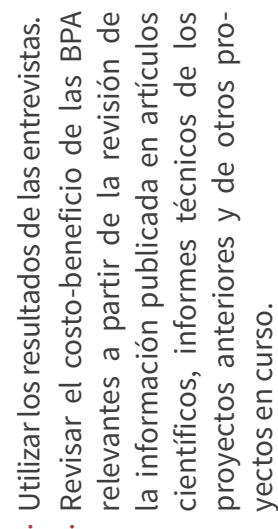 & 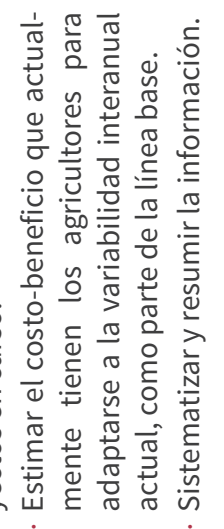 & 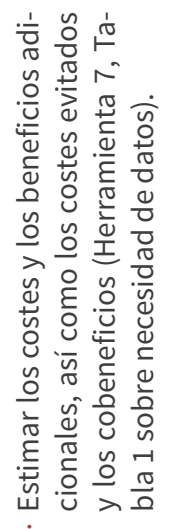 & 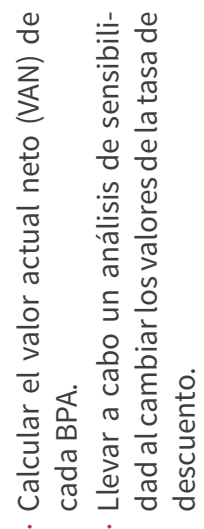 \\
\hline $\begin{array}{l}u \\
\stackrel{3}{*} \\
\stackrel{\circ}{\circ}\end{array}$ & 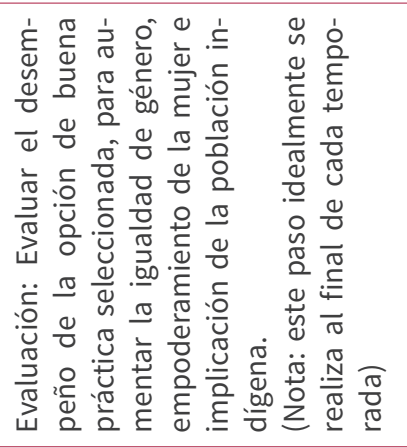 & 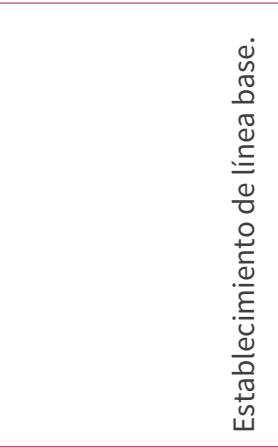 & & 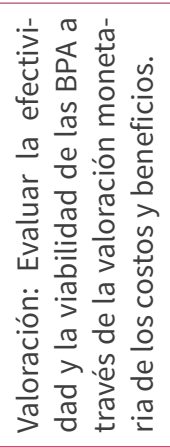 & 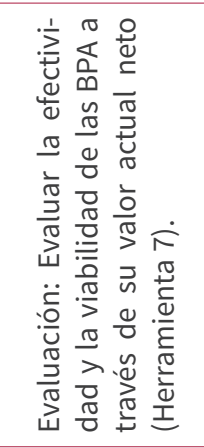 \\
\hline 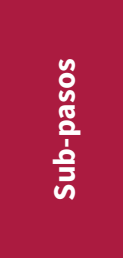 & 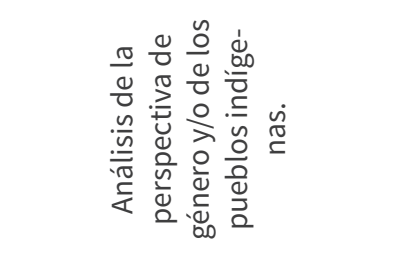 & & 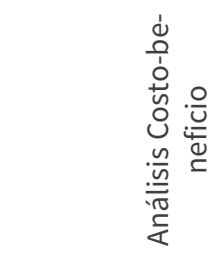 & & \\
\hline 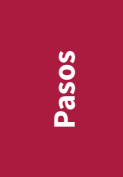 & & 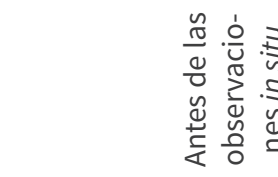 & & & \\
\hline
\end{tabular}




\begin{tabular}{|c|c|c|c|c|c|c|}
\hline 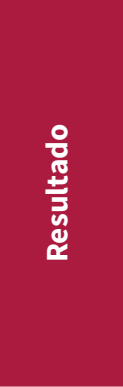 & 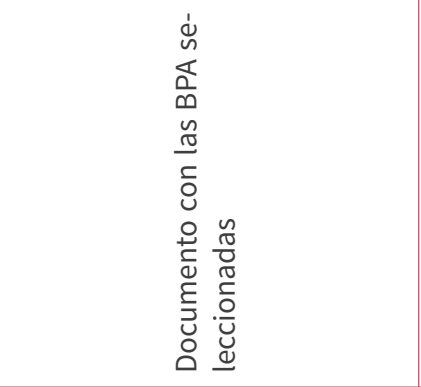 & 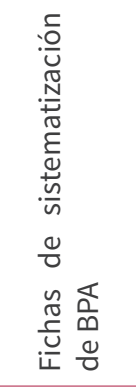 & 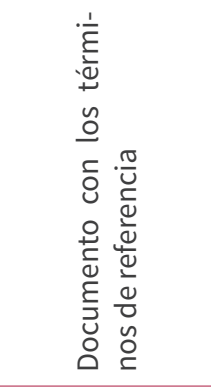 & 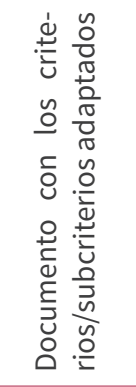 & 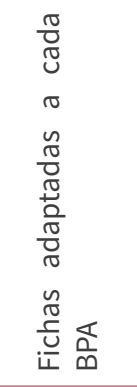 & 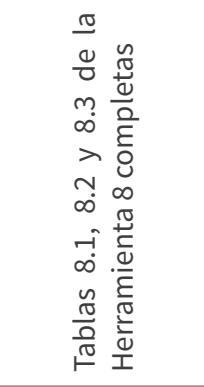 \\
\hline 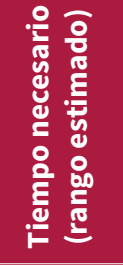 & 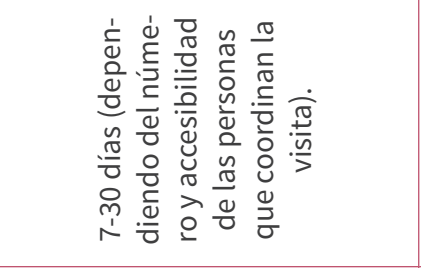 & 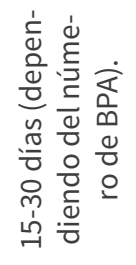 & 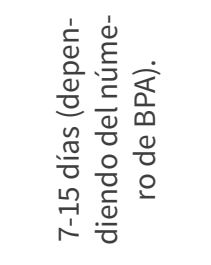 & 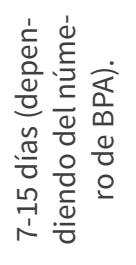 & 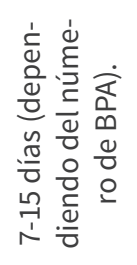 & 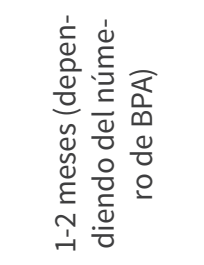 \\
\hline 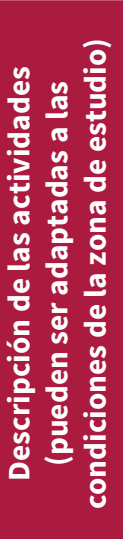 & 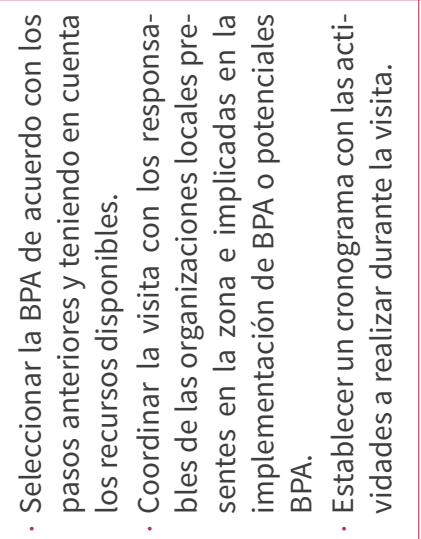 & 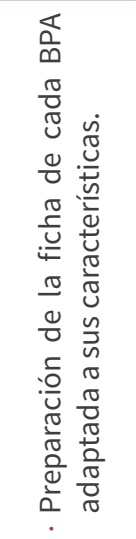 & 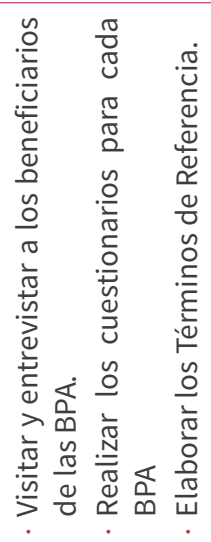 & 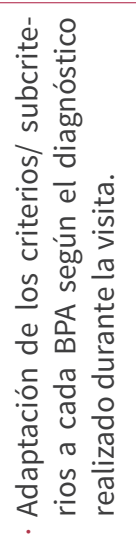 & 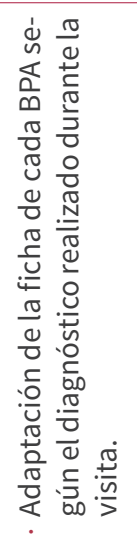 & 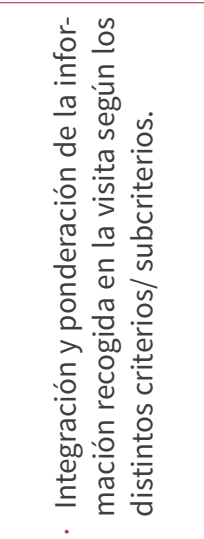 \\
\hline 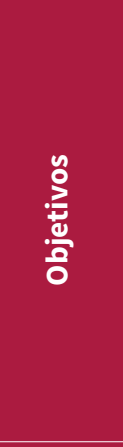 & 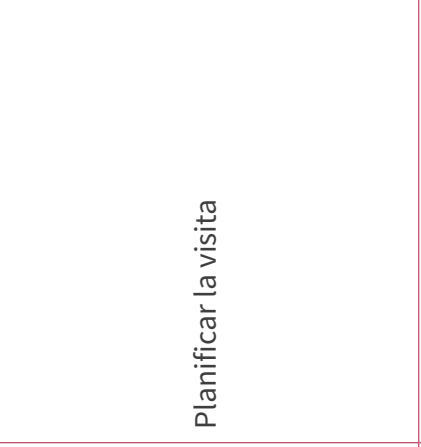 & 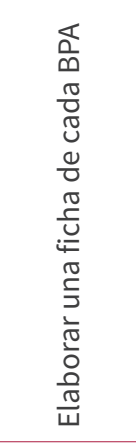 & 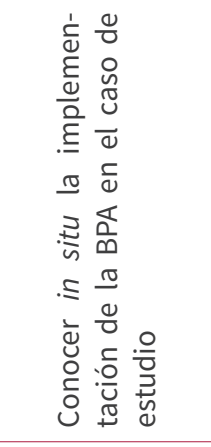 & 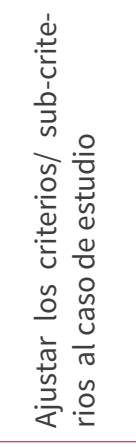 & 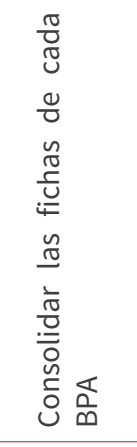 & 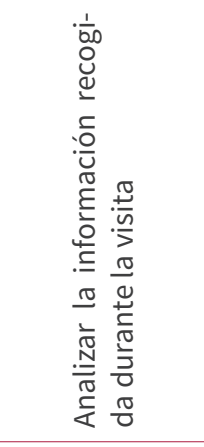 \\
\hline 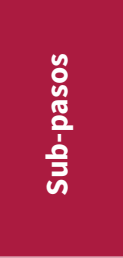 & 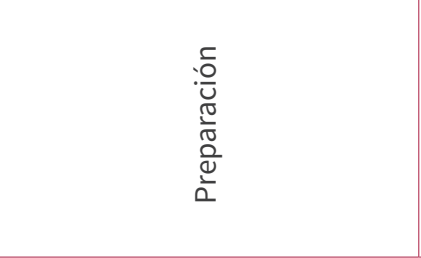 & 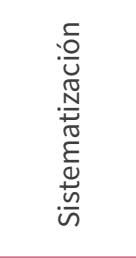 & 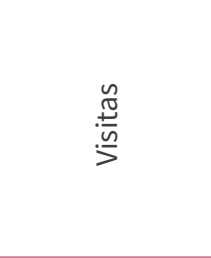 & 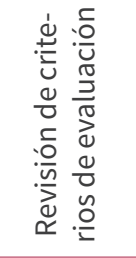 & 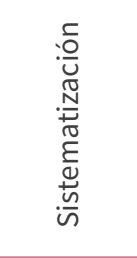 & 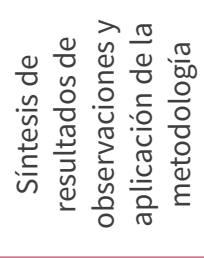 \\
\hline 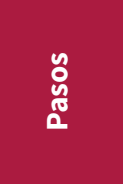 & \multicolumn{3}{|c|}{ 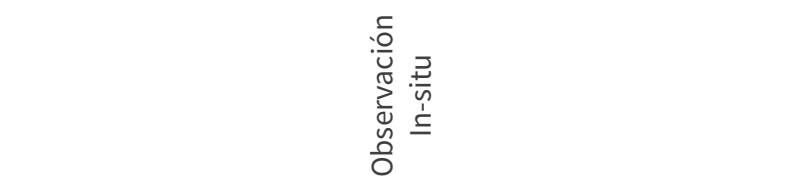 } & \multicolumn{2}{|c|}{ 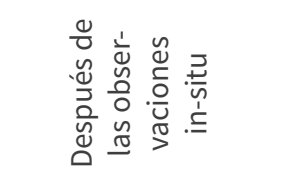 } & 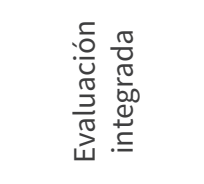 \\
\hline
\end{tabular}




\begin{tabular}{|c|c|c|}
\hline 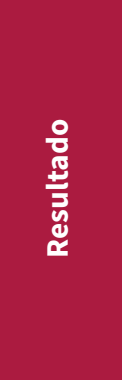 & 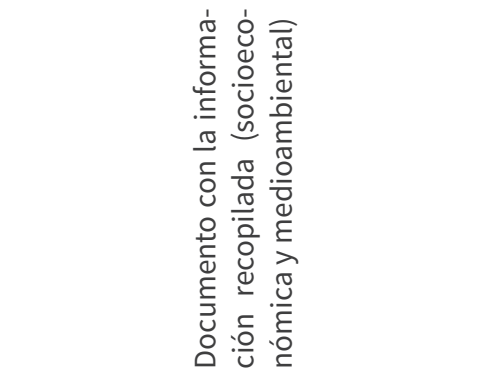 & 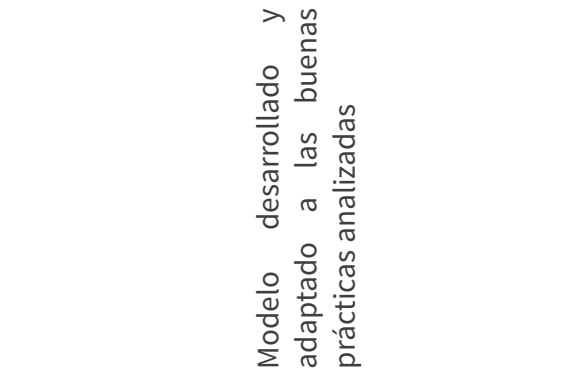 \\
\hline 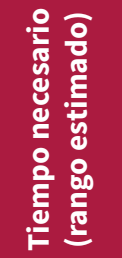 & & 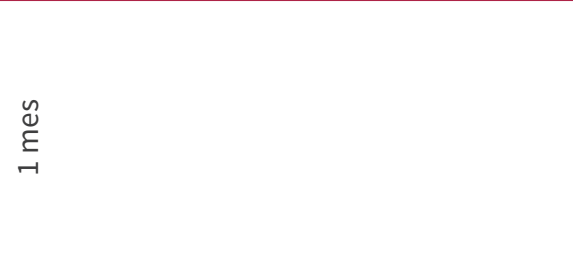 \\
\hline 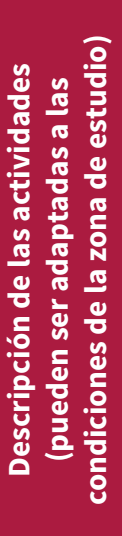 & 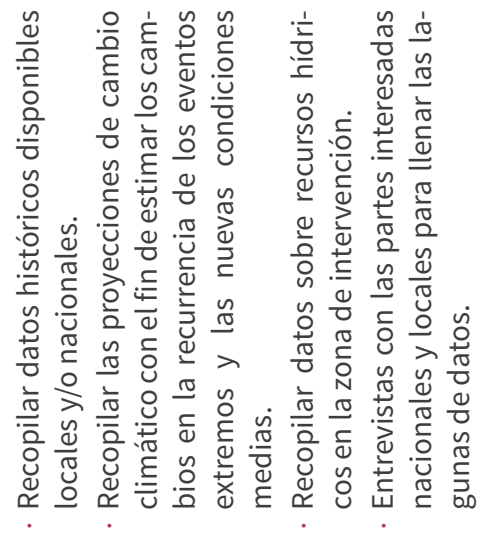 & 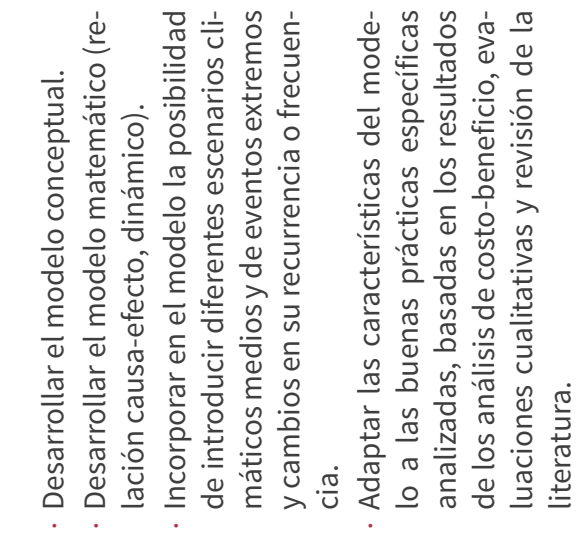 \\
\hline 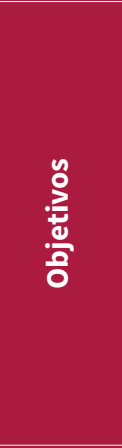 & 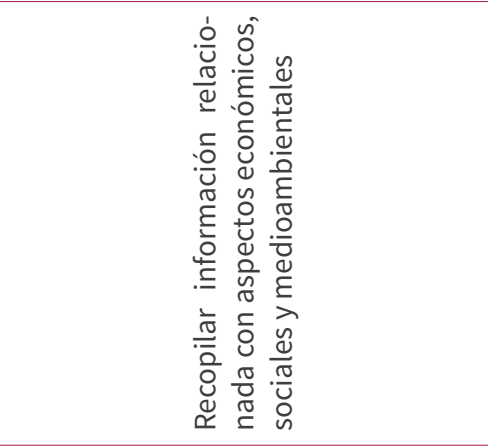 & 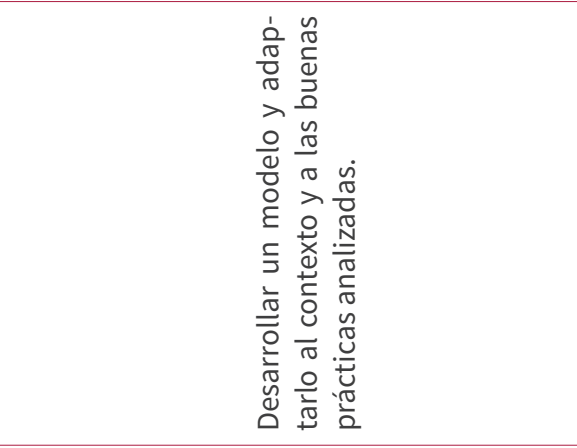 \\
\hline 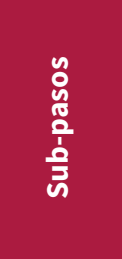 & 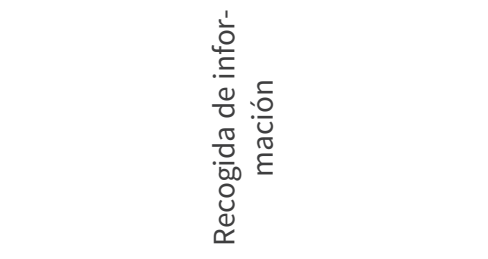 & 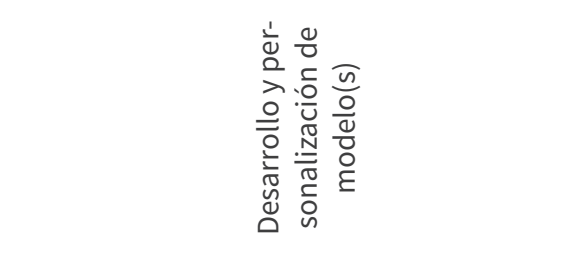 \\
\hline 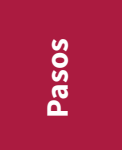 & & $\begin{array}{l}\frac{0}{0} \\
\frac{\pi}{0} \\
\frac{0}{0} \\
\frac{0}{2}\end{array}$ \\
\hline
\end{tabular}




\begin{tabular}{|c|c|c|c|}
\hline 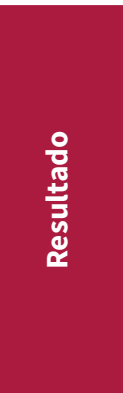 & $\begin{array}{l}\frac{0}{0} \\
\frac{\pi}{0} \\
\frac{0}{0} \\
\frac{0}{10} \\
\frac{0}{0} \\
\frac{0}{10} \\
\frac{0}{2}\end{array}$ & 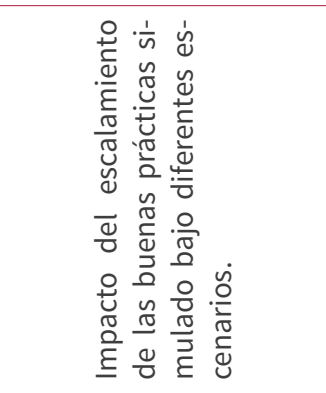 & 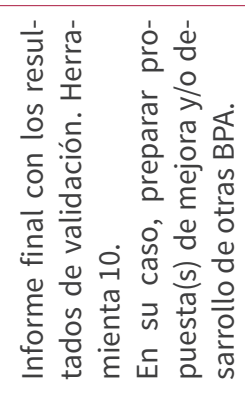 \\
\hline 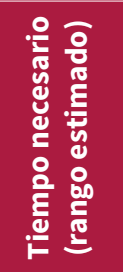 & \multicolumn{2}{|r|}{$\underset{ન}{\stackrel{\mathscr{J}}{\leftrightarrows}}$} & $\begin{array}{l}\tilde{N} \\
\stackrel{0}{\pi} \\
\text { Ln } \\
\dot{m}\end{array}$ \\
\hline 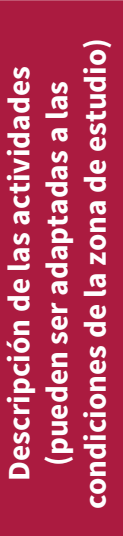 & 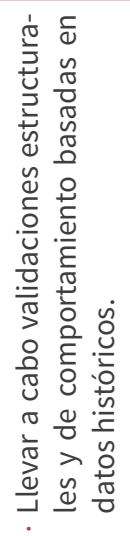 & 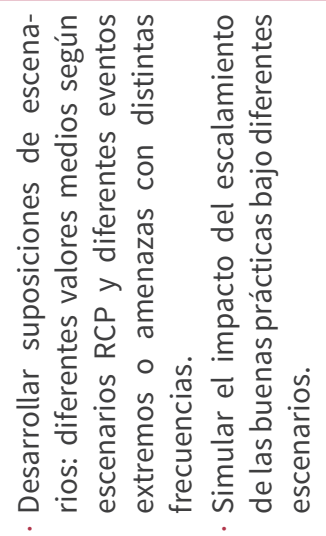 & 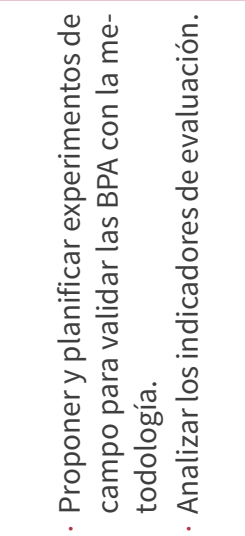 \\
\hline 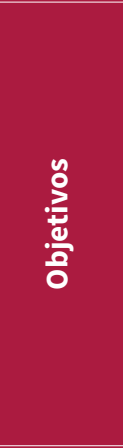 & 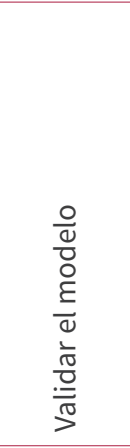 & 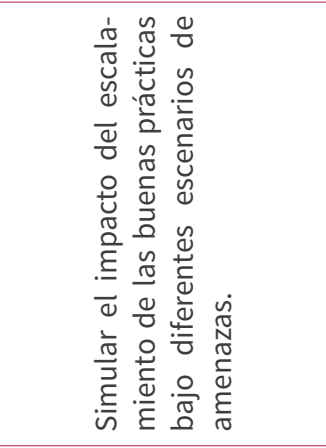 & 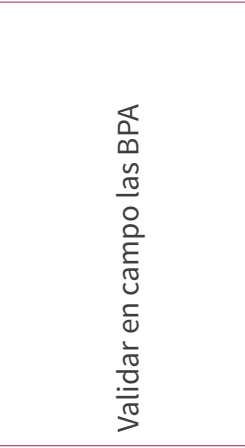 \\
\hline 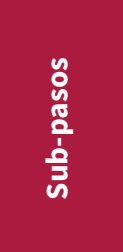 & 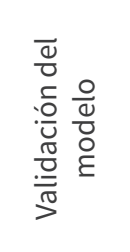 & 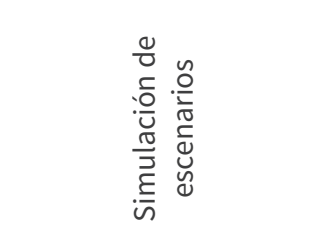 & 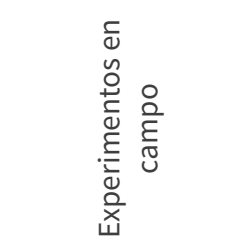 \\
\hline $\begin{array}{l}\text { ò } \\
\text { d. } \\
\text { ¿ }\end{array}$ & & $\begin{array}{l}\frac{0}{0} \\
\frac{\pi}{0} \\
\frac{\pi}{0} \\
\sum\end{array}$ & 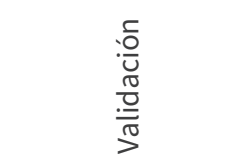 \\
\hline
\end{tabular}




\section{Herramienta 5: \\ Cuestionarios para la evaluación de BPA en el Corredor Seco Centroamericano y zonas áridas de la República Dominicana}

Para qué sirve la herramienta: Para caracterizar y evaluar la utilidad de las BPA, haciendo un seguimiento en el tiempo. Esta herramienta se ha diseñado a modo de cuaderno de campo (o cuaderno de bitácora según la terminología del CIMMYT en México).

Quién tiene que rellenar la tabla: Personal técnico encargado de rellenar las encuestas, puede existir la posibilidad que los propios agricultores se encarguen de completar este cuaderno de campo.

Cómo y cuándo se aplica: Antes y durante la realización de las encuestas. Se recomienda tomar la geo-referencia de las parcelas.

\section{Estructura del cuestionario}

\section{Encuesta para productores:}

caracterización del sistema productivo y evaluación de las BPA

- Bloque 1: Sistema de producción

- Bloque 2: Producción y manejo

- Bloque 3: Incidencia de amenazas climáticas y meteorológicas

- Bloque 4: Valoración BPA, problemas técnicos y apoyo recibido

- Bloque 5: Receptividad frente a una nueva práctica

\section{Encuesta para municipios:}

caracterización precios de insumos y productos agropecuarios

- Bloque 1: Precios de los insumos

- Bloque 2: Precios de venta de los productos agropecuarios 
Encuesta para productores. Caracterización de la unidad de producción y evaluación de las BPA.

Encuesta para productores: caracterización de la unidad de producción y evaluación de las BPA

Objetivo: recopilar datos para el establecimiento de la línea base de las explotaciones. Esta sección debería completarse al inicio de la evaluación.

La información debe referirse a todas las producciones (variedades de cultivos, razas ganaderas, etc.) presentes en la explotación, tanto de las parcelas con BPA como de las parcelas control.

Especificar el indicador utilizado (hectáreas, $\mathrm{kg} / \mathrm{mes}, \mathrm{kg} / \mathrm{ha}$, precio/ $\mathrm{kg}$, moneda utilizada, etc.).

Objetivo: monitorear las BPA y compararlas con las prácticas habituales (utilizadas antes de la implementación de las BPA o en las parcelas control).

Esta parte del cuestionario debería tener lugar al final de cada temporada de cultivo o tras la ocurrencia de un impacto. Se han de recopilar datos sobre los insumos utilizados para ambas prácticas, datos sobre producción y venta, así como testimonios de los productores sobre cambios observados, efectos secundarios (tales como, por ejemplo, plagas y enfermedades a raíz de una inundación) y percepciones acerca de las BPA. La información recogida servirá para realizar el análisis de viabilidad económica, junto con la recabada en la encuesta para municipios (acerca de precios). La información debe referirse a todas las producciones (variedades de cultivos, razas ganaderas, etc.) presentes en la explotación, tanto de las parcelas con BPA como de parcelas control.

Especificar el indicador utilizado (hectáreas, $\mathrm{kg} / \mathrm{mes}, \mathrm{kg} / \mathrm{ha}$, precio $/ \mathrm{kg}$, moneda utilizada, etc.). En caso de que no estén disponibles o no se puedan precisar medidas cuantitativas para algunos indicadores, se deberán realizar estimaciones a partir de la información disponible a nivel munidipal o en la literatura, indicando la fuente de la que provienen los datos.

Fecha: País: Departamento:

Municipio: Georreferencia:

Entrevistado (a): Edad:

Entrevistador(a): Género: Hombre/Mujer/otro

temporada de producción siembra (mes, año):

Cosecha (mes, año): Posición:

\section{Bloque 1: explotación agraria}

¿Cuántas personas habitan en la vivienda (comparten casa, trabajo y régimen alimenticio)?

1 Hombres adultos: Niños: Mujeres adultas: Niñas:

¿Cuántos miembros de la vivienda trabajan en la explotación? Hombres: Mujeres:

Tamaño total de la explotación (parcela + vivienda, indicar unidad): Superficie total: Superficie con BPA: Superficie control: 


\begin{tabular}{|c|c|}
\hline 4 & $\begin{array}{l}\text { ¿Arrenda tierra? } \square \text { Sí } \square \text { No } \\
\text { Si sí: Superficie total arrendada (indicar unidad): } \\
\text { Costo anual (indicar moneda): } \\
\text { Si no: ¿Es ud. el/la propietari@ legal? } \square \text { Sí } \square \text { No } \\
\text { Si no: ¿Quién es el/la propietari@ legal y qué acuerdo de explotación tienen? }\end{array}$ \\
\hline 5 & 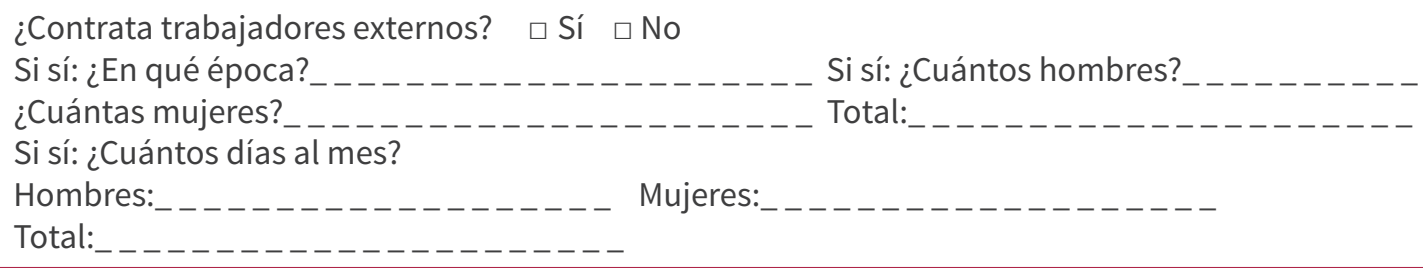 \\
\hline 6 & $\begin{array}{l}\text { ¿Contrata maquinaria externa? } \square \text { Sí } \square \text { No } \\
\text { Tipo: }------------------------- \text { No días y época: } \\
\text { Tipo de combustible: }-------------------------- \\
\text { Consumo (indicar unidad): }------------------\end{array}$ \\
\hline 7 & $\begin{array}{l}\text { ¿Desarrolla alguna otra actividad generadora de ingresos? (por ejemplo trabajo en agroindustria, ma- } \\
\text { quilas, turismo, venta de artesanías, empleo doméstico, industria/fábricas, tienda particular, etc.)? } \\
\square \text { Sí } \quad \square \text { No } \\
\text { Si sí: ¿Cuál? } \\
\text { Ingreso anual (indicar moneda): }\end{array}$ \\
\hline 8 & $\begin{array}{l}\text { ¿Dispone de agua la vivienda / explotación? } \square \text { Sí } \square \text { No } \\
\text { Si sí: ¿Continuamente y durante todo el año? } \square \text { Sí } \square \text { No } \\
\text { Si no: Periodos del año en que no dispone de agua de forma continua (p. ej.: época húmeda/seca) } \\
\text { y meses en los que se produce esa escasez) } \\
\text { Si no: Tiempo en el que recibe agua en ese/esos periodo(s) (h/día, días/semana): }---------- \\
\text { Si sí: ¿Cuál es la fuente del agua? } \\
\square \text { Subterránea } \square \text { Superficial: río } \square \text { Superficial: balsa } \square \text { Reutilizada } \square \text { Lluvia } \\
\square \text { Otra (especificar): }------------------------------------ \\
\text { Si sí: ¿Dispone de canalización para el abastecimiento de agua? } \square \text { Sí } \quad \square \text { No } \\
\text { Si sí: ¿Con qué sistema mueve? } \\
\square \text { Por gravedad u otro sin bombeo } \\
\square \text { Bombeo sin coste energético (por ejemplosolar) } \\
\square \text { Bombeo con gasto de combustible } \\
\square \text { Bombeo con gasto de electricidad } \\
\text { Si sí: ¿Dispone de algún sistema de almacenamiento de agua? } \square \text { Sí } \square \text { No } \\
\text { Si sí: ¿De qué tipo? } \square \text { Cosecha lluvia } \square \text { Reservorio } \square \text { Balsas } \square \text { Cisternas } \square \text { Tinajas } \square \text { Otros } \\
\text { (especificar): }------ \\
\text { Si sí: ¿Dispone de algún sistema para la depuración del agua? } \square \text { Sí } \square \text { No } \\
\text { Si sí: Especifique de qué tipo: }------------------------------------\end{array}$ \\
\hline
\end{tabular}


¿Cuáles son sus prioridades en el uso de agua?

$\square$ Doméstico $\square$ Riego $\square$ Ganadería $\square$ Otro (especificar):

¿Dispone de suministro de electricidad la vivienda/explotación? $\square$ Sí $\quad \square$ No

Si sí: Especifique de qué tipo:

$\square$ Red eléctrica $\square$ Paneles fotovoltaicos $\square$ Generador diésel/gasolina $\square$ Aerogeneradores

$\square$ Turbina hidráulica $\square$ Biodigestor $\square$ Otro (especificar):

Si sí: ¿Es propietaria/o del generador de electricidad? $\quad$ ¿Sí $\quad$ ¿No

10

Si sí: ¿Tiene disponibilidad todo el tiempo de electricidad? $\square$ Sí $\square$ No

Si no: Indique el tiempo en que dispone de electricidad (h/día, días/semana...):

Si no: ¿Tiene algún equipo de emergencia/respaldo? (generador eléctrico, baterías..)

口Sí $\square$ No

Si sí: Especificar:

Si sí: ¿Para qué aplicaciones utiliza la electricidad?

$\square$ Doméstico $\square$ Ganadería $\square$ Cultivos $\square$ Postcosecha $\square$ Acuicultura $\square$ Pesca

$\square$ Otros (especificar):

¿Dispone de iluminación en la explotación? $\square$ Sí $\square$ No

Si sí: ¿Qué fuente de energía utiliza para la iluminación?

$\square$ Electricidad de la red

๑ Lámparas con baterías

$\square$ Queroseno líquido (parafina)

$11 \square$ Electricidad con generador diésel / gasolina

$\square$ Lámparas con baterías

$\square$ Velas

$\square$ Electricidad con energía renovable

$\square$ Lámparas solares

$\square$ Otras (especificar):

¿Utiliza algún equipo con baterías? $\square$ Sí $\square$ No

Si sí: Indique cuál: $\square$ Teléfono móvil $\square$ Radio $\square$ Otros (especificar):

¿Qué fuente(s) de energía utiliza para cocinar?

$13 \square$ Carbón vegetal $\square$ Electricidad $\square$ Residuos agrícolas/ganaderos $\square$ Cilindro de gas $\square$ Leña

$\square$ Otras (especificar):

¿Qué tipo(s) de cocina utiliza?

$14 \square$ Tres piedras $\square$ Cocina básica de biomasa $\square$ Cocina mejorada de biomasa $\square$ Estufa eléctrica $\checkmark$ Quemador de gas $\square$ Otros (especificar):

¿Utiliza alguna fuente de energía para climatizar la vivienda o los espacios de trabajo?

$\square$ Sí $\square$ No

Si sí: Especifique de qué tipo: $\square$ Carbón vegetal $\square$ Cilindro de gas $\square$ Leña

15

$\square$ Residuos agrarios $\square$ Electricidad

$\square$ Otras (especificar):

Si sí:

¿Para qué usa la climatización? 


\section{Bloque 2: producción y manejo}

$1 \quad$ ¿Su explotación incluye cultivos? $\square$ Sí $\square$ No

1.1 Si sí: $\square$ BPA 口Control

Complete la siguiente tabla (indicando la unidad utilizada cuando sea necesario):

\begin{tabular}{|c|c|c|c|c|c|c|}
\hline Cultivo & Variedad & $\begin{array}{l}\text { Superficie } \\
\text { cultivada }\end{array}$ & $\begin{array}{c}\text { Producción } \\
\text { anual }\end{array}$ & $\begin{array}{c}\% \text { Autocon- } \\
\text { sumo }\end{array}$ & $\%$ Venta & $\begin{array}{l}\text { ¿Lo cultiva } \\
\text { cada año? }\end{array}$ \\
\hline \multicolumn{7}{|l|}{ Granos básicos } \\
\hline Maíz & & & & & & sí / no \\
\hline Frijol & & & & & & sí / no \\
\hline Frijol alacín & & & & & & sí / no \\
\hline Sorgo (maicillo) & & & & & & sí / no \\
\hline Arroz & & & & & & sí / no \\
\hline Hortalizas & & & & & & sí / no \\
\hline Papas & & & & & & sí / no \\
\hline Tomate & & & & & & sí / no \\
\hline Cebolla & & & & & & sí / no \\
\hline Chile & & & & & & sí / no \\
\hline Malanga/taro & & & & & & sí / no \\
\hline Quequisque & & & & & & sí / no \\
\hline \multicolumn{7}{|l|}{ Frutales } \\
\hline Mango & & & & & & sí / no \\
\hline Jocote & & & & & & sí / no \\
\hline Sandía & & & & & & sí / no \\
\hline Melón & & & & & & sí / no \\
\hline Plátano & & & & & & sí / no \\
\hline Papaya & & & & & & sí / no \\
\hline Cítricos & & & & & & sí / no \\
\hline Banano & & & & & & sí / no \\
\hline \multicolumn{7}{|l|}{ Otros cultivos } \\
\hline Maní & & & & & & sí / no \\
\hline $\begin{array}{l}\text { Hibisco (rosa de } \\
\text { Jamaica) }\end{array}$ & & & & & & sí / no \\
\hline Café & & & & & & sí / no \\
\hline Caña de azúcar & & & & & & sí / no \\
\hline Hierbas & & & & & & sí / no \\
\hline Soya & & & & & & sí / no \\
\hline Ajonjolí (sésamo) & & & & & & sí / no \\
\hline \multicolumn{7}{|l|}{ Otros } \\
\hline & & & & & & sí / no \\
\hline & & & & & & sí / no \\
\hline
\end{tabular}


¿Aplica fertilizantes en sus cultivos? $\square$ Sí $\square$ No

Si sí: ¿Qué tipo de fertilizante utiliza, en qué cantidad y frecuenca?

Tipo:

Químico / Orgánico

Casero / Industrial

Momento de aplicación:

Cantidad y frecuencia:

Tipo: Químico / Orgánico

Casero / Industrial

Momento de aplicación: Cantidad y frecuencia:

Tipo: Químico / Orgánico Casero / Industrial Momento de aplicación: Cantidad y frecuencia:

Tipo: Químico / Orgánico Casero / Industrial Momento de aplicación: Cantidad y frecuencia:

¿Para qué cultivos?

¿Aplica pesticidas en su cultivo? $\square$ Sí $\square$ No

Si sí: ¿Qué tipo de pesticida utiliza, en qué cantidad y frecuencia?

Tipo: Químico / Orgánico

Casero / Industrial Momento de aplicación: Cantidad y frecuencia:

Tipo: Químico / Orgánico

Casero / Industrial

Momento de aplicación: Cantidad y frecuencia:

Tipo: Químico / Orgánico Casero / Industrial Momento de aplicación: Cantidad y frecuencia:

Tipo: Químico / Orgánico

Casero / Industrial

Momento de aplicación: Cantidad y frecuencia:

¿Para qué cultivos?

¿Tiene sistema de riesgo? $\square$ Sí $\square$ No

Si sí: Fuente del agua: $\square$ Superficial ( $\square$ Nacimiento / $\square$ Ríos) $\square$ Subterránea $\square$ Otra: (especificar) Disponibilidad agua: $\square$ Todo el año $\square$ Sólo época de lluvias $\square$ Interminente en época seca $\square$ Otros:

Tipo de riego: $\square$ Gravedad $\square$ Aspersión $\square$ Goteo $\square$ Manual ¿Pagas por el agua? $\square$ Sí $\square$ No ¿Qué cultivos riegas y cuál es su consumo de agua? (indicar unidad) Tipo: Momento de aplicación: Cantidad y frecuencia:

¿Cómo y donde comercializa sus productos?

$1.6 \square$ Mercado $\square$ Parcela/Comunidad $\square$ Exportación alntermediario

$\square$ Restauración $\square$ Centros educativos $\square$ Otros:

¿Tiene marca propia para la comercialización? $\square$ Sí $\square$ No

1.7 Si sí: $\square$ Registrada formalmente almagen corporativa $\quad$ Etiqueta / distintivo $\square$ Sello calidad. Indicar cuál:

¿En qué modalidad(es) comercializa sus productos? $\square$ Fresco $\square$ Secado $\square$ Cocinado $\square$ Congelado $\square$ Otro:

1.9 Cantidad o porcentaje procesado antes de venta:

1.10 ¿Cuál es el precio de venta del producto procesado? 


\begin{tabular}{|c|c|c|c|c|c|c|c|c|c|c|c|c|c|c|c|c|c|}
\hline 2 & \multicolumn{17}{|c|}{ ¿Tiene producción animal en su explotación? $\square$ Sí $\square$ No } \\
\hline 2.1 & \multicolumn{17}{|c|}{ Si sí: $\square$ BPA $\square$ Control } \\
\hline \multirow{17}{*}{2.2} & \multicolumn{17}{|c|}{ Complete la siguiente tabla (indicando la unidad utilizada cuando sea necesario): } \\
\hline & Ganado & Raza & $\begin{array}{c}\mathrm{N}^{\circ} \\
\text { cabezas }\end{array}$ & \multicolumn{3}{|c|}{$\begin{array}{l}\% \text { animales } \\
\text { según condi- } \\
\text { ción corporal: } \\
\quad \text { baja (B), } \\
\text { media (M), } \\
\quad \text { alta (A) }\end{array}$} & \multicolumn{3}{|c|}{$\begin{array}{l}\% \text { animales } \\
\text { jóvenes }(J) \text {, } \\
\text { adultos }(A) \text {, } \\
\text { viejos }(V)\end{array}$} & $\begin{array}{c}\text { No }^{\circ} \\
\text { madres }\end{array}$ & $\begin{array}{l}^{\circ} \text { animales } \\
\text { comprados } \\
\text { / vendidos }\end{array}$ & \multicolumn{6}{|c|}{$\begin{array}{l}\text { Tasas anuales parición (P), } \\
\text { mortalidad total (Mt), por } \\
\text { amenazas naturales (Ma) y crías } \\
\text { muertas previo destete (Cm); } \\
\text { sacrificios producción }(\mathrm{Sp}) \text { y por } \\
\quad \text { enfermedad (Se) }\end{array}$} \\
\hline & \multirow{2}{*}{ Aves } & & & B & M & A & $\mathrm{J}$ & A & V & & & $\mathrm{P}$ & Mt & Ma & $\mathrm{Cm}$ & Sp & Se \\
\hline & & & & & & & & & & & & & & & & & \\
\hline & \multirow{2}{*}{ Bovinos } & & & B & M & A & J & A & V & & & $\mathrm{P}$ & Mt & Ma & $\mathrm{Cm}$ & $\mathrm{Sp}$ & $\mathrm{Se}$ \\
\hline & & & & & & & & & & & & & & & & & \\
\hline & \multirow{2}{*}{ Porcinos } & & & B & M & A & $\mathrm{J}$ & A & v & & & $P$ & Mt & $\mathrm{Ma}$ & $\mathrm{Cm}$ & $\mathrm{Sp}$ & Se \\
\hline & & & & & & & & & & & & & & & & & \\
\hline & \multirow{2}{*}{ Ovinos } & & & B & M & A & $\mathrm{J}$ & A & V & & & $\mathrm{P}$ & Mt & $\mathrm{Ma}$ & $\mathrm{Cm}$ & $\mathrm{Sp}$ & Se \\
\hline & & & & & & & & & & & & & & & & & \\
\hline & \multirow{2}{*}{ Caprinos } & & & B & M & A & $\mathrm{J}$ & A & v & & & $\mathrm{P}$ & Mt & $\mathrm{Ma}$ & $\mathrm{Cm}$ & $\mathrm{Sp}$ & Se \\
\hline & & & & & & & & & & & & & & & & & \\
\hline & Conejos & & & B & M & A & $\mathrm{J}$ & A & v & & & $P$ & Mt & $\mathrm{Ma}$ & $\mathrm{Cm}$ & $\mathrm{Sp}$ & Se \\
\hline & \multirow{2}{*}{ Otro: } & & & B & M & A & $\mathrm{J}$ & A & V & & & $P$ & $\mathrm{Mt}$ & $\mathrm{Ma}$ & $\mathrm{Cm}$ & $\mathrm{Sp}$ & $\mathrm{Se}$ \\
\hline & & & & & & & & & & & & & & & & & \\
\hline & \multirow{2}{*}{ Otro: } & & & B & M & A & $\mathrm{J}$ & A & v & & & $\mathrm{P}$ & Mt & $\mathrm{Ma}$ & $\mathrm{Cm}$ & $\mathrm{Sp}$ & Se \\
\hline & & & & & & & & & & & & & & & & & \\
\hline 2.3 & \multicolumn{17}{|c|}{ 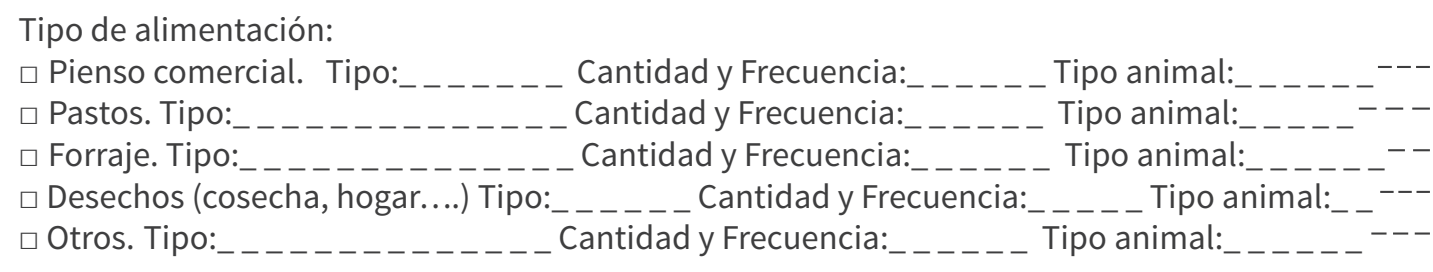 } \\
\hline 2.4 & \multicolumn{17}{|c|}{$\begin{array}{l}\text { ¿Utiliza suplementos alimenticios (vitaminas...)? } \quad \square \text { Sí } \quad \square \text { No } \\
\text { Si sí: } \\
\text { Tipo: } \\
\text { Tipo: } \text { : }_{-------} \text {Cantidad y Frecuencia: }{ }_{----} \text {Cantidad y Frecuencia: }{ }_{-----} \text {Tipo animal: } \\
\end{array}$} \\
\hline 2.5 & \multicolumn{17}{|c|}{ 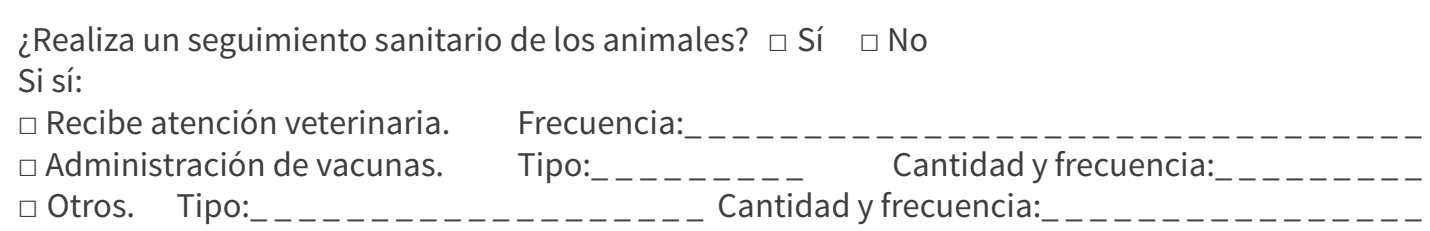 } \\
\hline
\end{tabular}




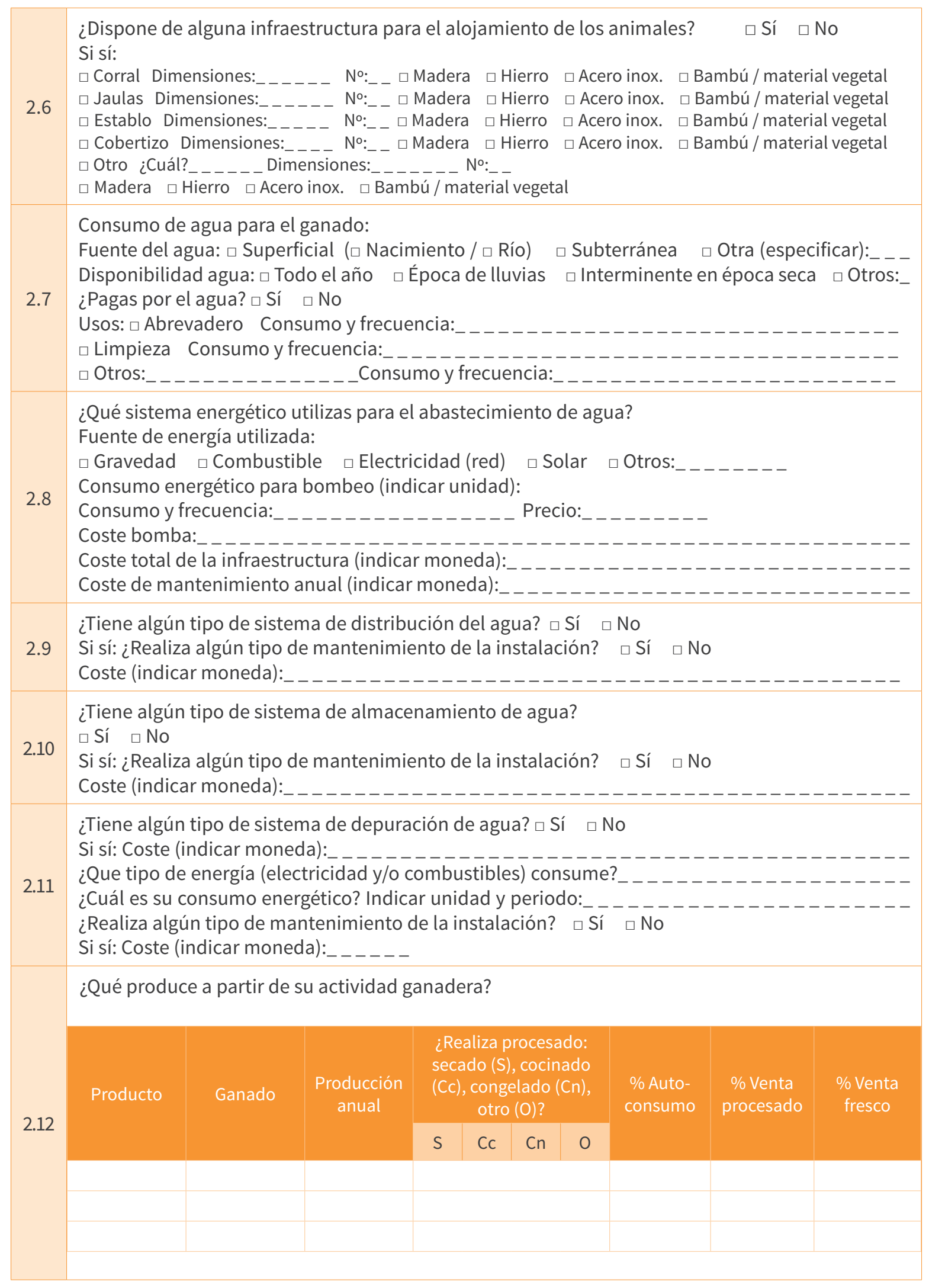


2.12

¿Cómo y dónde comercializa sus productos?

$\square$ Mercado $\square$ Parcela/Comunidad $\square$ Exportación $\square$ Intermediario $\square$ Restauración

$\square$ Centros educativos $\square$ Otros:

¿Tiene marca propia para la comercialización? $\square$ Sí $\quad \square$ No

Si sí: $\square$ Registrada formalmente $\quad$ Imagen corporativa $\square$ Etiqueta / distintivo

$\checkmark$ Sello calidad. Indicar cuál:

¿Tiene producción acuícola en su explotación? $\square$ Sí $\quad \square$ No

3.1 Si sí: $\square$ BPA $\square$ Control

3.2 Tipología: $\square$ Acuicultura continental $\square$ Acuicultura marina

Acuicultura continental:

Tipo: $\square$ Estanque enterrado $\square$ Estanque elevado $\square$ Cosecha de agua para peces

Dimensiones de la infraestructura (indicadr unidad):

Longitud:

Anchura:

Profundidad:

Volumen de agua (indicadr unidad):

Fuente del agua: $\square$ Superficial ( $\square$ Nacimiento / $\square$ Ríos) $\square$ Subterránea $\square$ Otra: (especificar)

Disponibilidad agua: $\square$ Todo el año $\square$ Sólo época de lluvias $\square$ Interminente en época seca

$\square$ Otros:

¿Pagas por el agua? $\square$ Sí $\square$ No

Material de construcción: $\square$ Natural $\square$ Geomembrana $\square$ Aluminio $\square$ Madera $\square$ Otros:

3.3

Otros materiales:

$\square$ Plástico $\square$ Tubería gruesa $\square$ Tubería fina $\square$ Otros:

Sistema energético: $\square$ Gravedad $\square$ Bombeo

Fuente de energía utilizada:

$\square$ Gravedad $\square$ Combustible $\square$ Electricidad (red) $\square$ Solar $\square$ Otros:

Consumo energético para bombeo (indicar unidad):

Cantidad y frecuencia:

Precio:

Coste bomba:

Coste total de la infraestructura (indicar moneda):

Coste de mantenimiento anual (indicar moneda):

Acuicultura marina:

Tipo: No de jaulas / estructuras:

Dimensiones (indicar unidad): Materiales:

3.4

Distancia de la costa (indicar unidad):

Tipo de embarcación utilizada:

Coste de transporte:

Coste total de la infraestructura (indicar moneda):

Coste de mantenimiento anual (indicar moneda): 
Manejo:

Especie:

Duración del ciclo productivo (meses):

No ciclos al año:

Alevines: $N$ No introducidos por ciclo: Densidad (alevines $/ \mathrm{m}^{2}$ ):

Mes idóneo de comienzo del ciclo:

3.5 Tipo de alimentación:

$\square$ Natural _ _ _ _ _ Especies utilizadas:

Precio:

$\square$ Concentrado _ _ _ _ Cantidad/ciclo:

Precio:

Frecuencia alimentación: No veces al día:

Recambio agua: $\square$ Sí $\square$ No

Si sí: Frecuencia:

Procedimiento:

Control calidad del agua:

Si sí: Frecuencia:

$\square$ Sí $\square$ No

Control sanitario: $\square$ Sí $\quad$ No

Si sí: Frecuencia:

Procedimiento:

Procedimiento:

Producción y comercialización

\begin{tabular}{|c|c|c|c|c|c|c|c|c|c|c|c|}
\hline \multirow{3}{*}{$N^{0}$ de peces } & \multicolumn{3}{|c|}{$\begin{array}{l}\text { Tamaño: } \\
\text { Grande, } \\
\text { Med., Pequ. }\end{array}$} & \multirow{3}{*}{ Peso total } & \multirow{2}{*}{\multicolumn{4}{|c|}{$\begin{array}{c}\text { ¿Realiza procesado: } \\
\text { secado }(\mathrm{S}) \text {, cocinado } \\
(\mathrm{Cc}) \text {, congelado }(\mathrm{Cn}) \text {, } \\
\text { otro }(\mathrm{O}) \text { ? }\end{array}$}} & \multirow{3}{*}{$\begin{array}{l}\% \text { Auto- } \\
\text { consumo }\end{array}$} & \multirow{3}{*}{$\begin{array}{c}\% \text { Venta } \\
\text { procesado }\end{array}$} & \multirow{3}{*}{$\begin{array}{c}\% \text { Venta } \\
\text { fresco }\end{array}$} \\
\hline & \multirow[b]{2}{*}{ G } & \multirow{2}{*}{ M } & \multirow{2}{*}{$P$} & & & & & & & & \\
\hline & & & & & S & Cc & $\mathrm{Cn}$ & 0 & & & \\
\hline & & & & & & & & & & & \\
\hline & & & & & & & & & & & \\
\hline & & & & & & & & & & & \\
\hline
\end{tabular}

¿Cómo y dónde comercializa sus productos?

$\square$ Mercado $\square$ Parcela/Comunidad $\square$ Exportación $\square$ Intermediario

$\square$ Restauración $\square$ Centros educativos $\square$ Otros:

¿Cuál es el precio de venta del producto procesado?

4

¿Realiza actividades pesqueras? $\square$ Sí $\square$ No

4.1 Si sí: $\square$ BPA घControl

4.2

Clase:

Especie: Producto comercializado:

4.3

Capturas totales (indicar unidad):

Producción total (indicar unidad):

4.4

¿Cuánto vende? Indicar unidad:

¿Cuánto destina a autoconsumo?

¿Realiza algún procesado antes de vender el producto? $\square$ Sí $\quad \square$ No

Si sí: $\square$ Secado $\square$ Cocinado $\square$ Congelado $\square$ Otro:

4.5 Indique el coste (indicar unidad y moneda):

Cantidad o porcentaje procesado antes de venta (indicar unidad):

¿Cuál es el precio de venta del producto procesado? Indicar unidad: 
¿Qué materiales utiliza para la pesca?

๑ Caña Cantidad utilizada y frecuencia de adquisición:

$\square$ Redes Cantidad utilizada y frecuencia de adquisición:

$\square$ Cebo Cantidad utilizada y frecuencia de adquisición:

Otros ¿Cuál?

Cantidad utilizada y frecuencia de adquisición:

4.7 ¿Qué tipo de embarcación utiliza?

¿Su embarcación utiliza combustible? $\square$ Sí $\square$ No

Si sí: ¿Qué tipo de combustible?

¿Cuánto consume? Indicar unidad y frecuencia:

¿Necesita energía para sus actividades, además de la locomoción del barco? $\quad \square$ Sí $\square$ No

Si sí: Fuente de energía:

¿Cuánto consume? Indicar unidad y frecuencia:

¿Realiza actividades forestales? $\square$ Sí $\square$ No

Si sí: $\square$ BPA $\square$ Control

Complete la siguiente tabla (indicando la unidad utilizada cuando sea necesario):

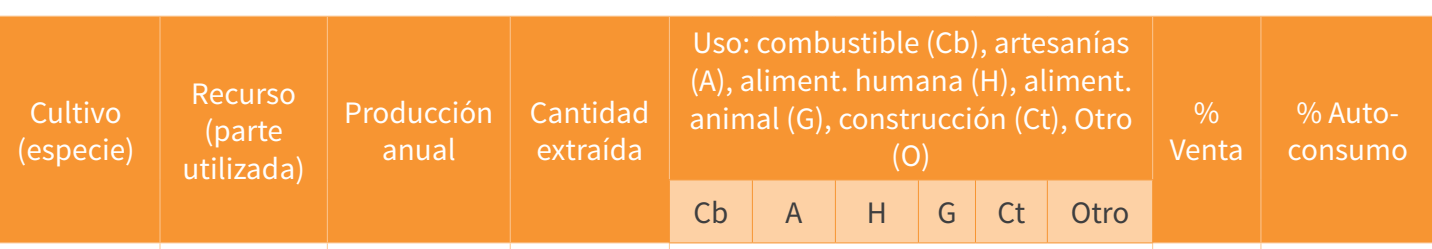

Manejo Forestal:

$\square$ Suelo $\square$ Tratamiento $\square$ Podas $\square$ Recolección $\square$ Otros:

Procesamiento:

Tipo procesamiento:

Cantidad o porcentaje procesado antes de venta:

¿Cuál es el precio de venta del producto procesado?

¿Cómo y donde comercializa sus productos?

$5.5 \square$ Mercado $\square$ Parcela/Comunidad $\square$ Exportación $\square$ Intermediario $\square$ Restauración $\square$ Centros educativos $\square$ Otros:

¿Tiene marca propia para la comercialización? $\square$ Sí $\square$ No

5.6 Si sí: $\square$ Registrada formalmente $\square$ Imagen corporativa

$\checkmark$ Sello calidad. Indicar cuál:

¿Necesita energía para sus actividades? $\square$ Sí $\square$ No

Si sí:Fuente de energía: 
¿Cuánto consume? Indicar unidad y frecuencia:

¿Se recoge leña para cocinar o para elaborar carbón vegetal? $\square$ Sí $\square$ No

De las siguientes prácticas, ¿cuáles realiza?

\section{Cultivos:}

$\square$ Siembra en asociación con leguminosas $\quad \square$ Quema de rastrojos $\quad \square$ Rotación de cultivos

$\square$ Incorporación de materia orgánica en el suelo $\square$ Laboreo reducido $\square$ Cobertura del suelo

$\square$ Cultivos intercalados

$\square$ Siembra directa

$\square$ Siembra contra pendiente

$\square$ Producción bajo cubierta / invernadero

$\square$ Cultivo de especies hortícolas en traspatio

$\square$ Franjas de vegetación entre parcelas

$\square$ Variedades locales y tradicionales

$\square$ Riego de cultivos

$\square$ Fertilización orgánica

$\square$ Variedades adaptadas a la sequía y las altas temperaturas

- Incorporación de árboles en los márgenes de la parcela o en combinación con los cultivos

$\square$ Otras (indicar):

\section{Ganadería:}

$\square$ Razas resistentes a la sequía y las altas temperaturas

$\checkmark$ Inseminación artificial

$\square$ Aprovechamiento de opciones locales para fabricación de piensos

$\square$ Razas locales y tradicionales

$6 \square$ Uso de suplementos y concentrados como complemento de la alimentación

$\square$ Otras (indicar):

- Incorporación del estiércol como fertilizante (con planificación)

\section{Pesca:}

$\square$ Estructuras agregadoras de peces cerca de la costa o río

$\square$ Otras (indicar):

\section{Acuicultura:}

$\square$ Estanque de peces

- Uso de desechos y subproductos agropecuarios para alimentación peces

$\square$ Cultivo peces en jaulas

$\square$ Reutilización agua del desagüe para riego de huerto o bebedero animales

- Otras (indicar):

\section{Forestal:}

$\square$ Gestión comunitaria de los recursos forestales

$\square$ Reforestación de zonas no aptas para la agricultura

$\square$ Reforestación fuentes de agua

$\square$ Otras (indicar):

\section{Bloque 3: incidencia de amenazas climáticas y meteorológicas}

¿Con qué frecuencia han tenido lugar los siguientes eventos extremos en los últimos 5 años?

1
a. Sequía:
$\square$ Nunca (0 veces)
$\square$ Poca (1 vez)
$\square$ Bastante (2-3 veces)
$\square$ Mucha (4-5 veces)
b. Inundación:
$\square$ Nunca (0 veces)
$\square$ Poca (1 vez)
$\square$ Bastante (2-3 veces)
$\square$ Mucha (4-5 veces)
c. Variabilidad interanual: $\square$ Nunca (0 veces)
$\square$ Poca (1 vez)
$\square$ Bastante (2-3 veces)
$\square$ Mucha (4-5 veces)
d. Plagas y enfermedades: $\square$ Nunca (0 veces)
$\square$ Poca (1 vez)
$\square$ Bastante (2-3 veces)
$\square$ Mucha (4-5 veces) 
En los últimos 5 años (20__-20__), ¿se ha visto afectado por algún fenómeno meteorológico extremo? $\square$ Sí $\square$ No

¿Cuál(es)? ¿Sequía $\square$ Inundación $\square$ Variabilidad interanual $\square$ Plagas y enfermedades

Si sí: ¿Cuál ha sido la magnitud/intensidad de los eventos?

2.1

a. Sequía: $\square$ Baja $\square$ Media $\square$ Alta

b. Inundación: $\square$ Baja $\square$ Media $\square$ Alta

c. Variabilidad interanual: $\square$ Baja $\square$ Media $\square$ Alta

d. Plagas y enfermedades: $\square$ Baja $\square$ Media $\square$ Alta

Si sí: ¿Cuál ha sido el nivel de daños y dónde se han sufrido?
a. Sequía:
b. Inundación:
c. Variabilidad interanual:
bajo / medio / alto
bajo / medio / alto
bajo / medio / alto
bajo / medio / alto
bajo / medio / alto
d. Plagas y enfermedades:
bajo / medio / alto
bajo / medio / alto
bajo / medio / alto

$\square$ BPA

$\square$ Control

$\square$ Sin daños

Si se ha visto afectado por algún fenómeno meteorológico/climático extremo en los últimos años, indicar, para cada uno de ellos por separado, cómo ha impactado su producción y sus condiciones de vida: Fenómeno 1 (especificar cuál):

3.1 a. Incremento en el $n^{\circ}$ de horas de trabajo al día:

Mujeres:

Total:

b. ¿Se dañó completa o parcialmente la producción?

$\square$ Sí (totalmente) $\square$ Sí (parcialmente) $\square$ No

c. Pérdidas y daños: $\square$ Sí $\square$ No

3.3 Materiales: $\square$ Vivenda $\square$ Parcela $\square$ Instalaciones/equipamiento

Humanos: $\square$ Lastimados $\square$ Fallecidos $\square$ Otras:

d. Impacto en cultivos:

i. Cultivo afectado:

ii. ¿Se ha reducido la producción? $\square$ Sí $\square$ No

Si sí: Cantidad (unidad):

\% Estimado:

3.4

iii. Superficie afectada (indique unidad):

iv. ¿Ha habido disminución de la calidad de la producción? $\square$ Sí $\square$ No

$\%$ Estimado:

Si sí: Especifique:

1. Tipo de daño:

2. Intensidad: $\square$ Poca $\square$ Media $\square$ Mucha

e. Impacto en ganadería:

i. Ganado afectado:

3.5

ii. No de unidades con tasa de crecimiento lento:

iii. No de cabezas muertas:

iv. Reducción en producción de leche/huevos (\% estimado):

f. Impacto en pesca:

3.6 i. Recurso pesquero afectado:

ii. Reducción de las capturas (\% estimado):

iii. Cambios en las especies capturadas (especifique): 
g. Impacto en acuicultura:

i. Especie afectada:

ii. Reducción en la producción (\% estimado):

iii. Reducción tamaño (\% estimado):

iv. Reducción calidad (\% estimado):

h. Impacto en los recursos forestales y agroforestales:

i. El recurso es: $\square$ Forestal $\square$ Agroforestal

ii. Recurso afectado:

iii. Reducción en la producción/recolección (\% estimado):

iv. ¿Ha habido disminución de la calidad de la producción? $\square$ Sí $\square$ No \% Estimado:

Si sí: Especifique: 1. Tipo de daño:

2. Intensidad: $\square$ Poca $\square$ Media $\square$ Mucha

i. Impactos en el componente agua:

i. Modificación de la cantidad de agua: $\square$ Sí $\square$ No \% Estimado:

ii. Tipo de fuente: $\square$ Superficial ( $\square$ Nacimiento / $\square$ Río) $\square$ Subterránea $\square$ Otra (especificar): _ _ iii. Modificación de aspectos visuales de la calidad de agua (turbidez, algas, arenas, sales...)

$\square \mathrm{Si} \quad \square$ No Si sí: Especificar:

Si sí: Haz una valoración cualitativa de la modificación : $\square$ Poca $\square$ Media $\square$ Mucha

iv. Los impactos en el componente agua de reducción de la calidad, ¿han afectado?

$\square$ Sí $\square$ No

$\square$ Cultivo Indicar cómo:

๑ Ganadería Indicar cómo:

$\square$ Acuicultura Indicar cómo:

$\square$ Producción forestal Indicar cómo:

$\square$ Otras actividades productivas Indicar cómo:

j. Impactos en el componente energía:

i. ¿Afectan las diferentes amenazas climáticas al suministro de energía?

Si sí: Interrupción del suministro eléctrico: $\quad$ Sí $\quad \square$ No

Si sí: Especificar porcentaje aproximado de la interrupción:

Si sí: Reducción de la oferta de combustibles: $\square$ Sí $\square$ No

Si sí: Especificar combustible afectado:

3.10

Si sí: Aumento del precio de los combustibles: $\square$ Sí $\square$ No

Si sí: Combustible afectado:

Si sí: Especificar la subida de precio (\% estimado):

Si sí: Disminución de la biomasa para combustible: $\square$ Sí $\square$ No

Si sí: Especificar \% estimado de la disminución:

Si sí: Daño de los equipos e infraestructuras: $\square$ Sí $\quad$ No

Si sí: Tipo de daños:

Si sí: Especificar el \% estimado de daños:

Si sí: Otros (especificar):

k. Otros impactos: 
Para el fenómeno 1, ¿qué otros impactos identifica que hayan impactado a sus condiciones de vida y a su explotación?

Seleccione las diferentes opciones del listado:

General:

$\square$ Aumento del precio de combustibles

$\square$ Reducción de la oferta de mano de obra

$\checkmark$ Reducción del acceso a la energía

$\square$ Gastos imprevistos. Especificar el tipo de gasto (p.ej., re-construcción de establos):

\section{Cultivos:}

$\square$ Erosión del suelo y pérdida de materia orgánica

$\square$ Aparición de plagas y enfermedades

$\square$ Pérdidas de producción por efecto de la fauna silvestre

$\checkmark$ Incremento del consumo de agua de riego

\section{Ganadería:}

$\square$ Imposibilidad de acceder a zonas de pastos

$\square$ Reducción del acceso/aumento del precio del alimento para ganado

4

$\square$ Reducción de acceso a agua para ganado

$\square$ Pérdidas de ganado por ataques de fauna salvaje

$\square$ Pesca

$\square$ Reducción del número de días en que se pudo salir a pescar

$\square$ Disrupción de los ciclos reproductivos

$\square$ Daños en los ecosistemas acuáticos

\section{Acuicultura:}

$\square$ Reducción del acceso a alimento para peces

$\square$ Disrupción de los ciclos reproductivos

$\square$ Aumento del precio de los alimentos para peces

$\square$ Aumento mortalidad de peces

$\square$ Aumento/reducción precio de los peces

$\square$ Aparición enfermedades

\section{Forestal:}

$\square$ Aparición de plagas y enfermedades

$\square$ Incendios

$\square$ Otros:

Especificar:

\section{Bloque 4: valoración BPA, problemas técnicos y apoyo recibido}

¿Ha contribuido la BPA a la reducción de impactos producidos por fenómenos extremos durante la temporada de cultivo?

1 Fenómeno 1 (especificar cuál):

$\square$ No: peor que con la práctica habitual $\square$ No: igual que con la práctica habitual

$\square$ Sí: mejor que con la práctica habitual 
¿Cuáles son los principales beneficios que ha obtenido de la BPA?

$\square$ Mayor producción agrícola

$\square$ Menor riesgo por mayor diversidad de productos

$\checkmark$ Mayor producción ganadera

$\square$ Mejor y mayor diversidad de alimentos

$\checkmark$ Mayor producción pesquera

$\square$ Mejora del servicio energético

$\square$ Mayores ingresos

$\square$ Menor riesgo por mayor diversidad de productos

$\square$ Menor gasto en insumos

- Mayor resistencia a limitaciones climáticas

$\square$ Prácticas de vida más segura

$\square$ Menor acceso a la calidad en el suministro del agua

$\square$ Menor esfuerzo laboral

$\square$ Mayor estabilidad de los rendimientos (si se tienen datos de varios años)

$\checkmark$ Menor consumo de agua

$\square$ Otras (especificar):

$\square$ Reducción erosión del terreno

Comentarios adicionales:

¿Cómo contribuye la BPA a los siguientes aspectos? Indique si observa un aumento (+), una reducción (-) o no ha observado diferencia (=):

Co-beneficios para la sostenibilidad ambiental y productiva:

a. Reciclaje de biomasa: incorporación de la materia orgánica en el ciclo de los nutrientes ( + / = / - )

b. Calidad del suelo: estructura, contenido en materia orgánica y actividad biológica $(+/=/-$ )

c. Conservación de los recursos hídricos ( + / = / - )

d. Diversidad biológica agrícola (cultivos, ganado, etc.) $(+/=/-)$

e. Variedades y razas autóctonas (cultivos, ganado, etc.) $(+/=/-$ )

f. Sistemas mixtos/integrados (agroforestería, agro-silvo-pastoralismo) (+ / = / )

g. Biodiversidad (salvaje) en la parcela y funcionamiento de los ecosistemas (+ / = / )

Co-beneficios socioculturales:

h. Pertenencia a organizaciones y colaboración dentro y fuera de la comunidad (+ / = / - )

i. Soberanía en el abastecimiento de alimentos en el hogar / en la comunidad (cantidad, diversidad y nutrición) $(+/=/-)$

j. Soberanía en el abastecimiento de insumos, energía, herramientas, etc. (+ / = / - )

k. Resiliencia frente a fenómenos meteorológicos y climáticos (+ / = / - )

l. Mejora del acceso a la energía, eficiencia energética y energías renovables (+ / = / - )

m. Eficiencia en el uso de los recursos hídricos $(+/=/-$ )

n. Eficiencia en el uso del tiempo (ahorra tiempo) $(+/=/-)$

o. Equidad de género y empoderamiento de las mujeres $(+/=/-)$

¿Ha habido impactos negativos a partir de la implementación de la BPA (por ejemplo, la BPA implicó más trabajo, las semillas distribuidas contenían hierbas o enfermedades, la nueva variedad del cultivo es más propensa a pestes y enfermedades)?

$\square$ Sí $\square$ No

Si sí: Indicar los impactos negativos y quién/qué fue afectado:

¿Ha habido alguna incidencia o problema técnico? $\square$ Sí $\square$ No

Si sí: Indicar los impactos negativos y quién/qué fue afectado: 


\begin{tabular}{|c|c|}
\hline 5 & $\begin{array}{l}\text { ¿Recibió alguna información relacionada con la previsión meteorológica (tiempo, amenazas)? } \\
\square \text { Sí } \quad \text { No } \\
\text { Si sí: Indicar: } \\
\text { a. Tipo de información y fuente: } \\
\text { b. ¿Quién recibió primero esta información en su vivienda? } \\
\text { c. ¿Influyó esta información en su planificación agrícola? } \square \text { Sí } \square \text { No Si sí: ¿Cómo? } \\
\text { Cambios en cultivos o variedades (especificar): } \\
\text { Cambios en el manejo (especificar): } \\
\text { Cambios en el tipo de ganado o raza (especificar): } \\
\text { Cambios en el manejo post-cosecha (especificar): }-------------------------------------- \\
\text { Cambios en la asignación y uso de los recursos hídricos (especificar): } \\
\text { Cambios en el uso de los recursos energéticos (especificar): }------------------------- \\
\square \text { Otros (especificar): }\end{array}$ \\
\hline 6 & $\begin{array}{l}\text { ¿Su vivienda recibió algún tipo de formación/información para la implementación de la BPA? } \\
\square \text { Sí } \quad \text { No } \\
\text { Si sí: ¿De dónde provino y quién la recibió? }\end{array}$ \\
\hline 7 & $\begin{array}{l}\text { ¿Ha recibido algún tipo de apoyo? Sí } \square \text { No } \\
\square \text { Económico } \square \text { Técnico } \square \text { Materiales } \square \text { Insumos producción } \square \text { Herramientas } \square \text { Mano de obra } \\
\square \text { Otros: }---------\end{array}$ \\
\hline 8 & $\begin{array}{l}\text { ¿Piensa replicar esta BPA por usted mismo/a en el futuro? (sin insumos gratuitos) } \\
\square \text { Sí } \square \text { No } \quad \square \text { No lo sé } \\
\text { ¿Por qué? }\end{array}$ \\
\hline 9 & $\begin{array}{l}\text { ¿Sugeriría alguna modificación de esta práctica en concreto? } \\
\square \text { Sí } \square \text { No } \\
\text { Si sí: ¿Cuál? }\end{array}$ \\
\hline 10 & ¿Cuál fue la inversión inicial para la implementación de la BPA? (especificar moneda) \\
\hline 11 & ¿Cuál es el coste anual de mantenimiento? (especificar moneda) \\
\hline 12 & Comentarios adicionales: ------------------------------------------ \\
\hline & Bloque 5: receptividad frente a nuevas prácticas \\
\hline 1 & 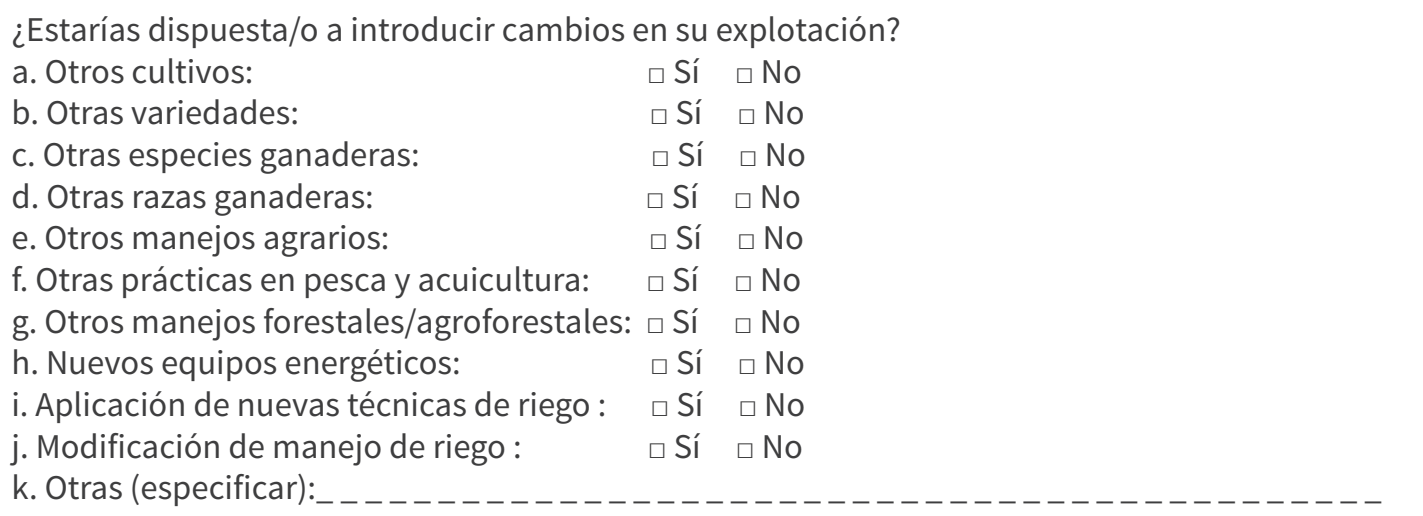 \\
\hline
\end{tabular}


De los cultivos, especies ganaderas y prácticas que conoce y no utiliza, ¿cuáles estaría dispuesto a utilizar?

a. Cultivos:

$\square$ No conozco pero aceptaría formación

b. Especies/razas ganaderas:

$\square$ No conozco pero aceptaría formación

c. Prácticas agropecuarias:

$\square$ No conozco pero aceptaría formación

d. Pesca y acuicultura:

$\square$ No conozco pero aceptaría formación

e. Prácticas forestales/agroforestales (suelo, fertilización, plagas y enfermedades, riego, cultivos intercalares, cultivos cubierta, rotaciones, diversificación, agro-forestal, cultivos de doble aptitud, cambios en la mano de obra/mecanización...):

$\square$ No conozco pero aceptaría formación

De las siguientes opciones para aumentar la disponibilidad y mejora de la gestión del agua, ¿cuáles conoces?

$\square$ Cisterna tipo tinaja

$\square$ Riego por goteo

$\square$ Captación de agua de lluvia (en techos)

$\square$ Riego por superficie/gravedad

$\square$ Micropresas desmontables

$3 \square$ Bomba de ariete

$\square$ Lagunetas para cosecha de agua

$\square$ Zanjas de almacenamiento de agua

$\square$ Cubierta vegetal para reducir la erosión

$\square$ Otras (especificar):

$\square$ Barreras vivas para reducir la escorrentía

$\square$ Riego por aspersión

$\square$ No conozco pero aceptaría formación

De las siguientes opciones para generar energía y/o mejorar la eficiencia energética, ¿cuáles conoces?

$\square$ Sistemas fotovoltaicos para la generación de electricidad

$\square$ Estufas mejoradas

$\square$ Equipos solares térmicos (para producir agua caliente sanitaria, ACS)

$\square$ Invernaderos

$4 \quad \square$ Bombeo con turbina tipo Pelton o bomba de Ariete

$\square$ Producción de biogás

$\square$ Bombeo o riego solar

$\square$ Otras (especificar):

$\square$ Bombeo o riego eólico

$\square$ Agricultura de conservación

$\checkmark$ No conozco pero aceptaría formación 
Encuesta para municipios. Precio, insumos y productos agropecuarios de la unidad de producción y evaluación de las BPA.

\section{Encuesta para municipios: precios insumos y productos agropecuarios}

Objetivo: caracterizar los precios de los productos agrarios y los costes (de insumos y otros) para la implementación de las BPA en los municipios de intervención. La información recogida servirá para realizar el análisis de viabilidad económica, junto con la recabada en la Sección II de la encuesta para productores.

Este cuestionario debe tener lugar durante o tras la implementación de la BPA, y hacerse una vez en cada municipio. En caso de no ser posible hacer la encuesta a un representante municipal, deberá hacerse a los productores.

Fecha: País: Departamento:

Municipio: Georreferencia:

Entrevistado (a): Edad:

Género: Hombre/Mujer/otro

Entrevistador (a): Posición:

Temporada de producción siembra (mes, año):

Cosecha (mes, año):

\section{Bloque 1: precios de los insumos}

\section{Cultivos:}

1. Semillas (indicar unidad y moneda):

\begin{tabular}{|l|l|l|l|l|l|l|l|}
\hline $\begin{array}{c}\text { Cultivo y } \\
\text { variedad }\end{array}$ & Precio & $\begin{array}{c}\text { Cultivoy } \\
\text { variedad }\end{array}$ & Precio & $\begin{array}{c}\text { Cultivo y } \\
\text { variedad }\end{array}$ & Precio & $\begin{array}{c}\text { Cultivo y } \\
\text { variedad }\end{array}$ & Precio \\
\hline & & & & & & & \\
\hline & & & & & & & \\
\hline & & & & & & & \\
\hline
\end{tabular}

2. Fertilizantes (indicar unidad y moneda):

Tipo: Químico / Orgánico

Casero / Industrial

Tipo: Químico / Orgánico

Tipo: Químico / Orgánico

Tipo: Químico / Orgánico Casero / Industrial Casero/Industrial Casero / Industrial

3. Pesticidas (indicar unidad y moneda):

Tipo:

Tipo: Uuímico / Orgánico

Tipo:

Tipo: Químico / Orgánico Químico / Orgánico Químico / Orgánico
Casero / Industrial Casero / Industrial Casero/Industrial Casero / Industrial 


\section{Ganado:}

4. Alimentación (indicar unidad y moneda):

\begin{tabular}{|l|l|l|l|l|l|l|l|}
\hline $\begin{array}{c}\text { Tipo de } \\
\text { alimento }\end{array}$ & Precio & $\begin{array}{c}\text { Tipo de } \\
\text { alimento }\end{array}$ & Precio & $\begin{array}{c}\text { Tipo de } \\
\text { alimento }\end{array}$ & Precio & $\begin{array}{c}\text { Tipo de } \\
\text { alimento }\end{array}$ & Precio \\
\hline & & & & & & & \\
\hline & & & & & & & \\
\hline
\end{tabular}

5. Vacunas (indicar unidad y moneda):

\begin{tabular}{|l|l|l|l|l|l|l|l|l|}
\hline $\begin{array}{c}\text { Tipo de } \\
\text { vacuna }\end{array}$ & Precio & $\begin{array}{l}\text { Tipo de } \\
\text { vacuna }\end{array}$ & Precio & $\begin{array}{l}\text { Tipo de } \\
\text { vacuna }\end{array}$ & Precio & $\begin{array}{l}\text { Tipo de } \\
\text { vacuna }\end{array}$ & Precio \\
\hline & & & & & & & \\
\hline & & & & & & & & \\
\hline
\end{tabular}

\section{Acuicultura:}

6. Alevines (indicar unidad y moneda):

\begin{tabular}{|l|l|l|l|l|l|l|l|}
\hline $\begin{array}{c}\text { Clase y } \\
\text { especie }\end{array}$ & Precio & $\begin{array}{c}\text { Clasey } \\
\text { especie }\end{array}$ & Precio & $\begin{array}{c}\text { Clasey } \\
\text { especie }\end{array}$ & Precio & $\begin{array}{c}\text { Clasey } \\
\text { especie }\end{array}$ & Precio \\
\hline & & & & & & & \\
\hline
\end{tabular}

7. Alimentación (indicar unidad y moneda):

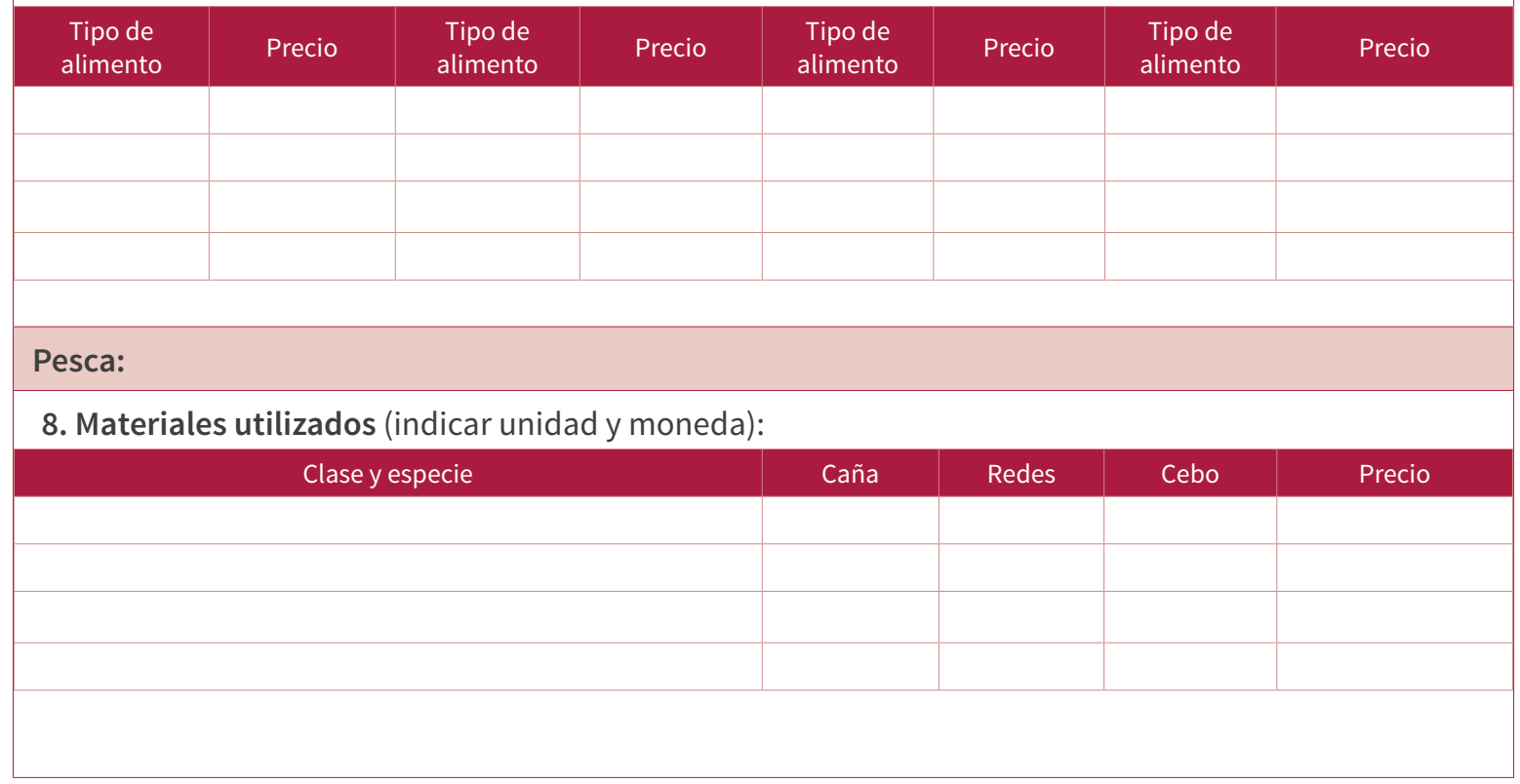




\section{Forestal:}

9. Mano de obra (indicar unidad y moneda):

\begin{tabular}{|l|l|l|l|l|l|}
\hline Recurso forestal & Tipo de coste & Precio & Recurso forestal & Tipo de coste & Precio \\
\hline & & & & & \\
\hline & & & & & \\
\hline
\end{tabular}

\section{Costes generales:}

10. Mano de obra (indicar unidad y moneda):

\begin{tabular}{|l|l|l|}
\hline Tareas & Jonales $\left(n^{\circ}\right)$ & Precio jornal \\
\hline & & $\square$ Hombre $\square$ Mujer \\
\hline & & $\square$ Hombre $\square$ Mujer \\
\hline & & $\square$ Hombre $\square$ Mujer \\
\hline & & $\square$ Hombre $\square$ Mujer \\
\hline & & $\square$ Hombre $\square$ Mujer \\
\hline & & $\square$ Hombre $\square$ Mujer \\
\hline
\end{tabular}

11. Alquiler de maquinaria. Indicar unidad (hora, día...) y moneda:

\begin{tabular}{|l|l|l|l|}
\hline Tipo de maquinaria & Precio & $\begin{array}{c}\text { iUsa combustible / } \\
\text { electricidad? Especificar }\end{array}$ & $\begin{array}{c}\text { iRequiere la contratación de operario } \\
\text { (a)? }\end{array}$ \\
\hline & & & \\
\hline & & & \\
\hline & & & \\
\hline & & & \\
\hline & & & \\
\hline
\end{tabular}

12. Agua (indicar unidad y moneda):

a.Canalizada:

b. Uso agrícola:

13. Energía (indicar unidad y moneda):

a. Electricidad:

b. Diésel:

c. Gasolina:

d. Queroseno:

e. LPG:

f. Otro (especificar): 


\section{Bloque 2: precios de venta de los productos agropecuarios}

1. Cultivos (indicar unidad y moneda):

Cultivo y variedad Modo venta Tipo de procesado

\begin{tabular}{|l|l|}
\hline & $\square$ Fresco $\quad \square$ Procesado \\
\hline & $\square$ Fresco $\quad \square$ Procesado \\
\hline & $\square$ Fresco $\quad \square$ Procesado \\
\hline & $\square$ Fresco $\quad \square$ Procesado \\
\hline & $\square$ Fresco \\
\hline Procesado \\
\hline Fresco & $\square$ Procesado
\end{tabular}

2. Ganadería (indicar unidad y moneda):

\begin{tabular}{|l|l|l|l|l|}
\hline Especie y raza & Modo venta & Tipo de procesado & Precio fresco & Precio procesado \\
\hline & $\square$ Fresco & $\square$ Procesado & & \\
\hline & $\square$ Fresco & $\square$ Procesado & & \\
\hline & $\square$ Fresco & $\square$ Procesado & & \\
\hline & $\square$ Fresco & $\square$ Procesado & & \\
\hline & $\square$ Fresco & $\square$ Procesado & & \\
\hline & $\square$ Fresco & $\square$ Procesado & & \\
\hline
\end{tabular}

3. Pesca y acuicultura (indicar unidad, moneda y si se trata de producto de la pesca o de la acuicultura):

\begin{tabular}{|l|l|l|l|l|}
\hline Clase y especie & Modo venta & Tipo de procesado & Precio fresco & Precio procesado \\
\hline & $\square$ Fresco & $\square$ Procesado & & \\
\hline & $\square$ Fresco & $\square$ Procesado & & \\
\hline & $\square$ Fresco & $\square$ Procesado & & \\
\hline & $\square$ Fresco & $\square$ Procesado & & \\
\hline & $\square$ Fresco & $\square$ Procesado & & \\
\hline$\square$ Fresco & $\square$ Procesado & & \\
\hline & $\square$ Fresco & $\square$ Procesado & & \\
\hline
\end{tabular}

4.Recursos forestales (indicar unidad y moneda):

Recurso y parte Modo venta Tipo de procesado

\begin{tabular}{|l|l|}
\hline & $\square$ Fresco $\quad \square$ Procesado \\
\hline$\square$ Fresco $\quad \square$ Procesado \\
\hline$\square$ Fresco $\quad \square$ Procesado \\
\hline$\square$ Fresco $\quad \square$ Procesado \\
\hline$\square$ Fresco $\quad \square$ Procesado \\
\hline$\square$ Fresco $\quad \square$ Procesado \\
\hline$\square$ Fresco & $\square$ Procesado \\
\hline
\end{tabular}




\section{Herramienta 6:}

\section{Nota de orientación para la cumplimentación de los cuestionarios}

Para qué sirve la herramienta: Orientar al personal técnico en la realización de las encuestas. Esta herramienta se ha diseñado a modo de cuaderno de campo (o cuaderno de bitácora según la terminología del CIMMYT en México).

Quién tiene que rellenar la tabla: Personal técnico encargado de rellenar las encuestas, puede existir la posibilidad que los propios agricultores se encarguen de completar el cuaderno de campo.

Cómo y cuándo se aplica: Antes y durante la realización de las encuestas. Se recomienda utilizar sistemas de recopilación digital de datos (p. ej.: Kobo Toolbox, Typeform, Fromstack, etc.).

\subsection{Descripción de los cuestionarios}

Los cuestionarios sirven para evaluar los beneficios y viabilidad de las BPA en comparación a las prácticas en agricultura habituales. Uno de ellos está orientado a la obtención de información por parte de los productores, y consta de 5 bloques, mientras que el otro está pensado para profundizar en los precios de los insumos y costes de la BPA y debe ser respondido por representantes municipales.

Tabla 6.1: Objetivos y destinatarios de las encuestas.

\begin{tabular}{|c|c|c|}
\hline \multicolumn{1}{|c|}{ Cuestionario } & Destinatario/a & Objetivo \\
\hline $\begin{array}{c}\text { Cuestionario 1 (C1): Caracterización y } \\
\text { evaluación de BPA }\end{array}$ & Productores/as & $\begin{array}{c}\text { Caracterización del sistema } \\
\text { productivo y monitoreo y evaluación } \\
\text { de la BPA }\end{array}$ \\
\hline Cuestionario 2 (C2): Precios y costes & $\begin{array}{c}\text { Representantes } \\
\text { municipales }\end{array}$ & $\begin{array}{c}\text { Caracterización de los precios de } \\
\text { insumos y productos agropecuarios }\end{array}$ \\
\hline
\end{tabular}

El objetivo del cuestionario para productores/as (C1) es la recopilación de datos para el establecimiento de la línea base de las unidades de producción: perfil del hogar, actividades agropecuarias, exposición a fenómenos meteorológicos extremos/amenazas climáticas, entre otros. Este cuestionario se aplica de forma periódica, lo que permite comparar los resultados y por tanto el desempeño de las prácticas analizadas a lo largo del tiempo o entre ellas:

- Al inicio de la evaluación, se rellena una primera vez para conocer si se está implementando alguna BPA en la unidad de producción y poder evaluar el impacto de las BPA a lo largo del tiempo. 
- Posteriormente, se vuelve a aplicar el cuestionario para el monitoreo de las BPA y su comparación con las prácticas habituales (utilizadas antes de la implementación de las BPA o en las parcelas control). Debe realizarse al final o durante cada temporada de cultivo, tanto en parcelas con BPA como en parcelas control.

Esta herramienta se ha planteado a modo de cuaderno de campo (o cuaderno de bitácora según la terminología del CIMMYT en México). Está diseñada para permitir la evaluación de los impactos de las BPA, a partir de la recopilación de testimonios de los productores sobre cambios observados y efectos secundarios (tales como, plagas y enfermedades a raíz de una inundación), así como sus percepciones acerca de las BPA.

El cuestionario sobre precios y costes (C2), dirigido a representantes municipales, está diseñado para caracterizar los precios de los insumos y productos agropecuarios en los municipios de intervención, tanto de las BPA como de las prácticas control. Ha de realizarse durante o tras la implementación de la BPA, una vez en cada municipio/zona. La información recogida servirá para realizar el análisis de viabilidad económica, junto con la recabada a través de la encuesta para productores/as (C1).

A su vez, cada cuestionario se divide en varios bloques, como muestra la Figura 5.1:

Figura 6.1: Estructura de los cuestionarios para productores/as (C1) y representantes municipales (C2)

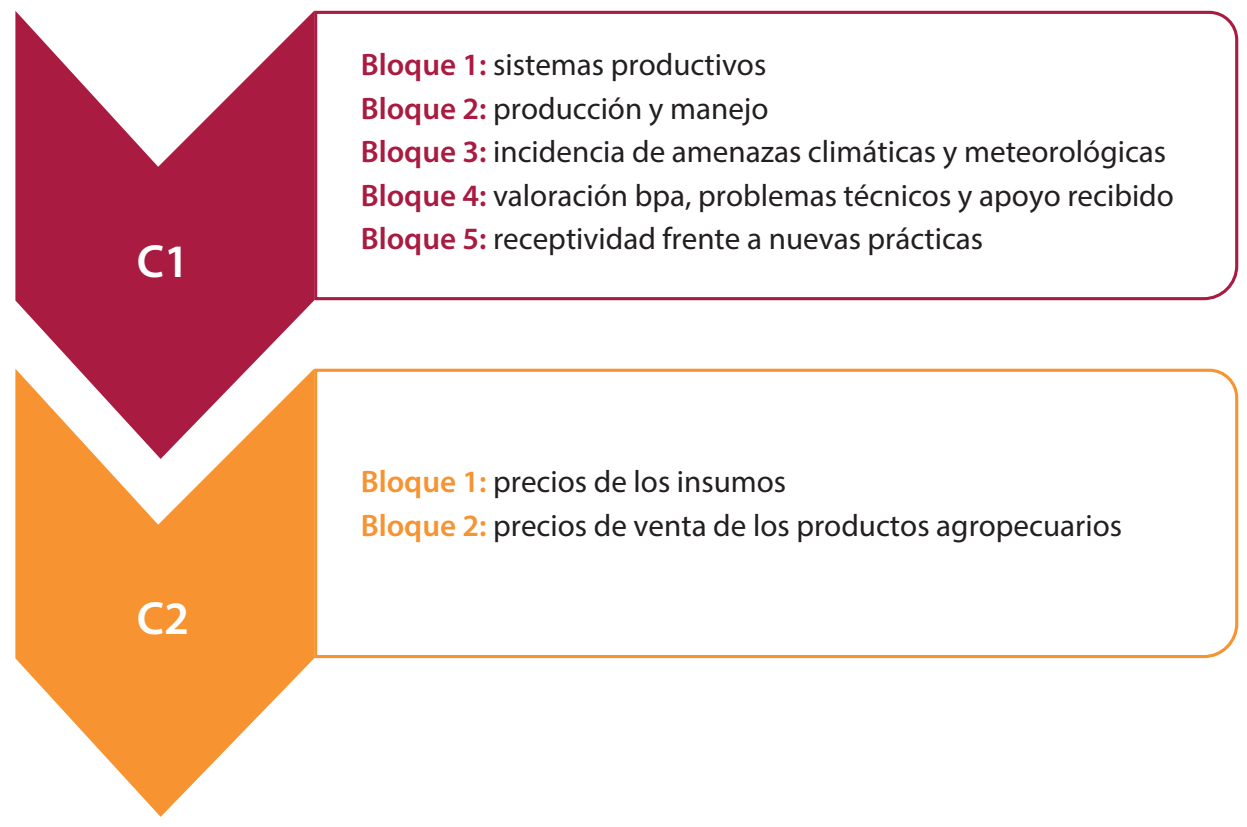




\subsection{Guía para la implementación de los cuestionarios}

\section{Previo a la entrevista}

1. Antes de la entrevista: lea detenidamente esta guía y el cuestionario, con el fin de poder realizar la entrevista de manera fluida y estar preparado para recabar toda la información necesaria.

2. Selección de unidades de producción/hogares: a realizar en coordinación con las instituciones competentes por cada país, departamento y municipio.

3. Elección de las personas a entrevistar: a realizar por el ente local a cargo de la implementación o evaluación de la BPA.

4. Elección del lugar de la entrevista: ha de ser un entorno tranquilo y evitar lugares en donde el entrevistado pueda ser perturbado (p. ej.: presencia de niños jugando alrededor, televisión o radio encendidas, etc.).

\section{Durante la entrevista}

1. Realizar entrevistas individuales cuando sea posible, ya que los agricultores podrían preferirlo. Se ha de permanecer receptivo y amable, dando tiempo al entrevistado para contestar, sin ponerle bajo presión, mostrar impaciencia ni valorar sus respuestas. Se recomienda utilizar un vocabulario sencillo y cotidiano, evitando palabras técnicas.

2. Casillas con opciones: se utilizan para facilitar el trabajo de los entrevistadores, dar ejemplos y guiar la discusión, pero las opciones no deben mencionarse en cada pregunta con el fin de no sesgar las respuestas.

3. Debe buscarse que los agricultores respondan a tantas preguntas como sea posible, especificando la mayor cantidad de datos cuantitativos posible. Sin embargo, en caso de que el agricultor no pueda responder a algunas preguntas, se debe dejar la pregunta en blanco y agregar un comentario sobre el porqué no se respondió. Lo mismo aplica en caso de que las preguntas no sean relevantes (p. ej. tipo de fertilizantes/pesticidas utilizados en el caso de producciones ganaderas).

4. Debe evitarse hacer comentarios sobre las respuestas y mantenerse neutral al formular las preguntas (p. ej. en lugar de "¿por qué no se tomó en cuenta información sobre el clima para planificar su cultivo?", preguntar "para planificar su cultivo, ¿cómo decidió tomar o no tomar en cuenta la información sobre el clima?").

5. La persona entrevistada debe responder con la unidad de su preferencia (a ser posible de forma cuantitativa), y esta unidad debe especificarse en cada pregunta. Si las unidades no son universales (p. ej. "sacos de arroz" en lugar de "kilogramos"), se ha de especificar la conversión a una unidad universal (p. ej., registrar el peso de cada bolsa). 


\subsection{Comentarios aclaratorios sobre las preguntas}

\section{Cuestionario 1}

Se debe utilizar únicamente una hoja de seguimiento para cada BPA o parcela control y la información recopilada se restringirá a dicha BPA (o la parte del sistema productivo que sirva de control para la BPA). Esta información debe registrarse al inicio del cuestionario (si se trata de parcela control o BPA y, en este caso, indicar la BPA sobre la que se recoge la información). Si el agricultor implementa la BPA en toda su tierra, se debe solicitar la cooperación de un agricultor vecino que todavía utilice la práctica habitual. En este caso, se deben tener en cuenta las diferencias en términos de gestión/manejo de la parcela. En caso de no encontrar parcelas similares a la parcela en que se haya implementado la BPA (p. ej. introducción de crianza de pollos), se puede comparar con la práctica anterior (antes de implementar la BPA).

Durante la conversación con el entrevistado, se debe tomar nota de todos los datos que pudieran ser útiles para el análisis.

A partir de la segunda vez que se rellene el cuestionario $\mathrm{C} 1$, en caso de que el entrevistado no pudiera proporcionar datos numéricos relacionados con datos cuantitativos (p. ej., sobre producciones, fertilizante aplicado, etc.), se debe tratar de obtener datos cualitativos en su lugar (p. ej., indicando "+", "-" o "="), explicitando si se compara con la práctica habitual o el año anterior. En este caso, si las parcelas que se comparan no son del mismo tamaño, se debe asegurar que el agricultor entienda que se están comparando sobre la base de áreas iguales. Por ejemplo., si el agricultor sabe que aplica $2 \mathrm{~L}$ de un pesticida en la superficie total (área de la BPA y área de la parcela control juntas), pero no recuerda la cantidad aplicada específicamente en cada parcela, la cantidad total debe registrarse y la siguiente pregunta a ser planteada debe ser: "Comparando, ¿aplicó usted más pesticidas en una de las dos parcelas o lo ha aplicado en igual cantidad a ambas?".

Tabla 6.2: Comentario sobre cuestionario 1

\section{Bloque 1}

Pregunta 1: no se deben contabilizar los niños que ya no viven en el hogar (emigró a otra ciudad/país), ni a las familias que habitan en el mismo hogar, pero cuya manutención depende de ingresos diferentes a la agricultura y/o no están involucrados en las actividades agropecuario del hogar.

Pregunta 2: con esta pregunta se busca identificar si todas las personas adultas que habitan en el hogar, trabajan o no en la granja, o sólo algunas de ellas.

Pregunta 6: comprobar que el precio del operador/mano de obra esté incluido, así como el consumo del combustible. Considerar también los costes en electricidad, de ser necesario. A partir de la segunda vez que se rellena este cuestionario $\mathrm{C} 1$ en una misma unidad de producción:

Preguntas 1 - 15: este bloque de preguntas busca conocer si ha habido algún cambio en los sistemas productivos. 


\section{Bloque 2}

Preguntas 1 - 6: se deben considerar todas las etapas del calendario de cultivos (p. ej., para los cultivos: la preparación del terreno, siembra, etc.; para el ganado: selección de la raza, manejo/control de plagas y enfermedades, gestión del hogar, etc.; para la pesca: construcción de jaulas, post-procesamiento, etc.). Es de especial interés la información sobre la producción que se destina a autoconsumo, por lo que es importante tomar nota de todos los datos mencionados en la respuesta (cuantitativos y cualitativos) que puedan ser útiles para la investigación.

Preguntas sobre procesado: se ha de indicar si se realiza algún tipo de procesado antes de vender el producto, $y$, en caso afirmativo, especificar el procesado realizado y el coste para el productor.

Preguntas sobre energía: indicar los tipos de energía utilizada en la producción (eléctrica, gasolina, etc.) y el consumo realizado.

Preguntas sobre agua: si el agricultor riega su parcela o parte de ella, se deben registrar los datos necesarios para calcular el coste del agua. A menudo, este coste será determinado por el precio del combustible utilizado en la bomba de agua. En este caso, se debe indicar el consumo energético realizado para el bombeo del agua, especificando el tipo de energía (eléctrica, diésel, etc.) y la cantidad consumida. Si el tipo de bombeo no conlleva gasto (p.ej., solar, bomba de Ariete, etc.), no es necesario indicar la cantidad consumida pero sí el tipo de bombeo.

Pregunta 6: esta pregunta busca conocer las prácticas o manejos que se realizan a la hora de implementar la BPA o en la parcela control. Se deben seleccionar tantos manejos como se lleven a cabo, pero atendiendo exclusivamente a la parcela sobre la que se está realizando la entrevista.

\section{Bloque 3}

Preguntas 3 y 4: responder de manera independiente para cada uno de los fenómenos extremos indicados en la especificar la pregunta 2.

En la pregunta 3.1, al registrar el tiempo adicional invertido por hombres/mujeres/ambos ("no de horas de trabajo al día"), además de incluir el trabajo agropecuario directamente relacionado con el impacto climático o meteorológico, ha de contabilizarse el tiempo dedicado a otras tareas imprescindibles para el mantenimiento del hogar-sistema de producción: por ejemplo, en el caso de una inundación, considerar, si es pertinente, el tiempo adicional invertido para cuidar a los niños limpieza, etc.

En la pregunta 3.5 (ganadería), "tasa de crecimiento lento" significa una disminución del peso del ganado, al final de la temporada de producción.

En la pregunta 4 se deben seleccionar los tipos de impacto que se han sufrido como consecuencia de la amenaza indicada en la pregunta 3. Si se ha incurrido en algún tipo de gasto imprevisto como consecuencia de la amenaza, éste debe describirse en la pregunta 4.1. Si el agricultor) indica algún otro tipo de impacto no incluido en el listado, éste debe recogerse en la pregunta 4.6 . 


\section{Bloque 4}

Este bloque tiene la finalidad de conocer las percepciones de las/os productoras/os sobre el impacto de la BPA.

Pregunta 2: en esta pregunta se busca que la/el agricultor(a) valore la BPA, en comparación con la práctica habitual, indicando si nota diferencias cuando se vive algún fenómeno meteorológico/climático extremo.

Pregunta 3: esta pregunta sirve para valorar la BPA con relación a algunos aspectos específicos. Para cada apartado (a-o) debe indicarse si la BPA produce mejores resultados (+), peores resultados (-) o si no se observa ninguna diferencia con respecto a la práctica habitual (=).

Pregunta 4.1: especificar los impactos negativos que el productor asocie a la implementación de la BPA, en caso de existir.

Pregunta 4.2: con esta pregunta se quiere conocer si se produjo alguna incidencia durante la campaña agrícola que haya podido afectar a la producción, tales como dificultades a la hora de implementar alguna práctica, retraso del momento de la siembra por enfermedad de algún miembro de la familia, etc.

Pregunta 5: indique la información meteorológica recibida por parte del agricultor (por ejemplo, medios de comunicación: televisión, radio, etc.) y cómo influyó en su planificación y producción en agricultura.

Pregunta 8: con esta pregunta se busca conocer si la BPA es útil para el agricultor, y por tanto piensa seguir implementándola, aunque en el futuro no disponga de apoyo externo (en forma de insumos u otro tipo de ayuda). Es importante no condicionar la respuesta del/ de la entrevistado/a, y asegurarse de que cuando ésta es afirmativa el agricultor(a) tenga una intención real. Asimismo, se ha de recoger las razones por las que se piensa implementar en el futuro, y, más importante aún, las razones por las que no se implementaría o se tienen dudas al respecto.

Pregunta 12: se deben registrar todos los datos cualitativos que puedan ser útiles, es decir, datos que puedan ayudar a entender si un evento impactó de forma diferenciada a las dos parcelas (p. ej., si solamente una de las dos parcelas fue regada), así como otras observaciones pertinentes (p. ej., la BPA desempeñó mejor que la práctica local hasta que una amenaza destruyó el 100\% de la producción).

\section{Bloque 5}

Bloque 4 (preguntas 1 - 4): estas preguntas tienen la finalidad de conocer la receptividad e idoneidad de las/os productoras/os para la implementación de BPA. 


\section{Cuestionario 2}

Este cuestionario debe ser completado una única vez a nivel municipal con ayuda, por ejemplo, de un técnico agropecuario. El nombre y cargo del técnico se deben registrar en el espacio "informante" y "posición". En caso de no ser posible obtener la información de la mano de un representante municipal, este cuestionario deberá rellenarse a nivel de sistema productivo, junto con la Sección II del cuestionario para productores.

Las preguntas del Bloque 1 sirven para obtener información de los precios de compra de diferentes insumos y otros costes de las producciones agropecuarias, mientras las preguntas del Bloque 2 sirven para recabar información sobre los precios de venta de los productos agropecuarios.

Tabla 6.3: Comentario sobre cuestionario 2

\section{Bloque 1}

Pregunta 1: Indicar las diferentes variedades sembradas para cada cultivo (granos básicos, hortalizas, frutas u otros cultivos) producido a nivel municipal, y el precio de coste de las semillas. Añadir tantos cultivos y variedades como se produzcan en el municipio.

Preguntas 2 y 3 : Indicar los diferentes tipos de fertilizantes/pesticidas utilizados en el municipio, así como el precio de adquisición (o coste de producción, en caso de ser casero) de cada uno de ellos. Agregar tantos tipos como sean utilizados en el municipio.

Preguntas 4 y 5 : Indicar los tipos de alimentos y vacunas utilizadas en cada municipio, así como su precio de compra para los productores, especificando la unidad utilizada y la moneda (p. ej.: córdobas/kilogramo de soja).

Preguntas 6 y 7 : Indicar las clases y especies acuícolas producidas y el precio y tipo de insumos utilizados (alevines y alimentos), añadiendo tantos tipos (clases, especies y alimentos) como sea necesario.

Pregunta 8: Indicar las clases y especies pesqueras capturadas, así como los materiales utilizados por los pescadores en el municipio y el comprador (cuando se trata de materiales típicamente adquiridos mediante compra, y no fabricados por el pescador sin coste alguno).

Pregunta 9: Indicar los recursos y productos que se extraen de los bosques en el municipio, indicando si son para venta o para autoconsumo, y el uso que se le da al recurso. Por ejemplo, del recurso "pino" un producto extraído podría ser "acículas", y, su destino/uso, la fabricación de artesanías.

Pregunta 10: Si el salario promedio varía entre diferentes actividades, indicar el salario para cada tipo de actividad.

Pregunta 13: Indicar el precio por unidad de consumo de cada una de las opciones energéticas (kilovatio hora, litro, etc.).

Pregunta 1: Indicar los precios de venta de las diferentes variedades sembradas para cada cultivo (granos básicos, hortalizas, frutas u otros cultivos) producido a nivel municipal. Añadir tantos cultivos y variedades como se produzcan en el municipio. 


\section{Bloque 2}

Pregunta 2: Indicar los precios de venta de los diferentes productos pecuarios producido a nivel municipal. En "especie y raza" especificar si se trata de ganado caprino, ovino, etc., así como la raza, en caso de conocerse. Añadir tantos productos como se produzcan en el municipio.

Pregunta 3: Indicar los precios de venta de los diferentes productos pesqueros capturados a nivel municipal especificando si se comercializan frescos o procesados y, en este caso, el procesado realizado. Añadir tantos productos como sean capturados por los pescadores del municipio.

Pregunta 18: Indicar los precios de venta de los diferentes productos de la acuicultura producidos a nivel municipal, especificando si se comercializan frescos o procesados $y$, en este caso, el procesado realizado. Añadir tantos productos como sean producidos en el municipio.

Pregunta 19: Indicar los precios de venta de los diferentes productos procedentes de los bosques recolectados a nivel municipal. Añadir tantos productos como sean capturados por los pescadores del municipio.

\section{Herramienta 7:}

\section{Análisis costo-beneficio incluyendo los componentes de agua y energía}

Para qué sirve la herramienta: Para calcular la relación entre el coste y el beneficio que deriva de la implantación de una BPA. Complementa a las otras formas de evaluación de BPA (Herramientas 1 a 6)

Quién realiza el análisis: Personal técnico o del equipo evaluador

Cómo y cuándo se aplica: Se aplica con la práctica "normal" y después de la aplicación de la BPA, cuando se disponen de los datos de beneficios obtenidos.

El análisis costo-beneficio ( $A C B)$, es una herramienta que permite evaluar los cambios en el bienestar de la sociedad relacionado con la implementación de medidas de adaptación al cambio climático. A través de este análisis se cuantifican los costes y beneficios asociados a la implementación de un proyecto a lo largo de un tiempo determinado y se comparan con otros proyectos alternativos o con el statu quo (con y sin proyecto), para determinar su eficiencia económica y viabilidad. En este análisis deben evaluarse todos los efectos financieros, económicos, sociales, medioambientales, etc., para valorar si un proyecto es eficiente a nivel económico, social, medioambiental, etc.

Para esto, es importante reconocer el concepto de eficiencia económica y de bienestar social. La eficiencia económica se define a partir del concepto eficiencia de Pareto, que establece que una asignación de recursos (por ejemplo: tierra, agua o mano de obra) es "Pareto eficiente" si no 
existe otra asignación alternativa que pueda mejorar la situación de una persona sin empeorar la situación de otra (Perman et al., 2003; Nicholson y Snyder, 2008; Boardman et al., 2011). Pero como en la realidad es difícil conseguir que nadie se vea afectado negativamente, una alternativa se considera eficiente cuando se producen mayores cambios positivos que compensan los negativos.

Entre las técnicas de ACB los indicadores utilizados más frecuentemente son: el valor actual neto (VAN), que considera el flujo de bienes y servicios generados (ingresos) y demandados (costes) en términos monetarios actualizados durante la inversión, operación y cierre del proyecto; el período de recuperación de la inversión o payback (PRI), que mide el número de años requeridos para recuperar el capital invertido en el proyecto; y la tasa interna del rendimiento o tasa de retorno (TIR), que se define como aquella tasa de descuento que hace cero el valor actual neto.

El monitoreo y evaluación de las BPA para la adaptación al cambio climático y la gestión integral del riesgo de desastres requiere de la aplicación de técnicas de ACB con el fin de comparar el desempeño de las BPA con respecto a prácticas y tecnologías agropecuarias convencionales en el corto, mediano y largo plazo. El ACB se realiza una vez que todos los agricultores participantes han implementado una BPA (o una combinación de dos o más BPA) durante una o más temporadas y han respondido al cuestionario de evaluación sobre las BPA. También se puede realizar un ACB previo a la implementación de BPA, con el fin de definir cuál BPA se espera que desempeñe mejor. En este caso son estimados los costes y beneficios (márgenes).

El desempeño de la parcela en que se ha implementado o se desea implementar una BPA se compara con una parcela de control en la que se implementan prácticas y tecnologías convencionales, siempre que sea posible.

Los datos necesarios para realizar el ACB se obtienen principalmente de tres fuentes:

1. Respuestas de los agricultores a los cuestionarios (Herramienta 5) de evaluación de las BPA. Las respuestas de los agricultores a los cuestionarios proporcionan datos cuantitativos y cualitativos clave, de tipo histórico (p. ej., producción/rendimientos en años normales, frecuencia e intensidad de los desastres inducidos por amenazas naturales en los últimos cinco años promedio), impactos en la producción y productividad, así como los costes de implementación de la adopción de la nueva práctica o tecnología. Opcionalmente, se pueden considerar los márgenes y costes evitados al adoptar la BPA.

2. Estadísticas nacionales y subnacionales relevantes. Dependiendo de las BPA implementadas y las características de las zonas seleccionadas (p. ej. zonas agro-ecológicas, exposición, condiciones socioeconómicas) diferentes tipos de datos deberán ser recolectados de las estadísticas disponibles a nivel nacional y subnacional. Estos pueden incluir, por ejemplo, los datos históricos sobre la población, ingresos, composición del hogar, cosecha y producción, el uso de insumos agropecuarios, etc. Adicionalmente, en el caso de estar disponibles, se considerarán datos de frecuencia, duración e intensidad de las amenazas naturales, etc. 
3. Revisión de la literatura. Una revisión de la literatura debe llevarse a cabo con el fin de recabar la información pertinente sobre la zona y las BPA evaluadas. La revisión debe centrarse en :(1) proyectos relevantes realizados previamente en el área; (2) estudios de análisis de costo-beneficio existente para las BPA a ser evaluadas (si existen); y (3) revisión y comparación de otras BPA del inventario como alternativas.

Los datos recabados de la parcela donde se ha implementado los BPA se utilizan para evaluar la efectividad y la viabilidad de las BPA, en comparación con la de parcela de control (donde no se ha implementado la BPA) y con los datos históricos, tanto en condiciones normales, como en presencia de amenazas (Ver Herramienta 10):

- Condiciones normales. El análisis en condiciones normales busca evaluar la relación costoefectividad y la viabilidad socioeconómica de la BPA cuando las condiciones climáticas se encuentran dentro de los promedios históricos para la zona en cuestión. Una BPA que produce beneficios socioeconómicos netos en condiciones normales se considera una medida "sin arrepentimiento".

- Condiciones con presencia de amenazas. Las BPA son seleccionadas en función de su potencial para aumentar la capacidad de resiliencia de los medios de vida en las zonas propensas a desastres para cada país. Cuando las amenazas naturales impactan la zona en cuestión, se evalúa el papel de las BPA en la reducción de los daños y pérdidas. El monitoreo y la evaluación de los beneficios de las BPA ante el impacto de una amenaza natural es esencial para evaluar su pertinencia en la reducción del riesgos de desastres, la adaptación al cambio climático y el fortalecimiento de la capacidad de resiliencia. La estimación del periodo medio de recurrencia actual de eventos extremos y de amenazas naturales se calcula, si hay datos disponibles, a partir de los datos históricos obtenidos de cuestionarios, estadísticas nacionales y subnacionales, así como de estudios existentes. Para las estimaciones a futuro, estas recurrencias se deben calcular a partir de proyecciones de cambio climático para la zona de estudio, para los escenarios RCP seleccionados (ver análisis presentado en la Parte 1).

\section{Pasos}

La metodología ACB se compone de tres pasos lógicos: (1) establecimiento de la línea base; (2) valoración de los costes y beneficios asociados a las BPA, y (3) la evaluación del desempeño de las BPA.

1. Establecimiento de la línea base. Con el fin de cuantificar los rendimientos netos de la aplicación de BPA implementadas en diferentes condiciones, se debe establecer una línea base que se construirá a partir de dos tipos de datos: (1) datos históricos (p. ej. cosecha, producción, ingresos) en el nivel más pequeño disponible (idealmente a nivel de sistema productivo/hogar, o a nivel de comunidad/municipio), y (2) datos recogidos en las parcelas control, donde se implementan las prácticas locales. Los datos clave para el establecimiento de la línea base se recaban a través de entrevistas estructuradas a nivel sistema productivo (cuestionarios de la Herramienta 5), que recolectan datos relacionados con cultivos, 
ganadería, producción acuícola o pesquera/forestal, así como datos relacionados con la frecuencia y el impacto de amenazas naturales sobre la agricultura y los medios de vida. Los datos no disponibles se completan por medio de la información secundaria recabada en estudios de caso análogos, así como en estadísticas oficiales nacionales o locales.

2. Valoración. Frente a la evaluación financiera propia del sector privado, que comparan flujo de ingresos y costes, descontados según una tasa de descuento privada, en el ACB se trata de llegar a la valoración de todos los efectos tanto sociales como ambientales, positivos (beneficios) y negativos (costes). La efectividad y la viabilidad de las BPA se evalúa a través de la valoración de costes, ingresos y beneficios, como resultado de la implementación de la BPA. Así mismo, los beneficios colaterales no monetarios se cuantifican y se incluyen en el análisis, en caso de que apliquen. Estos pueden incluir el valor de las emisiones de carbono evitadas y el valor de los servicios por conservación de los ecosistemas entre otros. En esta guía se utilizan ambos enfoques, de mercado y de no-mercado.

\subsection{Análisis financiero}

Se determina el valor de los costes e ingresos para el período de vida del proyecto según la información brindada y se construye el flujo de caja actualizado (DCF, Discounted Cash Flow), en el que sólo se tiene en cuenta el importe real del efectivo abonado o recibido por el proyecto, es decir la diferencia entre ingresos (ordinarios y extraordinarios) y los costes (de inversión, ordinarios y extraordinarios) cada año de vida del proyecto. Así, por ejemplo, no deben incluirse en el análisis DCF partidas contables no monetarias como la depreciación y las reservas para contingencias. El período de análisis para proyectos suele calcularse en torno al tiempo estimado de depreciación o vida útil de la infraestructura.

Se considera el beneficio como la diferencia entre los ingresos y costes a lo largo del periodo de análisis. Los tipos de costes e ingresos varían dependiendo del tipo de BPA que se van a evaluar. Cada tipo puede pueden incluir costes agrupados en tres categorías: generales, componente de agua y componente de energía. A continuación, se definen y estiman cada uno de ellos:

Costes de inversión: comprende todas las partidas de la inversión en la ejecución y puesta en marcha de la BPA.

\section{Generales}

- Costes de maquinaria, construcción de infraestructuras e instalaciones.

- Obra civil: caminos, presas, excavaciones, explanaciones, etc.

- Mano de obra para ejecutar las obras e instalaciones necesarias.

- Terrenos y mejoras de instalaciones ya existentes.

- Licencias, concesiones, permisos.

- Otros. 


\section{Componente Agua}

- Infraestructuras (balsas para acuicultura, tanques o sistemas de almacenamiento, plantas o sistemas de depuración o tratamiento del agua)

- Instalaciones de sistemas de riego.

- Obras accesorias.

- Maquinaria (ej. bomba de agua).

\section{Componente energía}

- Sistemas de generación de energía eléctrica:

- Instalación de sistemas de energías convencional (conexión a red o generadores diésel/ gasolina), incluidas las líneas para el transporte o distribución de la electricidad.

- Instalación de sistemas de energías renovables (sistemas fotovoltaicos, aerogeneradores, biogás, etc.), incluidas las líneas para el transporte o distribución de la electricidad.

- Instalación de los sistemas de conversión como transformadores.

- Sistemas de generación de energía térmica:

- Sistemas de energía solar térmica.

- Sistemas térmicos basados en energía geotérmica.

- Calderas alimentadas con biomasa.

- Biocombustibles para alimentar bombas de calor reversibles para calefacción/ refrigeración alimentados con energía eléctrica autoabastecida.

- Sistemas de conversión energética: sistemas de conversión de residuos agropecuarios en biocombustibles.

- Sistemas de almacenamiento energético:

- Baterías eléctricas.

- Almacenamientos térmicos subterráneos.

- Tanques de almacenamiento de agua caliente.

- Sistemas de generación complementarios para seguridad de suministro: grupos electrógenos como sistema de abastecimiento de reserva en caso de fallo del suministro principal.

- Medidas de eficiencia energética: adquisición de maquinaria nueva más eficiente, aislamiento térmico que permita un menor consumo energético en instalaciones que necesiten regulación térmica (refrigeración o calefacción).

- Maquinaria en campo: reconversión de maquinaria para uso de la utilización de otra fuente de energía.

- Equipos para cocinar, agua caliente sanitaria, o calentar espacios.

- Costes de instalación o ejecución: Costes de instalación de todos los equipos incluidos en los sistemas energéticos anteriores. En caso de sistemas energéticos que requieran de un proyecto, permisos, estudio de impacto ambiental, etc., dichos costes deberían ser añadidos como costes de ejecución de dichos proyectos. 
Costes del sistema productivo: son los desembolsos que se efectúan anualmente debidos a la actividad de la unidad de producción. Estos están divididos en costes ordinarios y extraordinarios como se refleja a continuación:

\section{Costes ordinarios}

\section{Generales}

- Costes de operaciones y mantenimiento (O\&M), tanto de instalaciones como de maquinaria.

- Costes de los insumos (p. ej. energía, agua, combustible, fertilizantes, pesticidas).

- Manejo de la cubierta vegetal (desbrozadora), labranza, poda anual, ....

- Cosecha de la producción.

- Transporte del producto al mercado o punto de venta.

- Gastos de personal.

- Arrendamiento de equipos o maquinaria.

- Imprevistos.

\section{Componente agua}

- Mantenimiento de los sistemas e infraestructuras de riego (elementos de riego: bombas, canales, equipo de riego).

- Energía: Uso de energía eléctrica en los sistemas de riego (por ejemplo: el coste de la electricidad a la hora de bombear).

- Agua: Consumo de agua para riego u otras actividades productivas.

\section{Componente energía}

- Costes de las fuentes de energía ya existentes (combustibles, electricidad...).

- Repuestos.

- Costes de las nuevas fuentes de energía implementadas con la BPA: Coste de combustibles o electricidad usados en nuevos sistemas energéticos o en maquinaria.

\section{Costes extraordinarios}

\section{Generales}

- Préstamos.

- Pagos por renovación de alguno de los elementos de la inversión (dentro del periodo de vida útil de la misma).

\section{Componente agua}

- Reemplazo de componentes como tuberías principales, bomba, balsa, elementos de red de riego, entre otros.

\section{Componente energía}

- Reemplazo de componentes de los sistemas energéticos. 
Ingresos del sistema productivo: comprende las entradas de recursos monetarios en caja que tienen lugar en la unidad de producción, normalmente resultan al multiplicar la cantidad de producto por precio de venta. Hay una entrada por cada diferente producto que cada productor ponga a la venta. Estos están divididos en ingresos ordinarios y extraordinarios como se refleja a continuación:

\section{Ingresos ordinarios}

\section{Generales}

- Venta del producto, donde se puede distinguir entre las diferentes formas en que se puede comercializar un determinado producto (por ejemplo, fresco o procesado, a granel o empaquetado).

- Venta de subproductos del sistema productivo.

2. Ingresos extraordinarios (Son debido a las actividades atípicas)

Generales: si hay alguno de los siguientes supuestos:

- Cobros por la venta de equipos que se sustituyen.

- Alquiler de maquinaria.

- Pagos por servicios ambientales.

\section{Componente agua}

- Venta de agua de manera puntual.

\section{Componente energía}

- Venta de energía: biomasa para combustibles o electricidad (puntual).

\subsection{Análisis no financiero}

En este análisis hay que tener en cuenta también coste que no son monetarios para el productor, pero sí lo son para la organización promotora (costes de mano de obra de las comunidades, asistencia técnica, etc.)

\section{Cobeneficios sociales y ambientales a nivel de finca}

\section{Generales}

- Mantenimiento o mejora de los agroecosistemas.

- Enriquecimiento de la flora y fauna del suelo y conservación de este.

- Reducción de la erosión del suelo.

- Mayor biodiversidad.

- Mejora en la calidad e inocuidad del producto.

- Mejora la calidad de vida de los productores. 


\section{Componente agua}

- Mejora de la eficiencia en el uso de los recursos hídricos escasos en épocas de escasez o sequía.

- Mejora de la disponibilidad y acceso a fuentes de agua en cuanto a calidad y cantidad.

- Mejora la garantía en el suministro para afrontar las variaciones atípicas en las temperaturas y lluvias, etc.

\section{Componente energía}

- Aumenta de la asequibilidad, fiabilidad y seguridad de los sistemas energéticos.

- Aumenta la resiliencia frente a eventos climáticos extremos.

- Reducción de la variación en el precio de los recursos energéticos.

\section{Cobeneficios sociales y ambiental a nivel de comunidad (si aplica):}

\section{Generales}

- Costes en salud evitados.

- Costes ambientales evitados (p.ej. costes de reposición de servicios de ecosistema).

- Generación de nuevos puestos de trabajo.

- Valor de las emisiones de GEI reducidas.

\section{Componente agua}

- Inocuidad de productos tratados con agua.

- Reducción de la contaminación de los recursos hídricos.

- Gestión integrada de los recursos hídricos.

- Mayor eficiencia del uso del agua por lo que aumenta la resiliencia a la sequía, olas de calor, tormentas e inundaciones.

\section{Componente energía}

- Reducción de emisiones GEI gracias al uso de energías renovables, biocombustibles.

- Reducción de la contaminación interior del aire, y de los problemas de salud asociados.

- Reducción de la deforestación por recogida de leña o producción de carbón vegetal.

- Reducción del tiempo de recogida de combustibles y de preparación y uso de los equipos.

- Mejora de las condiciones de vida de las mujeres (al analizar los cobeneficios de los sistemas de cocinado es conveniente desagregar por sexos, ya que las mujeres son las encargadas de estas tareas en muchas zonas).

En el ámbito de esta metodología, resaltan otros beneficios importantes que siguen la línea de clasificación de una buena práctica en agricultura relacionados con los siguientes criterios: 


\section{Criterios:}

- Criterios socioeconómicos.

- Criterios agroecológicos.

- Criterios de resiliencia.

- Criterios ambientales.

\section{Otros:}

- Agua.

- Energía.

- Cambio climático.

- Género y pueblos indígenas.

- Gobernanza y alianzas.

\subsection{Análisis de rendimiento económico}

Para realizar el análisis del rendimiento económico se utilizan varias herramientas. La efectividad y la viabilidad de la BPA se evalúa en función de su valor actual neto (VAN), que corresponde al valor de los flujos de efectivo, menos el valor presente. EI VAN es la ganancia total del proyecto que se genera durante los años de vida útil. La fórmula para calcular el valor actual neto es:

$$
V A N=-k+\sum_{i=1}^{n} \frac{R_{i}}{(1+r)^{i}}
$$

Ecuación. Valor actual neto, VAN

\section{Donde:}

$\mathrm{K}$ : inversión de capital inicial (si existe) en la BPA.

$\mathrm{R}_{\mathrm{i}}$ : flujos de caja en el año i, es decir el flujo de efectivo neto, calculado como la diferencia entre los costos e ingresos totales de la BPA durante el período de tiempo determinado.

$\mathrm{n}$ : vida útil del proyecto

r: tasa de descuento utilizada para calcular el valor presente de los costos e ingresos.

i: número de años del proyecto

Un VAN positivo indica que el valor presente de los beneficios es mayor que el valor actual de los costos durante un período de tiempo determinado, y por lo tanto es conveniente cambiar de las prácticas en agricultura convencionales a las BPA. Por el contrario, un VAN negativo indica que los costos iniciales y de funcionamiento no están totalmente cubiertos por los beneficios agregados en un periodo de tiempo determinado. Es decir, cuando el VAN es mayor que cero, el proyecto es viable, mientras que cuando el VAN es menor que cero el proyecto no es viable. 
Asimismo, se calcula la Tasa Interna de Retorno (TIR), que corresponde a la tasa de actualización para el cual el VAN se igual a cero. Consideraremos que una inversión es viable si su TIR es mayor que el tipo de interés para que la tasa máxima de descuento de la BPA sea considerada rentable. El TIR se calcula mediante la siguiente expresión:

$$
V A N=0=-k+\sum_{i}^{n} \frac{R_{i}}{(1+\lambda)^{i}}
$$

Ecuación. Tasa interna de rendimiento (TIR)

Donde:

k: inversión inicial.

$\mathrm{R}_{\mathrm{i}}$ : flujos de caja en el año i

$\mathrm{n}$ : vida útil del proyecto.

i: número del año del proyecto

$\lambda$ : valor de la tasa de descuento $r$ que hace que VAN $=0$

Si $\lambda>r$ entonces la inversión es viable.

Por otro para estudiar la viabilidad del proyecto son imprescindibles otros dos factores:

El Ratio Beneficio-coste (B/C) es el cociente entre el valor absoluto de los costes y los beneficios, actualizados al valor presente. Si B/C es $>1$, indica que los beneficios superan a los costes por lo cual el proyecto es viable y debe ser considerado; si $B / C=0$, significa que no hay ganancias ni pérdidas, en este caso, estudiando los efectos de los beneficios sociales y ambientales se debe tener en cuenta; $\mathrm{Y} \mathrm{B} / \mathrm{C}<1$, muestra que los costos superan a los beneficios por lo que el proyecto no debería ser considerado. El Ratio Beneficio-coste se calcula mediante la siguiente ecuación:

$$
\begin{gathered}
\mathrm{B} / \mathrm{C}=\mathrm{VAI} / \mathrm{VAC} \\
\text { Ecuación. Ratio Beneficio-Coste }
\end{gathered}
$$

Donde:

VAI: Valor Actual de los Ingresos totales netos o beneficios netos.

VAC: Valor Actual de los Costos de inversión o costos totales.

Período de recuperación (Payback) se define como el tiempo en el que se recupera la inversión inicial del proyecto, o número de años que transcurre hasta que se recupera la inversión inicial. 


\subsection{Análisis de sensibilidad}

Este análisis permite contemplar la variabilidad que tienen las diferentes variables evaluadas ante la incertidumbre del futuro. Para ello se aumentan o disminuyen los valores de las variables de interés, una por una, y un porcentaje fijo y se vuelve a calcular el VAN con esta variación, calculando al final el cambio del porcentaje del VAN respecto a su valor base. Esto se realiza por medio de la conversión de valores para la tasa de descuento. El análisis de sensibilidad permite analizar la vulnerabilidad que presentan las diferentes opciones, es decir, indicará cuánto debe caer o aumentar su valor para que el proyecto no sea rentable. El análisis de sensibilidad se calcula mediante la siguiente expresión:

$$
\Delta \% V A N=\frac{V A N\left( \pm 10 \% \text { de } x^{-}\right) V A N \text { base }}{V A N \text { base }}
$$

Ecuación. Sensibilidad del VAN respecto a la variable X.

Si se incluye el componente de energía, a la hora del análisis de sensibilidad se deben tomar en consideración aquellos parámetros sobre los cuales se tenga mayor incertidumbre y que tengan mayor impacto en el resultado del análisis de viabilidad del proyecto energético:

- Tasa de descuento utilizada para actualizar a valor presente futuros flujos de caja (beneficios, costes).

- Costes de inversión.

- Costes de combustibles.

- Costes de la energía eléctrica.

De forma complementaria se pueden hacer análisis de riesgo, incorporando probabilidades a las diferentes variables que se utilizan.

Una vez se ha obtenido la información necesaria se debe interpretar para finalmente hacer una recomendación final sobre la rentabilidad y viabilidad de la BPA.

\subsection{Comparación entre BPA}

La comparación puede ser unitaria: por año, por beneficiario, por inversión, por coste anual.

Para los beneficios que no se pueden cuantificar se define una escala, como se muestra en la tabla que sigue.

También puede ser útil hacer una matriz que indique el número de subcriterios que cumple cada práctica (Herramienta 2 lista de subcriterios), para cuantificar en qué medida se cumplen dichos criterios. 
A continuación, se muestra un ejemplo del resumen análisis coste-beneficio aplicado en una BPA en Guatemala, donde se muestra el análisis financiero, el no financiero y por último un análisis global. Siguiendo este procedimiento para cada BPA se pueden realizar comparaciones entre ellas y analizar si son rentables no solo a nivel económico sino a nivel social y ambiental.

Tabla 7.1. Resumen análisis coste-beneficio para comparar BPA a nivel económico, social y ambiental

\begin{tabular}{|c|c|c|c|c|c|c|c|}
\hline 1 & 2 & 3 & \multicolumn{5}{|c|}{4} \\
\hline \multicolumn{8}{|l|}{ Costes } \\
\hline $\begin{array}{l}\text { Coste financiero inversión inicial } \\
\text { (USD) }\end{array}$ & 1400,3 & 0 & $>1000$ USD & $\begin{array}{l}1000- \\
500 U S D\end{array}$ & 500-250USD & 250-50USD & $<50$ USD \\
\hline $\begin{array}{l}\text { Coste financiero inversión por } \\
\text { año (USD) }\end{array}$ & 70,02 & 0 & $>100$ USD & 100-50USD & 50-25USD & $25-5 U S D$ & $<5$ USD \\
\hline $\begin{array}{l}\text { Coste financiero del sistema } \\
\text { productivo (USD) }\end{array}$ & 1,00 & 4 & $>1000$ USD & $\begin{array}{l}1000- \\
500 U S D\end{array}$ & 500-250USD & 250-50USD & $<50$ USD \\
\hline $\begin{array}{l}\text { Coste financiero del sistema } \\
\text { productivo por año (USD) }\end{array}$ & 1,00 & 4 & $>100$ USD & 100-50USD & 50-25USD & 25-5USD & $<5$ USD \\
\hline \multicolumn{8}{|l|}{ Ingresos del sistema productivo } \\
\hline Ingresos anuales por productor & & & >20USD & 20-10USD & 10-5USD & 5-1USD & $<1$ USD \\
\hline \multicolumn{8}{|l|}{ Balance financiero } \\
\hline $\begin{array}{l}\text { Periodo de retorno de la } \\
\text { inversión financiera }\end{array}$ & & & $\begin{array}{l}\text { No se } \\
\text { retorna }\end{array}$ & 10 años & 5 años & 3 años & 1 año \\
\hline \multicolumn{8}{|c|}{ Análisis no financiero } \\
\hline \multicolumn{8}{|l|}{ Costes } \\
\hline \multicolumn{3}{|c|}{$\begin{array}{l}\text { Coste no financiero inversión inicial: Valoración } \\
\text { de aportación de terrenos, insumos, etc. (USD) }\end{array}$} & $>1000$ USD & $\begin{array}{l}\text { 1000- } \\
\text { 500USD }\end{array}$ & 500-250USD & 250-50USD & $<50$ USD \\
\hline \multicolumn{3}{|c|}{$\begin{array}{l}\text { Coste no financiero inversión inicial por año: } \\
\text { Valoración de aportación de terrenos, insumos } \\
\text { (USD) }\end{array}$} & $>100$ USD & 100-50USD & 50-25USD & 25-5USD & $<5$ USD \\
\hline \multicolumn{3}{|c|}{$\begin{array}{l}\text { Coste no financiero inversión inicial: Valorización } \\
\text { de mano de obra (USD) }\end{array}$} & $>1000$ USD & $\begin{array}{l}1000- \\
500 U S D\end{array}$ & 500-250USD & 250-50USD & $<50$ USD \\
\hline \multicolumn{3}{|c|}{$\begin{array}{l}\text { Coste no financiero inversión inicial por año: } \\
\text { Valorización de mano de obra (USD) }\end{array}$} & >100USD & 100-50USD & 50-25USD & 25-5USD & $<5$ USD \\
\hline \multicolumn{3}{|c|}{$\begin{array}{l}\text { Coste no financiero inversión inicial: Valoración } \\
\text { de asistencia técnica (USD) }\end{array}$} & $>1000$ USD & $\begin{array}{l}\text { 1000- } \\
\text { 500USD }\end{array}$ & 500-250USD & 250-50USD & $<50$ USD \\
\hline \multicolumn{3}{|c|}{$\begin{array}{l}\text { Coste no financiero inversión inicial por año: } \\
\text { Valoración de asistencia técnica (USD) }\end{array}$} & >100USD & 100-50USD & 50-25USD & 25-5USD & $<5$ USD \\
\hline \multicolumn{8}{|l|}{ Ingresos del sistema productivo } \\
\hline \multicolumn{3}{|c|}{$\begin{array}{l}\text { Ingresos no financieros del sistema productivo } \\
\text { por año (Valorización de todos los ingresos (USD)) }\end{array}$} & $>100$ USD & 100-50USD & 50-25USD & 25-5USD & $<5$ USD \\
\hline
\end{tabular}




\begin{tabular}{|c|c|c|c|c|c|c|}
\hline \multicolumn{7}{|c|}{ Análisis no financiero } \\
\hline \multicolumn{7}{|l|}{ Costes } \\
\hline \multicolumn{7}{|l|}{ Beneficios cualitativos según criterios } \\
\hline Criterios socioeconómicos & 3 & 0 & $1-2$ & $3-4$ & $5-6$ & $>6$ \\
\hline Criterios agroecológicos & 1 & 0 & $1-2$ & $3-4$ & $5-6$ & $>6$ \\
\hline Criterios de resiliencia & 2 & 0 & $1-2$ & $3-4$ & $5-6$ & $>6$ \\
\hline Criterios ambientales & 1 & 0 & $1-2$ & $3-4$ & $5-6$ & $>6$ \\
\hline Otros criterios & 2 & 0 & $1-2$ & $3-4$ & $5-6$ & $>6$ \\
\hline Agua & 4 & $\begin{array}{c}\text { Muy } \\
\text { negativo }\end{array}$ & Negativo & Neutro & Positivo & $\begin{array}{c}\text { Muy } \\
\text { positivo }\end{array}$ \\
\hline Energía & 3 & $\begin{array}{c}\text { Muy } \\
\text { negativo }\end{array}$ & Negativo & Neutro & Positivo & $\begin{array}{l}\text { Muy } \\
\text { positivo }\end{array}$ \\
\hline Cambio climático & 3 & $\begin{array}{c}\text { Muy } \\
\text { negativo }\end{array}$ & Negativo & Neutro & Positivo & $\begin{array}{l}\text { Muy } \\
\text { positivo }\end{array}$ \\
\hline Género y pueblos indígena & 4 & $\begin{array}{c}\text { Muy } \\
\text { negativo }\end{array}$ & Negativo & Neutro & Positivo & $\begin{array}{l}\text { Muy } \\
\text { positivo }\end{array}$ \\
\hline Gobernanza y alianzas & 2 & $\begin{array}{c}\text { Muy } \\
\text { negativo }\end{array}$ & Negativo & Neutro & Positivo & $\begin{array}{c}\text { Muy } \\
\text { positivo }\end{array}$ \\
\hline \multicolumn{7}{|c|}{ Análisis global } \\
\hline Valoración financiera (media aritmética) & 2,00 & & & & & \\
\hline $\begin{array}{l}\text { Valoración no financiera (media } \\
\text { aritmética) }\end{array}$ & 2,50 & & & & & \\
\hline $\begin{array}{l}\text { Valoración financiera y no financiera } \\
\text { (media aritmética) }\end{array}$ & 2,36 & & & & & \\
\hline
\end{tabular}

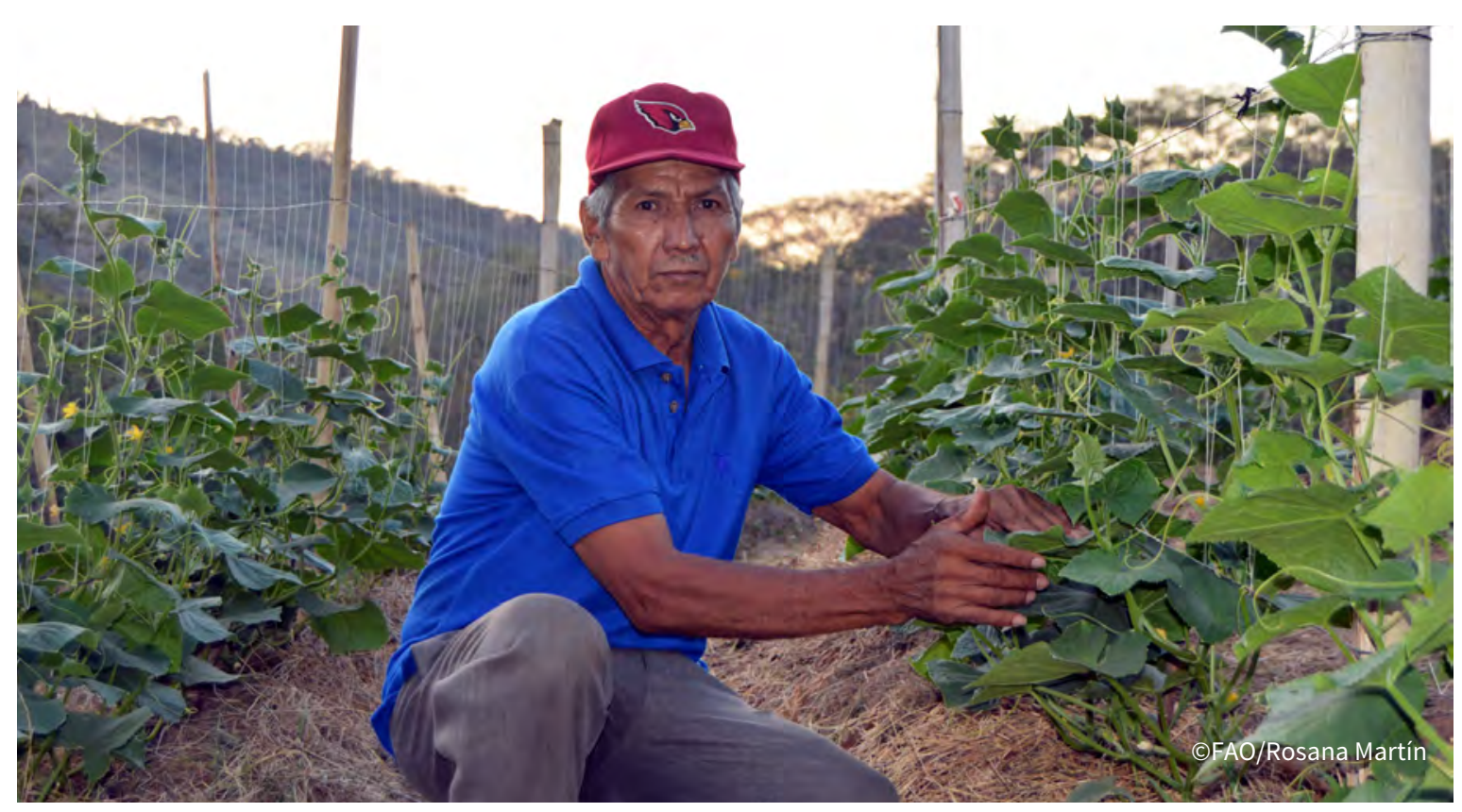


Tabla 7.2. Datos necesarios para el análisis costo-beneficio (ACB)*

* Nota. El siguiente listado de datos necesarios es genérico, y debe ser adaptado para cada BPA específica.

\begin{tabular}{|c|c|c|}
\hline Categoría & Datos & Fuentes \\
\hline Coste de la BPA & $\begin{array}{l}\text { Coste capital de la tecnología (si aplica). } \\
\text { Costes de operación y manejo. } \\
\text { Coste de desechos. } \\
\text { Coste de mano de obra. } \\
\text { Costes de entrenamiento/Fortalecimiento de capacidades. } \\
\text { Parte de los costes de la BPA absorbido por los agricultores. }\end{array}$ & $\begin{array}{l}\text { Cuestionarios } \\
\text { (Herramienta 5) } \\
\text { Revisión de la } \\
\text { literatura }\end{array}$ \\
\hline $\begin{array}{l}\text { Producción } \\
\text { agropecuaria y } \\
\text { medios de vida }\end{array}$ & $\begin{array}{l}\text { - Insumos laborales. } \\
\text { - Insurio de trabajadores agropecuario. } \\
\text { - pesticidas, agua, energía. } \\
\text { - Costes de los insumos agropecuario. } \\
\text { - Costes del agua. } \\
\text { - Costes de la energía. } \\
\text { - Cultivos. } \\
\text { - Producción. } \\
\text { - Variabilidad interanual de la producción (CV o SD, en caso } \\
\text { de datos plurianuales) } \\
\text { - Porcentaje de la producción comercializado en el mercado } \\
\text { local. } \\
\text { mecios de los productos agropecuarios (precios en el } \\
\text { mercado local). }\end{array}$ & $\begin{array}{l}\text { Cuestionarios } \\
\text { (Herramienta 5) } \\
\text { Estadísticas na- } \\
\text { cionales y subna- } \\
\text { cionales relevan- } \\
\text { tes }\end{array}$ \\
\hline Desastres & $\begin{array}{l}\text { Frecuencia histórica de presencia de amenazas naturales/ } \\
\text { eventos extremos en el área analizada (por tipo de evento). } \\
\text { - Impacto histórico de amenazas naturales/eventos extremos } \\
\text { en la producción agropecuario (por tipo de evento). } \\
\text { Ocurrencia (frecuencia), duración e intensidad e impacto } \\
\text { (costo de los daños) de amenazas naturales/eventos } \\
\text { extremos durante la implementación de la BPA (BPA y } \\
\text { parcela control). }\end{array}$ & $\begin{array}{l}\text { Cuestionarios } \\
\text { (Herramienta 5) } \\
\text { Estadísticas na- } \\
\text { cionales y subna- } \\
\text { cionales relevan- } \\
\text { tes } \\
\text { Revisión de la } \\
\text { literatura }\end{array}$ \\
\hline $\begin{array}{l}\text { Cobeneficios (si } \\
\text { aplica) }\end{array}$ & $\begin{array}{l}\text { Valor de los servicios de ecosistemas. } \\
\text {. Ingresos sadicionales de nuevos trabajadores. } \\
\text {. Valor de las emisiones de GEI reducidos. } \\
\text {. Usos alternativos (ej. forrajes, nuevos usos). }\end{array}$ & $\begin{array}{l}\text { Revisión de la } \\
\text { literatura } \\
\text { Valoración cuali- } \\
\text { tativa a partir de } \\
\text { observaciones }\end{array}$ \\
\hline
\end{tabular}




\section{Herramienta 8:}

\section{Instrumento para la evaluación integrada}

Para qué sirve la herramienta: Pretende ayudar a valorar las BPA de manera integrada para el conjunto de criterios considerados en base a los datos recopilados con las diferentes herramientas presentadas anteriormente.

Quién realiza el análisis: Personal técnico que esté aplicando la metodología.

Cómo y cuándo se aplica: Se realiza una valoración cuantitativa de la matriz de criterios.

Esta herramienta se inspira en la herramienta de evaluación creada para el estudio "Impulsando el crecimiento verde en el Delta del río Mekong - Enfoque multi-actoral para la identificación de opciones clave de políticas" (Global Green Growth Institute, 2014).

Los criterios de análisis de las BPA se dividen en sub-criterios que se valoran a través de una escala cualitativa (Bajo - Medio - Alto) que mide el grado en el que la BPA incorpora cada uno de los subcriterios. Esta valoración se puede realizar con base en una serie de fuentes de información, que se recomienda usar para cada subcriterio tal y como se muestra en la Tabla 1:

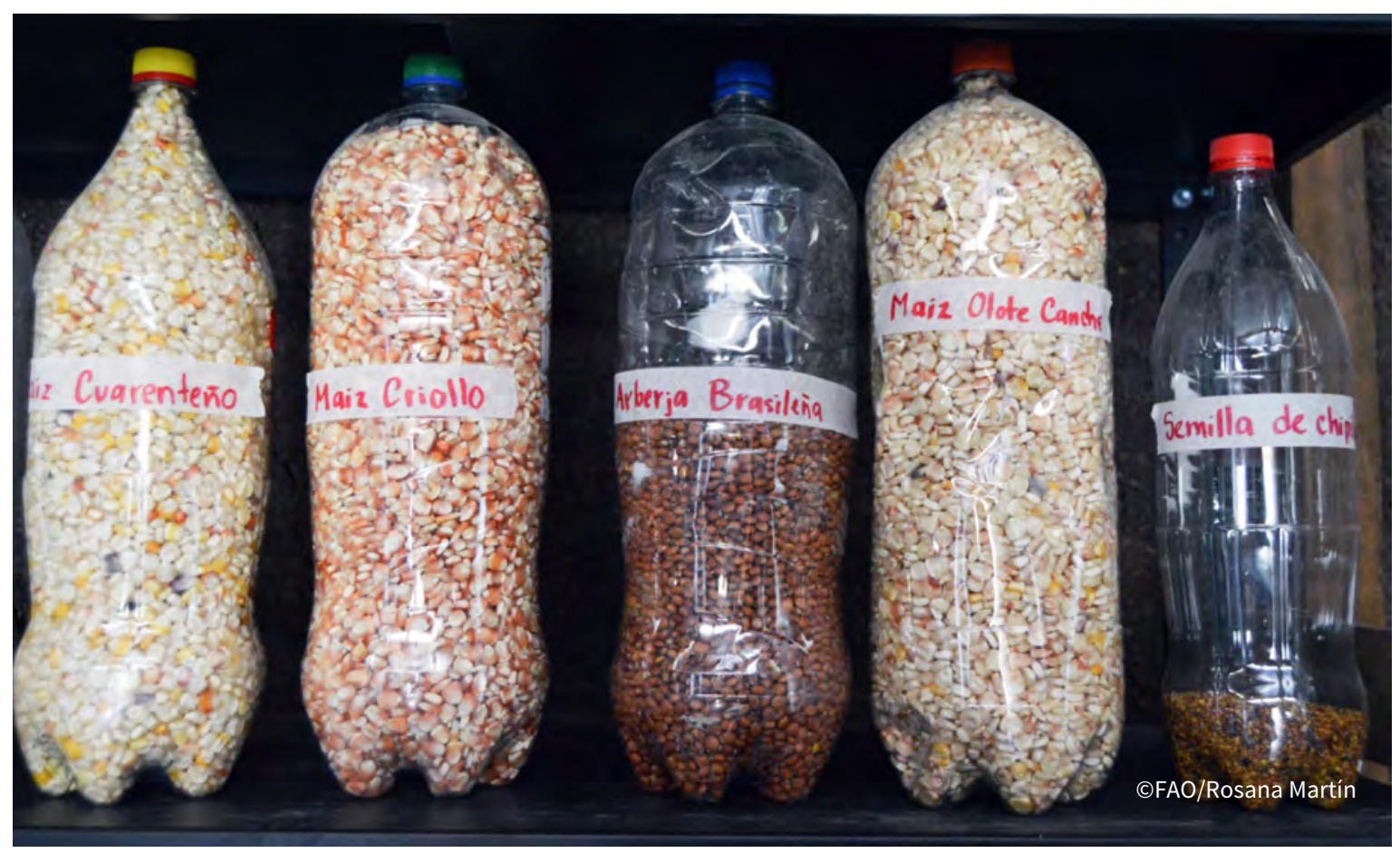




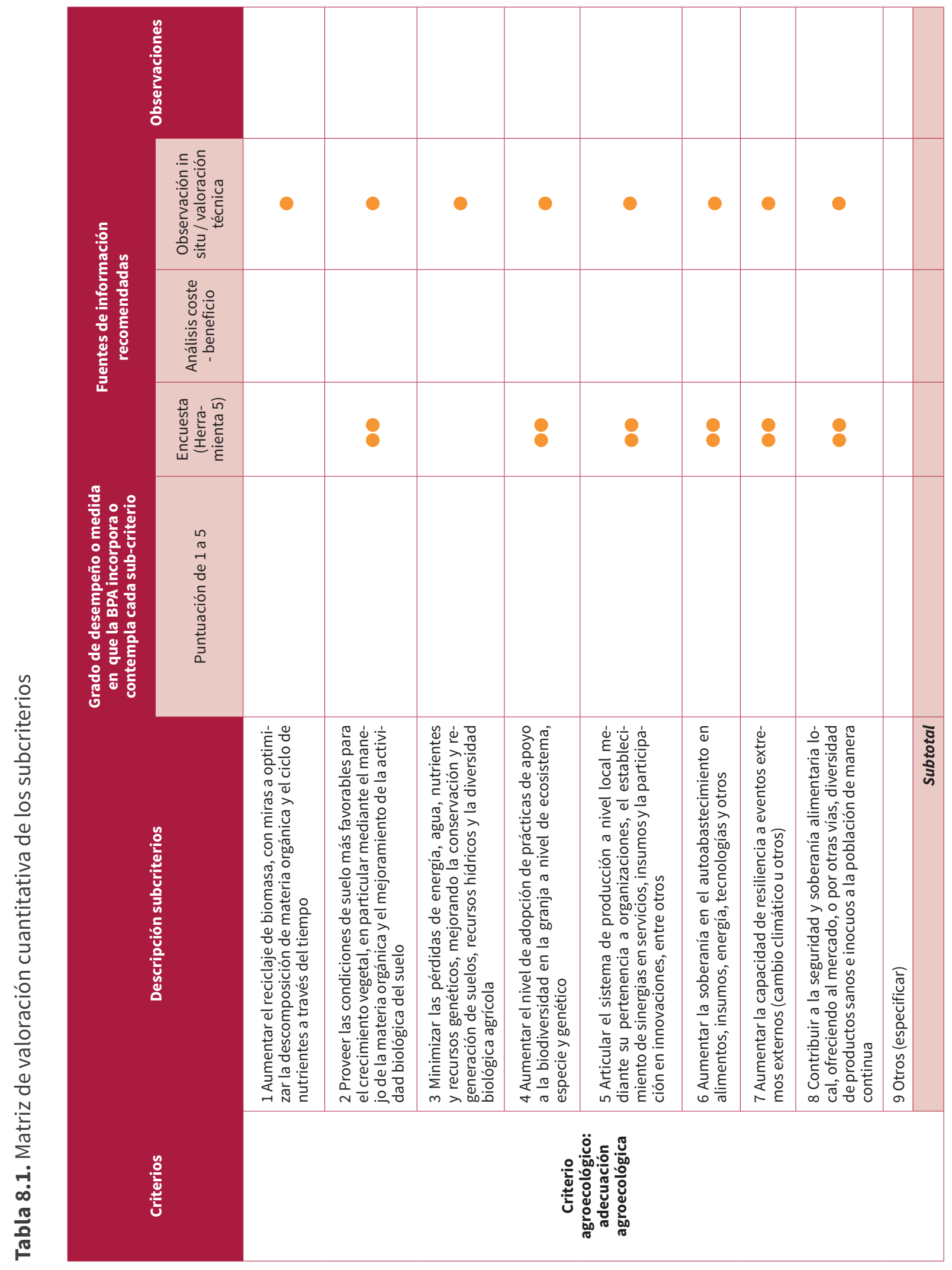




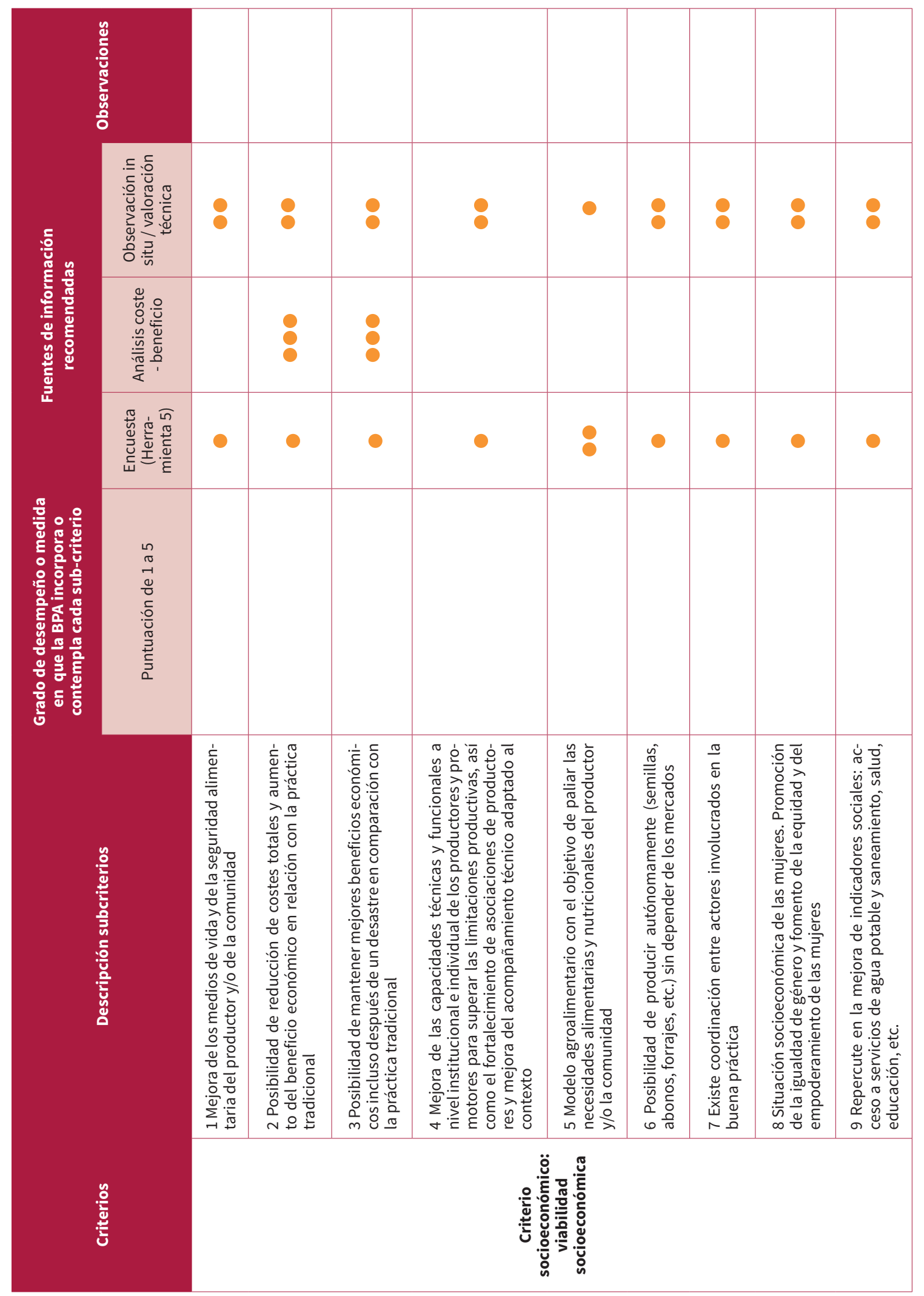




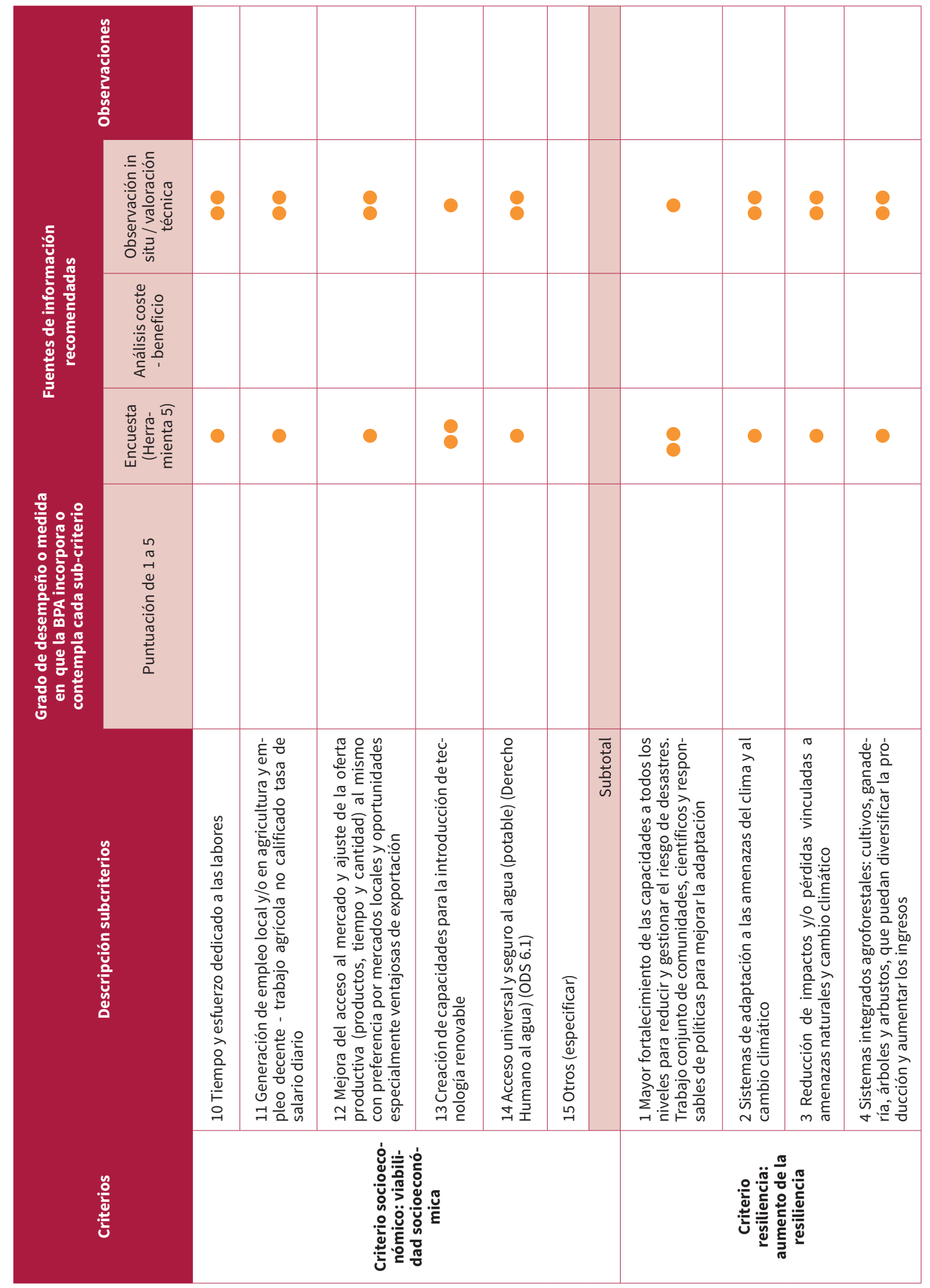




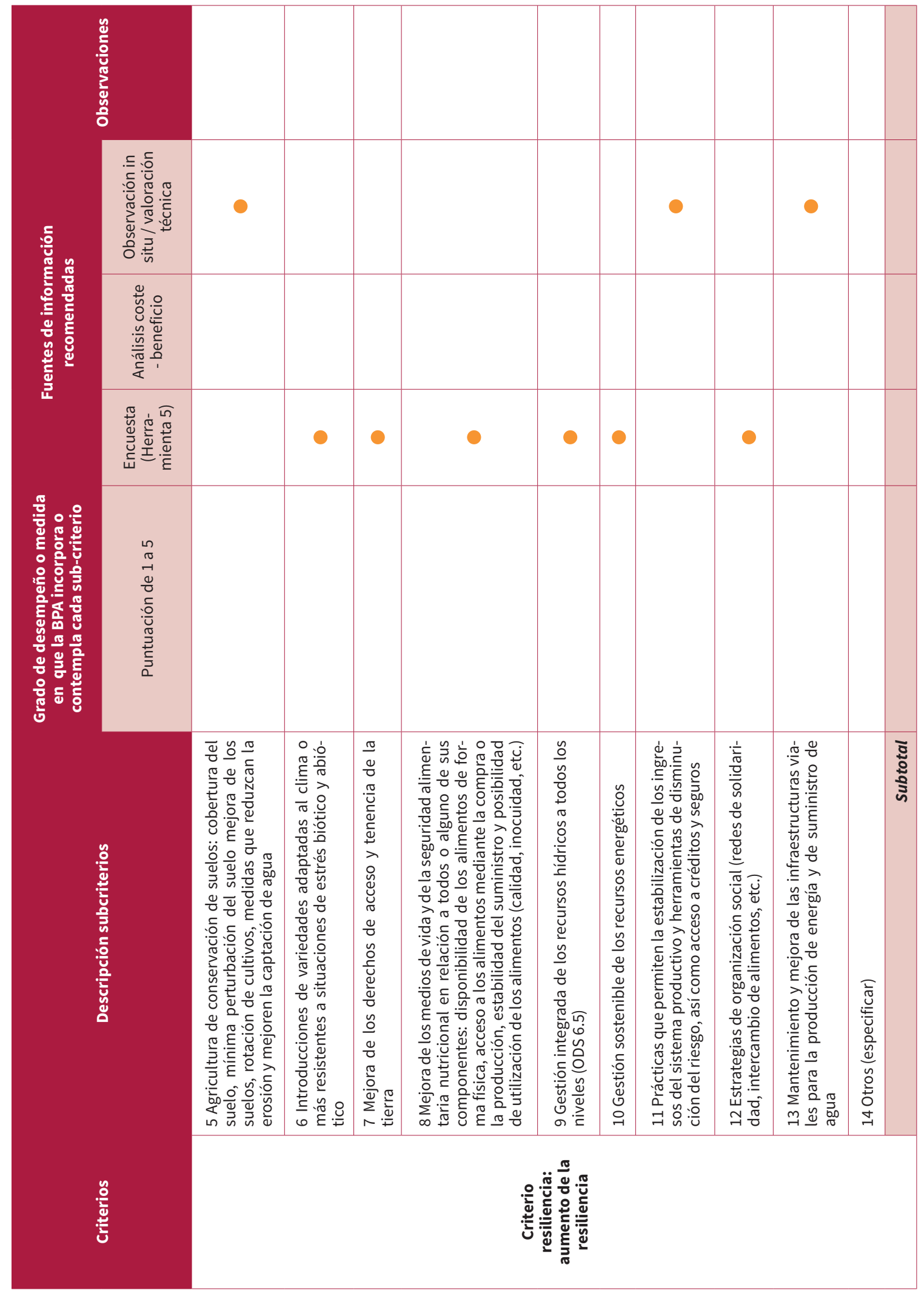




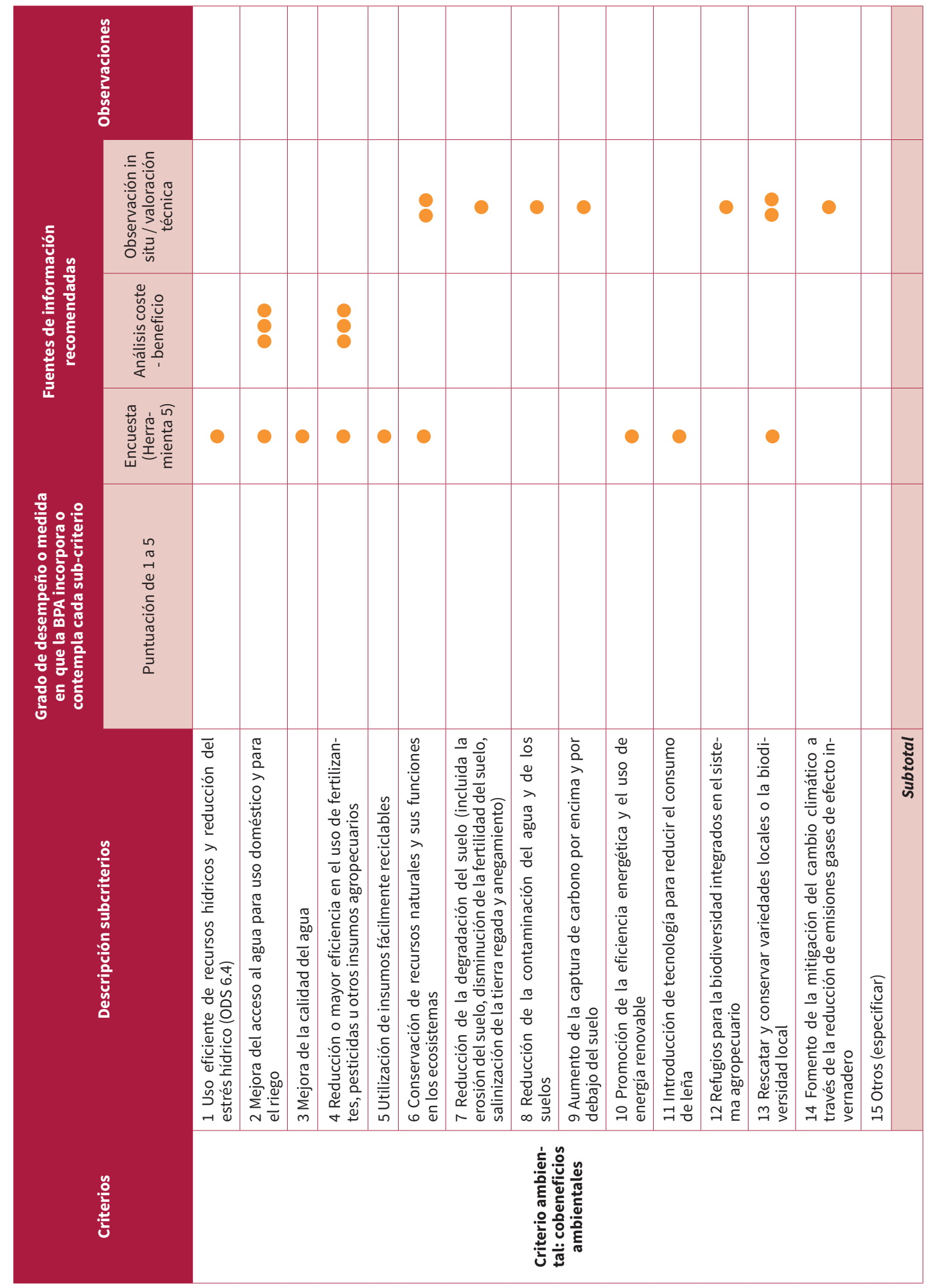




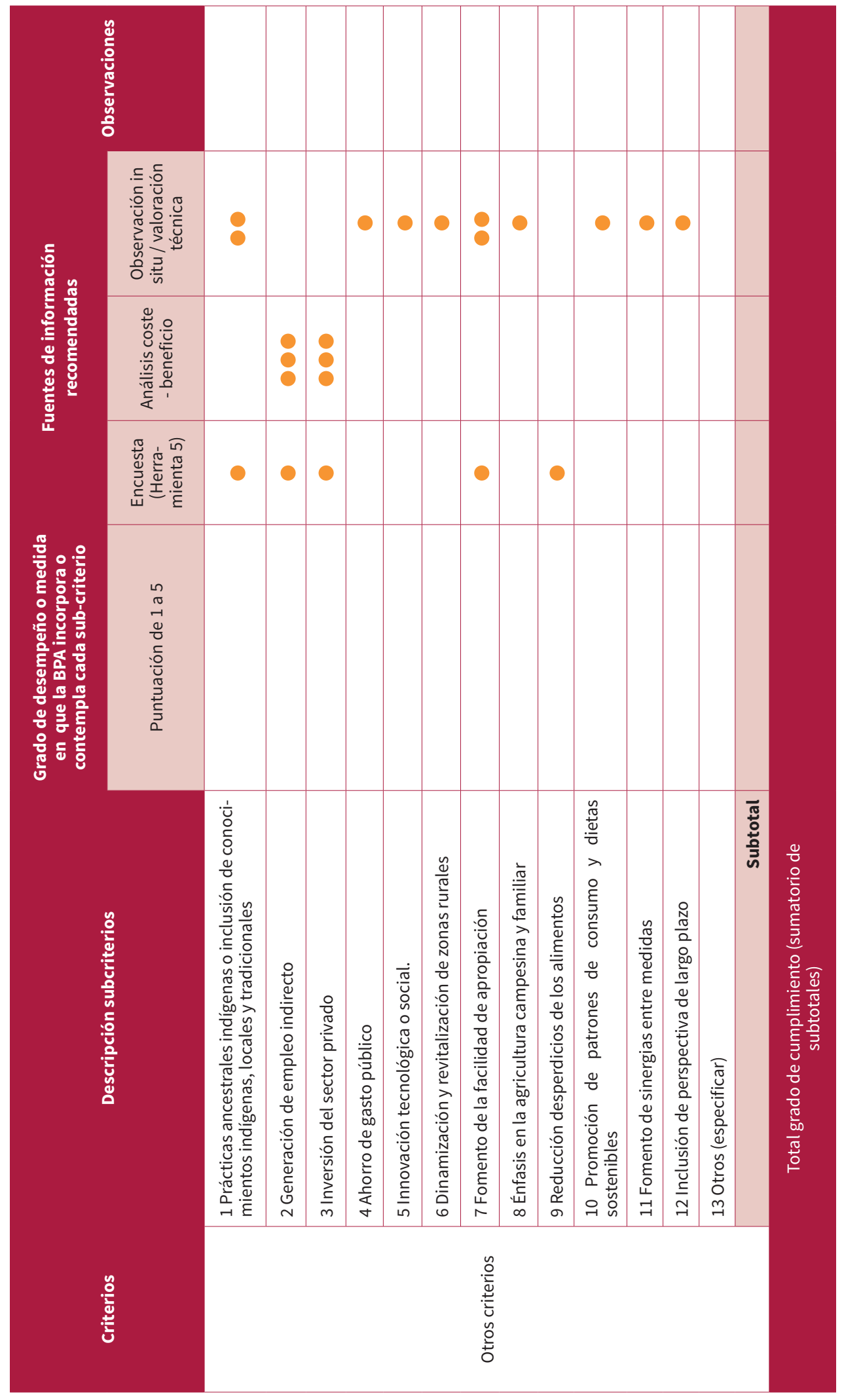


El uso de una escala cuantitativa permite analizar los criterios en una amplia gama de contextos y para diferentes amenazas, permitiendo diferentes combinaciones y siendo, a su vez, fácil de usar a nivel local.

La inclusión en la matriz de las recomendaciones sobre el uso de diferentes herramientas para la recolección de la información necesaria para valorar cada subcriterio aseguran la flexibilidad de adaptación y uso. Estas recomendaciones deben revisarse y adaptarse para cada caso concreto de aplicación, ya que pueden variar en función del tipo de práctica que se esté analizando y la información disponible al respecto. En particular, la valoración de las fuentes de información se indica de la siguiente manera:

\begin{tabular}{|c|c|}
\hline 00 & Principal fuente de información recomendada \\
\hline \multirow{2}{*}{00} & Fuente de información alternativa recomendada \\
\hline 000 & Fuente de información complementaria recomendada \\
\hline
\end{tabular}

Una vez completada la matriz, se puede valorar de manera global cada subcriterio sumando el conjunto de las puntuaciones obtenidas para todos los valores y dividiendo por el número de valores.

Tabla 8.2. Resumen de valoración de cada tipo de criterio según el desempeño de los subcriterios.

\begin{tabular}{|l|c|c|}
\multicolumn{1}{c|}{ Criterios } & Ponderación & Valoración sub-criterios \\
\hline Pertinencia agroecológica & 0,25 & 1 a 5 \\
\hline Viabilidad socioeconómica & 0,25 & 1 a 5 \\
\hline Resiliencia & 0,25 & 1 a 5 \\
\hline Cobeneficios ambientales & 0,15 & 1 a 5 \\
\hline Otros criterios & 0,10 & 1) a 5 \\
\hline
\end{tabular}

La combinación de la información proveniente de los subcriterios demostrará el valor agregado de las buenas prácticas para la adaptación al cambio climático y la gestión integral del riesgo de desastres. De hecho, si el indicador muestra un resultado positivo durante varias temporadas, será un argumento positivo para su replicabilidad escalamiento en contextos más amplios. 
Tabla 8.3. Resumen de valoración global de los criterios.

\begin{tabular}{|c|c|c|c|c|c|}
\hline \multirow{2}{*}{$\begin{array}{l}\text { Resumen } \\
\text { valoración } \\
\text { criterios }\end{array}$} & \multirow{2}{*}{$\begin{array}{l}\text { Valoración por } \\
\text { sub-criterios }\end{array}$} & \multicolumn{4}{|c|}{ Incidencia global } \\
\hline & & Sequía & Inundaciones & $\begin{array}{l}\text { Variabilidad inte- } \\
\text { ranual }\end{array}$ & $\begin{array}{c}\text { Plagas y } \\
\text { enfermedades }\end{array}$ \\
\hline Criterios & $\begin{array}{l}\text { Valor medio para } \\
\text { el conjunto de } \\
\text { sub-criterios } \\
\text { considerados }\end{array}$ & $\begin{array}{l}\text { Valor medio de } \\
\text { la puntuación } \\
\text { obtenida para } \\
\text { los sub-sectores } \\
\text { Cultivos+ganade- } \\
\text { ría+Pesca+Forestal }\end{array}$ & $\begin{array}{l}\text { Valor medio de } \\
\text { la puntuación } \\
\text { obtenida para } \\
\text { los sub-sectores } \\
\text { Cultivos+ganade- } \\
\text { ría+Pesca+Forestal }\end{array}$ & $\begin{array}{c}\text { Valor medio de } \\
\text { la puntuación } \\
\text { obtenida para los } \\
\text { sub-sectores Culti- } \\
\text { vos+ganadería+Pes- } \\
\text { ca+Forestal }\end{array}$ & $\begin{array}{c}\text { Valor medio de } \\
\text { la puntuación } \\
\text { obtenida para los } \\
\text { sub-sectores Culti- } \\
\text { vos+ganadería+Pes- } \\
\text { ca+Forestal }\end{array}$ \\
\hline \multicolumn{6}{|l|}{$\begin{array}{l}\text { Pertinencia } \\
\text { agroecológica }\end{array}$} \\
\hline \multicolumn{6}{|l|}{$\begin{array}{l}\text { Viabilidad socio- } \\
\text { económica }\end{array}$} \\
\hline \multicolumn{6}{|l|}{ Resiliencia } \\
\hline \multicolumn{6}{|l|}{$\begin{array}{l}\text { Co-beneficios } \\
\text { ambientales }\end{array}$} \\
\hline Otros criterios & & & & & \\
\hline
\end{tabular}

Cabe señalar que los criterios de pertinencia agroecológica y viabilidad socioeconómica deben obtener una valoración mínima medio-alta como requisito para definir una BPA, además debe puntuar en al menos alguno de los otros dos criterios de resiliencia y cobeneficios ambientales.

\section{Herramienta 9:}

\section{Modelización de los impactos de una BPA}

Para qué sirve la herramienta: Para evaluar la posibilidad de replicar la práctica a gran escala, sus beneficios e impactos y las tecnologías empleadas en la GIRD, en el incremento de la resiliencia, aumento de la producción agropecuaria sostenible y de los medios de vida rurales en zonas propensas a desastres.

Quién realiza el análisis: Personal técnico que esté aplicando la metodología.

Cómo y cuándo se aplica: El enfoque propuesto utiliza como fundamento el método "Dinámica de Sistemas".

El monitoreo y la evaluación del desempeño de las BPA tiene como objetivo mejorar la comprensión del impacto de las prácticas en agricultura y tecnologías para la Adaptación al Cambio Climático y la Gestión Integral del Riesgo de desastres en el incremento de la resiliencia de la producción 
sostenible y los medios de vida rurales en zonas propensas a desastres. El fin último es evaluar la efectividad de las BPA y la proyección del impacto potencial del escalamiento a nivel nacional y/o regional de la BPA. La interacción dinámica entre los indicadores económicos, sociales y ambientales, incluyendo agroecológicos, en diferentes escenarios, puede ser analizada mediante modelos de simulación.

El enfoque propuesto se fundamenta en el método de "dinámica de sistemas" que sirve principalmente como un integrador de conocimientos. El modelado de la dinámica de sistemas es un tipo de modelo de simulación por computadora, diseñado para facilitar un enfoque integral de planificación del desarrollo a mediano y largo plazo. Hasta la fecha se han creado varios modelos con esta metodología, incluidos modelos de energía, agricultura, manejo de residuos y gestión del agua, los cuales son completamente adaptables tanto al problema a analizar, como al contexto local ${ }^{3}$.

Una característica clave de los modelos de dinámica de sistemas (MDS) es que pueden integrar las tres esferas del desarrollo sostenible en el proceso analítico, apoyando así los ejercicios de planificación integrada. Los MDS simulan datos históricos de un período determinado (generalmente una década por lo menos), y comparan los resultados de simulación con los datos disponibles. El propósito de este tipo de modelos no es hacer predicciones precisas del futuro; sino explorar escenarios alternativos con el fin de identificar las inversiones, políticas y proyectos que podrían mejorar las condiciones futuras y contribuir al logro de las metas y objetivos deseados. Un ejemplo de aplicación de modelos de Dinámica de Sistemas en Centro América es el estudio de Marín-González et al. (20184), donde se testó un modelo biofísico y socioeconómico (el modelo SASAHACA) en explotaciones de pequeños agricultores de maíz y fríjol en intercultivo. El modelo fue capaz de evaluar la seguridad alimentaria para diferentes escenarios, proporcionando una estimación de la incertidumbre de los resultados.

Para efectos de este estudio, se utilizarán MDS para generar proyecciones de los costes económicos, sociales y ambientales, así como de los beneficios de las BPA a nivel nacional o regional, y proporcionar un análisis integrado de los efectos esperados de las BPA en la resiliencia en la agricultura.

Los elementos clave de los Modelos de Dinámica de Sistemas desarrollados para la evaluación de las BPA incluyen:

- Límites: En el modelo se incluyen tanto variables endógenas como exógenas. Por ejemplo, el PIB, población y variables clave relacionadas con la agricultura se determinan de forma endógena. Otras variables que tienen una influencia importante en las BPA analizadas, pero

\footnotetext{
${ }^{3}$ Ver, por ejemplo: UNEP (2014), Using Models for Green Economy Policymaking.

${ }^{4}$ Marín-Gonzalez, O.; Parsons D.; Arnes-Prieto E.; Díaz-Ambrona, C.G.H. 2018. Building and evaluation of a dynamic model for assessing impact of smallholder endowments on food security in agricultural systems in highland areas of central America. Agricultural systems, 164:152-164. https://doi.org/10.1016/j.agsy.2018.02.005
} 
que son sólo débilmente influenciadas por los temas analizados, están representados de forma exógena.

- Desagregación: Dependiendo del alcance de la evaluación, el modelo se adapta a un entorno geográfico determinado (nivel regional, nacional, sub-nacional y local) y los datos se agregan a ese nivel.

- Horizonte temporal: El modelo está construido para escenarios que van del corto al medio plazo. Idealmente la simulación incluye el pasado, siemprey cuando la disponibilidad de datos lo permita, y se extiende hasta alrededor de uno o cinco periodos posteriores, dependiendo de la BPA a ser evaluada. La recopilación de los datos para la conformación de la línea base es un tema crítico. Los resultados de los análisis de costo beneficio se utilizan para alimentar el modelo. El resto de los datos necesarios pueden ser extrapolados o reemplazados por representación de datos (data proxy).

- Estructura: Se utiliza un modelo relativamente pequeño y simple para evaluar el impacto de las BPA. Para definir relaciones causales clave entre los indicadores se crean módulos estándar básicos, tanto dentro como entre sectores. Posteriormente los módulos se pueden adaptar completamente a cada BPA y contexto específico, a partir de las aportaciones de los actores locales, los resultados de los cuestionarios y los análisis de costo-beneficio realizados. Los módulos estándar clave incluyen: (1) población; (2) PIB; (3) ingresos y gastos del gobierno; (4) ingresos, consumo e inversiones de los hogares; (5) producción agropecuaria y GIRD (adaptada en función de las BPA analizadas), en los dos últimos periodos se puede incluir el impacto de las pérdidas por el cambio climático, de modo indirecto.

Los principales resultados del ejercicio de modelado incluyen proyecciones de las inversiones necesarias para implementar las BPA deseadas, junto con otros beneficios adicionales (o consecuencias no deseadas) y costos evitados asociados con la implementación de la BPA. Entre los beneficios, los indicadores incluyen el valor agregado sectorial, la creación de empleo directo e ingresos relativos generados, así como mejoras eventuales de capital natural (inventarios, flujos, bienes y servicios de ecosistema). Los costos evitados incluyen ahorros por daños y pérdidas evitadas a partir del impacto de amenazas naturales, la reducción en el consumo de insumos (p. ej. agua), y costos de restauración de ecosistemas evitados. Todos estos se comparan con los costos y daños potenciales calculados a partir de la línea base y por la BPA implementada.

Mediante la generación de escenarios sistémicos, amplios e intersectoriales, el modelo simula los principales impactos a corto, mediano y largo plazo para la inversión en estrategias de GIRD. La contribución más importante de este modelo es su estructura sistémica, ya que incluye enlaces endógenos dentro y a través de los sectores económicos, sociales y ambientales por medio de una variedad de circuitos de retroalimentación ${ }^{5}$.

5 La retroalimentación es un proceso en el que una causa inicial influye en una cadena causal que en última instancia se influye nuevamente a sí misma. Ver: Roberts, N., et al., 1983: Introduction to computer simulation, A system dynamics modelling approach, System Dynamic Series, Productivity Press, Portland, Oregon. 
Los diagramas causales se utilizan como punto de partida en la representación de las relaciones entre las variables del sistema. Un diagrama causal es una representación de las principales relaciones causales que caracterizan el sistema analizado, ilustrando los vínculos y retroalimentaciones entre las variables del sistema. Los modelos se desarrollan a partir de esta amplia conceptualización, mediante la traducción de los circuitos causales en un conjunto de relaciones matemáticas.

La Figura 9.1 representa un diagrama de causa simplificado del módulo de la agricultura. Las relaciones causales entre los diferentes usos de la tierra (p. ej. bosques, tierras agrícolas y tierras degradadas) son factores clave para todos los indicadores en este sector, ya que mantienen el sistema en equilibrio. Otro vínculo de equilibrio que caracteriza la relación entre la brecha de las tierras agrícolas y la expansión de tierras agrícolas (p. ej. un aumento en tierras agrícolas reduce la brecha y eventualmente reduce la necesidad de más tierras agrícolas). Por último, se destaca una serie de vínculos de refuerzo entre las inversiones en BPA, GIRD, productividad agrícola y producción agrícola.

Figura 9.1. Ejemplo de diagrama causa-efecto: producción agrícola y BPA para la adaptación al cambio climático y la gestión integral del riesgo de desastres

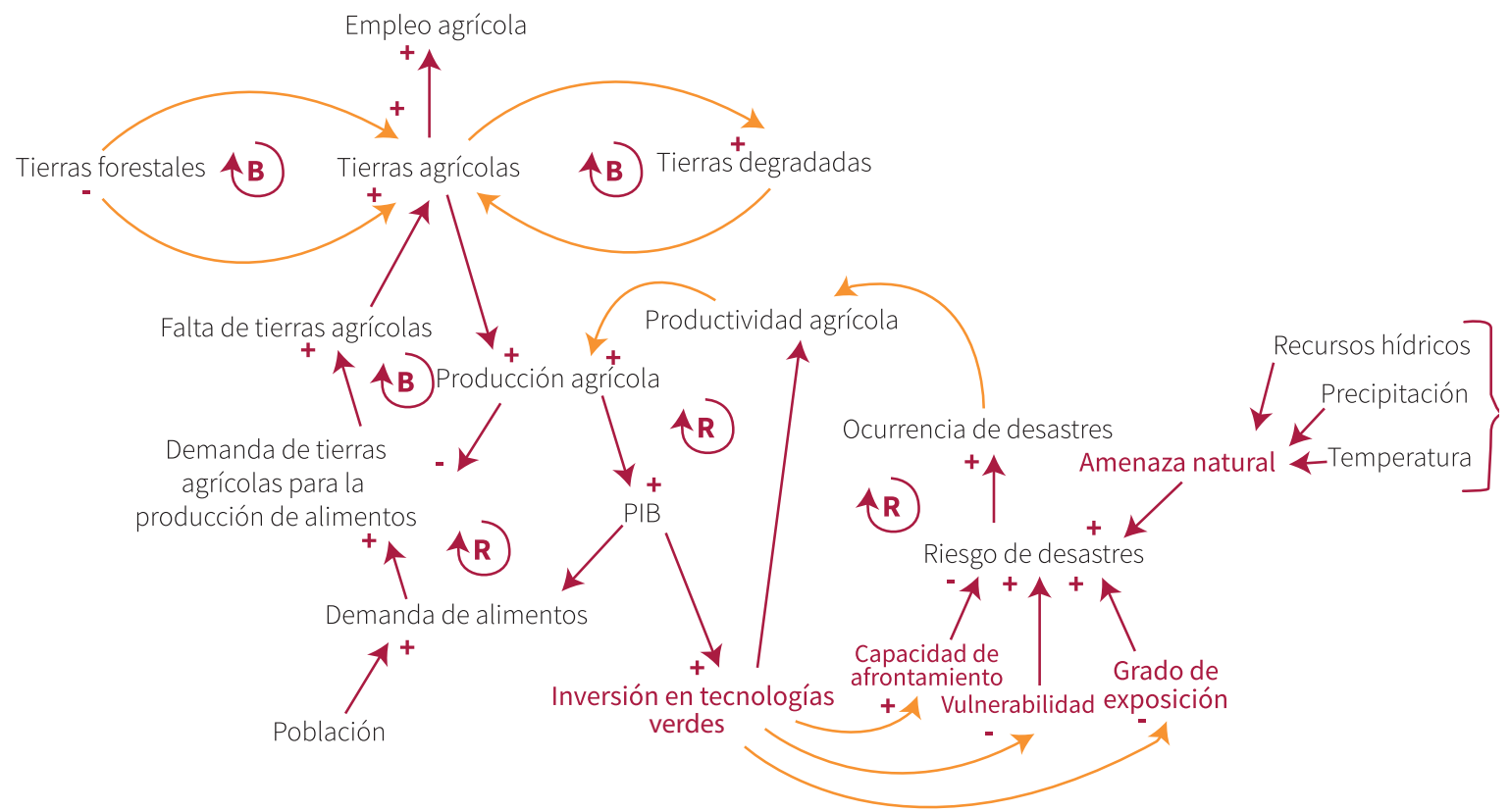

Nota. Un vínculo de causa de la variable $A$ a la variable $B$ es positivo si el cambio en A produce un cambio en $\mathrm{B}$ en la misma dirección. Por el contrario, un vínculo causal de la variable $\mathrm{A}$ a la variable $B$ es negativo si el cambio en A produce un cambio en B en dirección opuesta.

La Figura 9.2 representa el diagrama de flujo correspondiente del modelo SASHACA (Marín et al., 2018), como ilustración de implementación del enfoque de la modelización de la Dinámica de Sistemas. 


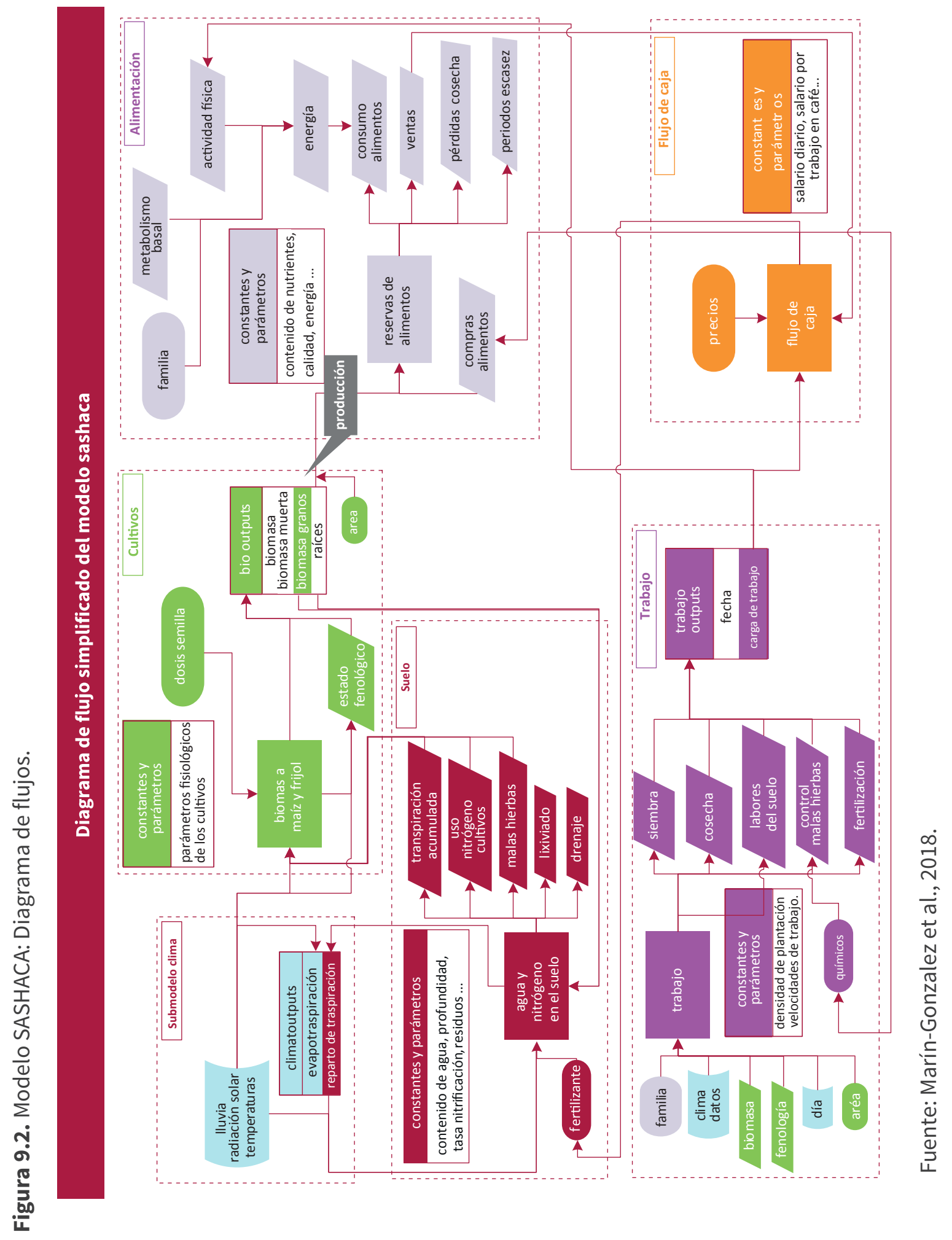


Los sub-modelos se encierran en líneas discontinuas, el nombre del submodelo aparece en la esquina derecha superior. Los rectángulos representan las principales variables de estado. Los paralelogramos representan otras variables importantes. Los rectángulos de esquinas redondeadas muestran los parámetros más importantes de cada submodelo. Los rectángulos apilados indican otras constantes y parámetros. Las flechas representan las interacciones entre constantes, parámetros y variables.

\section{Herramienta 10:}

\section{Evaluación comparativa de los beneficios por unidad de producción/finca}

La siguiente figura describe como aplicar la evaluación comparativa de los beneficios por unidad de producción/ finca a partir de las buenas prácticas para la Adaptación al Cambio Climático y la Reducción del Riesgo de desastres.

Figura 10.1. Esquema de la evaluación comparativa.

\section{Línea Base}

Datos históricos sobre el rendimiento medio de la práctica local previamente utilizada durante los últimos $x$ años
Año normal

(sin peligro, el desastre no ocurre)

Realización de las buenas prácticas para la RRD en comparación con el desempeño de la práctica local utilizada anteriormente (parcela de control)

\section{Condición de amenaza}

aguda

Rendimiento de la buena práctica de RRD en comparación con el desempeño de la práctica utilizada anteriormente (parcela control) en una condición de peligro agudo

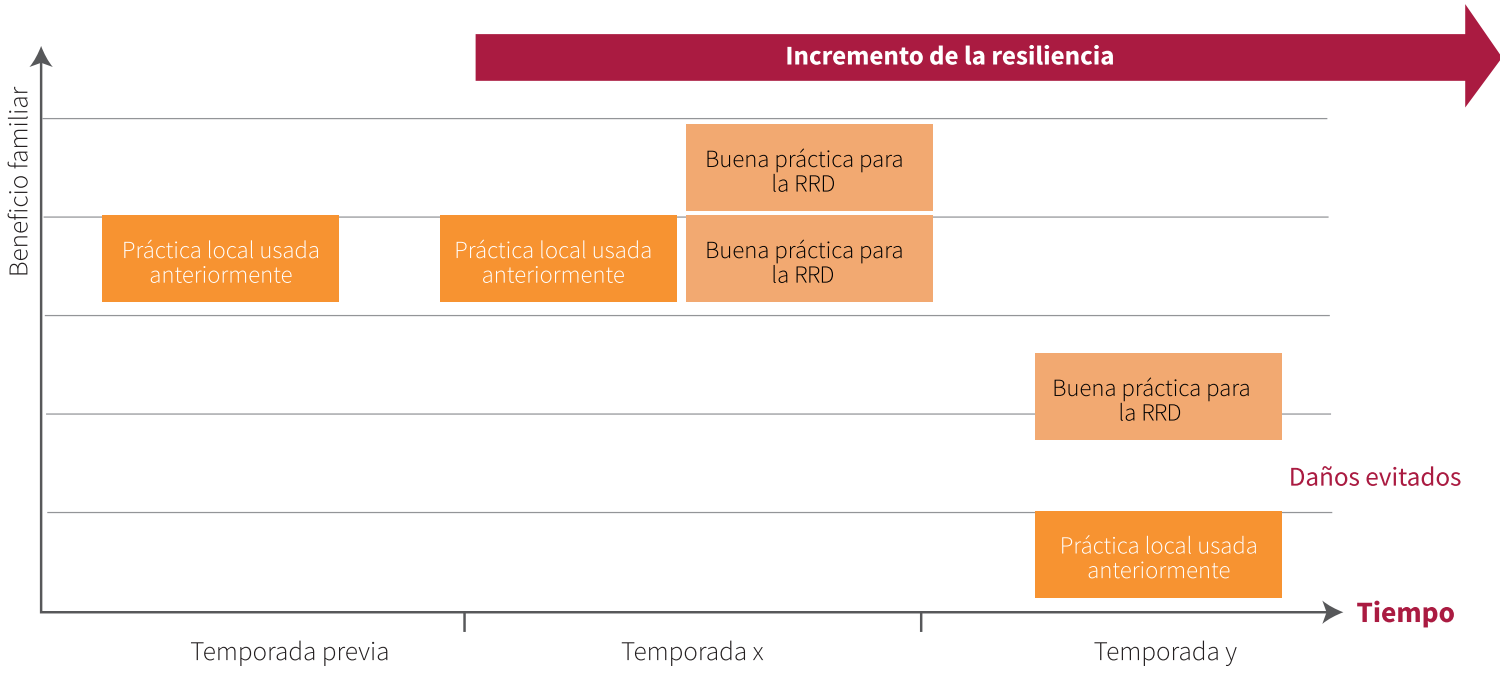

Fuente: FAO, 2019. Disaster risk reduction at farm level: Multiple benefits, no regrets. 


\section{Bibliografía}

Alonso, R., Serrano, A. 2010. Economía de la empresa agroalimentaria. $3^{\text {a }}$ edición. Ediciones Mundi-Prensa; Madrid.

Boardman, A., Greenberg, D.; Vining, A.; Weimer, D. 2011. Cost-Benefit Analysis: Concepts and Practice, 4th edition. Prentice Hall.

FAO. 2013. Buenas prácticas en la FAO: Sistematización de experiencias para el aprendizaje continuo. 164 pp. (disponible en http://www.fao.org/3/ap784s/ap784s.pdf). Acceso: 07 de noviembre de 2019.

FAO. 2017. Benefits of Farm-Level Disaster Risk Reduction Practices in Agriculture - Preliminary Findings. 33 pp. (disponible en: http://www.fao.org/3/a-i7319e.pdf). Acceso: 07 de noviembre de 2019.

FAO. 2019. Disaster risk reduction at farm level: Multiple benefits, no regrets. 160 pp. (disponible en: http://www.fao.org/3/ca4429en/CA4429EN.pdf). Acceso: 07 de noviembre de 2019.

FAO, PNUD. 2019. Guía de análisis costo beneficio. Aplicación para medidas de adaptación al cambio climático en el sector agropecuario en Uruguay. Montevideo. 163 pp. (disponible en: http://www.fao.org/3/ca2795es/ca2795es.pdf ). Acceso: 07 de noviembre de 2019.

Grupo Banco Mundial, Global Facility for Disaster Reduction and Recovery (GFDRR). 2013. Gestión financiera y aseguramiento de riesgo de desastres. 64pp. (disponible en: http:// documents1.worldbank.org/curated/en/115161468179340561/pdf/101133-SPANISH-WPP128311-PUBLIC-Box393259B.pdf). Acceso: 07 de noviembre de 2019.

Global Green Growth Institute (GGGI). 2014. Anual Report. 98 pp. (disponible en: http://gggi. org/wp-content/uploads/2015/11/gggi_annual_report_2014_web.pdf). Acceso: 31 de julio de 2020.

Marín-González, O., Parsons D., Arnes-Prieto E., Díaz-Ambrona, C.G.H. 2018. Building and evaluation of a dynamic model for assessing impact of smallholder endowments on food security in agricultural systems in highland areas of central America (SASHACA). Agricultural System. 164:152-164 pp. (disponible en: https://doi.org/10.1016/j.agsy.2018.02.005). Acceso: 07 de noviembre de 2019.

Nicholson W., Snyder, C. 2008. Microeconomic theory: Basic principles and extensions, 10th ed. Thomson South-Western, Mason, OH, USA. 763 pp.

Perman, R., Ma, Y., McGilvary, J., Common, M. 2003. Natural Resource and Environmental Economics. 3. ${ }^{\text {a }} \mathrm{ed}$. Harlow: Pearson, USA.

Roberts, N. 1983: Introduction to computer simulation, A system dynamics modelling approach, System Dynamic Series, Productivity Press, Portland, Oregon. 562 pp.

UNEP. 2014. Using Models for Green Economy Policymaking. (disponible en: https://www. uncclearn.org/sites/default/files/inventory/unep_models_ge_for_web.pdf). Acceso: 07 de noviembre de 2019. 
Metodología para el monitoreo y evaluación de buenas prácticas en agricultura para la adaptación al cambio climático y la gestión integral del riesgo de desastres 